University of San Diego

Digital USD

2002

\title{
Modeling the Effects of Financial Aid on Student Enrollment Decisions: A Quantitative Case Study of a Private Catholic University
}

Linda Siefert EdD

University of San Diego

Follow this and additional works at: https://digital.sandiego.edu/dissertations

Part of the Leadership Studies Commons

\section{Digital USD Citation}

Siefert, Linda EdD, "Modeling the Effects of Financial Aid on Student Enrollment Decisions: A Quantitative Case Study of a Private Catholic University" (2002). Dissertations. 697.

https://digital.sandiego.edu/dissertations/697

This Dissertation: Open Access is brought to you for free and open access by the Theses and Dissertations at Digital USD. It has been accepted for inclusion in Dissertations by an authorized administrator of Digital USD. For more information, please contact digital@sandiego.edu. 


\title{
MODELING THE EFFECTS OF FINANCIAL AID ON STUDENT ENROLLMENT DECISIONS: A QUANTITATIVE CASE STUDY OF A PRIVATE CATHOLIC UNIVERSITY
}

\author{
by \\ Linda Siefert \\ A dissertation submitted in partial fulfillment \\ of the requirements for the degree of \\ Doctor of Education \\ University of San Diego \\ 2002 \\ Dissertation Committee \\ Dr. Fred Galloway, Ed.D.. Director \\ Dr. Robert Donmoyer, Ph.D. \\ Dr. Russell Robins, Ph.D.
}




\begin{abstract}
Over the last two decades, many institutions of higher education have experienced admissions-related problems due to fluctuations in student enrollment and the increasing need for institutional financial aid. Because of this, administrators need tools that can help them modify policy as the market changes. The purpose of this research was to develop a tool for a private, more selective institution that would answer the following questions: (1) what is the probability of enrollment for each admitted student, and (2) how would changes in the financial aid package affect this probability?
\end{abstract}

The model in this research was based on both economic theory and the results of other empirical work, and was refined through statistical analysis. Its goal was to develop the best predictive model using the data collected by the institution and available to it at the time admission and financial aid decisions are made. The methodology was carried out in three steps. First, an enrollment probability model was estimated using three years (1998-2000) of admissions data from the institution, using both logistic and probit regression. The model included a unique set of explanatory variables, including religious affiliation and distance from home, showing the ease at which institutions can look at the variables that are important for their goals, policies, and practices. The second step was a temporal validation against additional data. The model was tested for predictive accuracy against the admissions data for 2001. After rerunning the model for all four years, the final step in the methodology was to simulate the effects on enrollment of various changes in the tuition and financial aid policy, and to calculate price sensitivity.

The results of this study, for the most part. confirmed economic theory and general empirical findings. The signs and significance of most coefficients were as expected. A 
unique finding was that a linear, constantly decreasing functional form for net price was not the best fit for the data. Rather, a cubic relationship between net price and enrollment probability provided a better fit. Classification accuracy within each model and predictive accuracy for 2001 were all near $70 \%$. Sensitivity to price was calculated differently in this research than in other existing research. Due to mathematical shortcomings discussed in the study, delta-Ps and student price response coefficients (SPRC) were not used. Rather, sensitivity to a $\$ 1,000$ decrease in net price was calculated for each student. The mean sensitivity to a $\$ 1,000$ decrease in net price was .02 . That is, on average, a $\$ 1,000$ decrease in net price increased the probability of enrollment by $2 \%$, for example, from $20 \%$ to $22 \%$. The results of the present study are lower than most existing research, which is consistent with the discussions in the field that statistics such as delta-Ps and SPRCs, calculated only at the mean, can overestimate sensitivity. The implication for policy makers is that they need to look at specific students, or groups of similar students. when estimating the effect of policy decisions, and not rely solely on an average estimate. This research not only provided such price sensitivities for students with various characteristics of interest to the institution, but also provided the institution with a tool to use with each entering class of freshman. 


\section{ACKNOWLEDGMENTS}

I will forever be grateful and indebted to all those who provided me with support during this process, varying from generous doses of time and inspiration to simple acts of kindness. I am amazed that He always provides these at the needed time.

This research is the result of study started many years ago in economics combined with years of work and interest in education. So my first thanks go to those who were with me at the beginning and the end. Thank you to my husband Dan, who supported me through more years of education than he thought possible. You provided me the freedom to pursue my goals. and for that I am eternally grateful. Thank you to my committee chairman. Fred Galloway, who reappeared in my life at the right time to push me into using my previous training and doing my best with it. Your encouragement and belief in my abilities were foundational to this work. Thank you to Russell Robins, whom I studied, complained, and laughed with years ago, and who graciously accepted the invitation to join my committee and add the input of his years of experience to this effort.

Throughout this program. my children were often called upon to do without for my benefit - to do without my support when they may have needed it more than I needed theirs. Thank you for your encouragement and, yes, nagging which helped keep me on track. Nick and Suzie. during these four years. you have grown into young adults of strong character who use your independence gracefully and wisely.

I am also grateful to a number of people I met during these endeavors. I thank my final committee member. Robert Donmoyer. You provided me with perspectives that were outside my typical way of looking at things. and this enriched not only this product. but also the perspective I will now carry with me. To the professor who opened my eyes 
to looking at leadership from the inside out, Theresa Monroe: I thank you for your innovative teaching style. And to Andre Murphy, my lifeline while completing this dissertation long distance, I give my gratitude and affection for your friendship, support, and inspiration.

A special thank you goes to Stephen Pultz and Warren Muller for providing the data for this research, information on the admissions process. and other helpful suggestions and information along the way. Additional gratitude goes to my previous employers at CompassLearning, Inc. for funding most of my work in this program. My hat goes off to this company and others who demonstrate that they truly value education by supporting their employees' continuing education efforts. Final gratitude goes to my present employers at the Success for All Foundation for providing me with the leave time and working facilities to complete this goal. 


\section{TABLE OF CONTENTS}

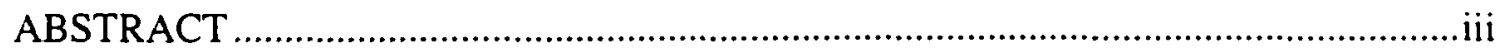

ACKNOWLEDGMENTS ..................................................................................... vi

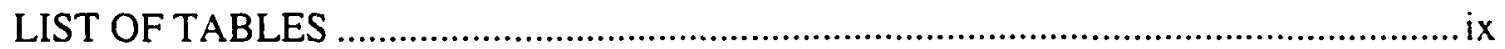

LIST OF FIGURES

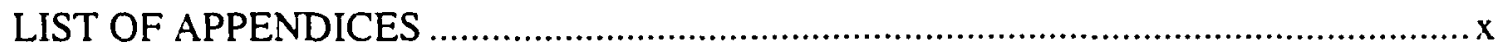

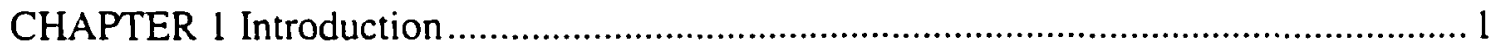

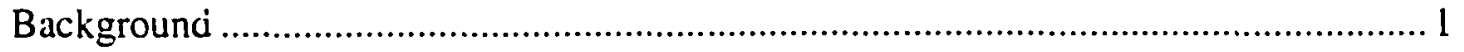

Statement of the Problem ....................................................................................

Purpose of the Study .......................................................................................

Research Questions .......................................................................................

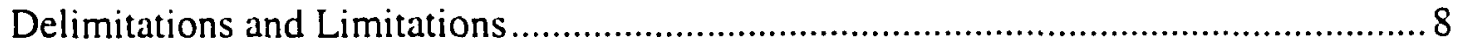

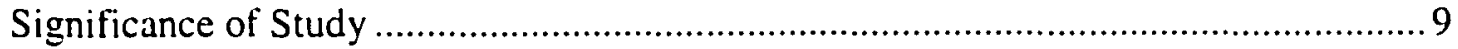

CHAPTER 2 Review of Literature .................................................................. 11

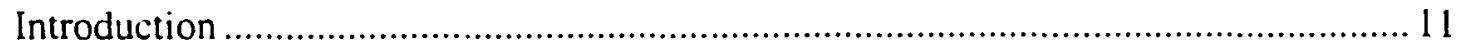

Human Capital and Rates of Return on Investment .................................................. 1 I

Human Capital Theory ..................................................................................... 11

Estimates of the Returns to Investment in Education ............................................. 15

Consumer Choice Theories and Price Sensitivity ………....................................... 19

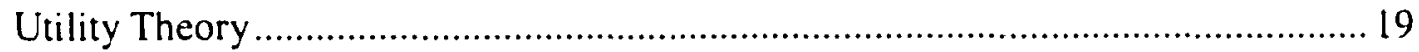

Demand Theory .............................................................................................21

Price and Financial Aid Effects on College Enrollment Decisions ..........................24

Institutional and Public Policies Issues Regarding Financial Aid.................................. 37

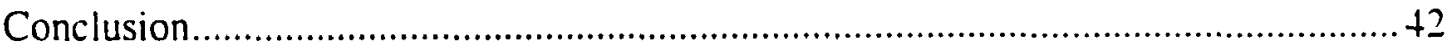

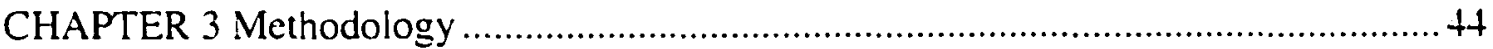

The Theoretical Model ........................................................................................

Operationalizing the Model...................................................................................

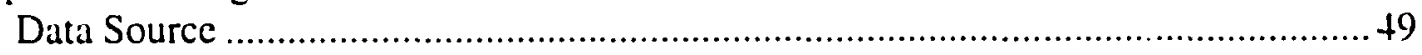

Statistical Methodology................................................................................... 50

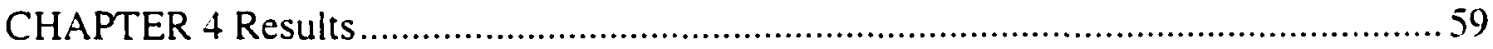

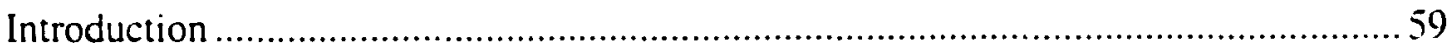

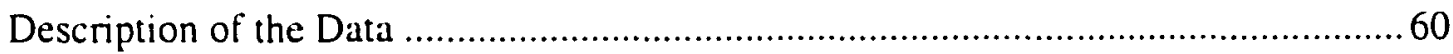

Regression Results from Three-Year Data Set ..........................................................69

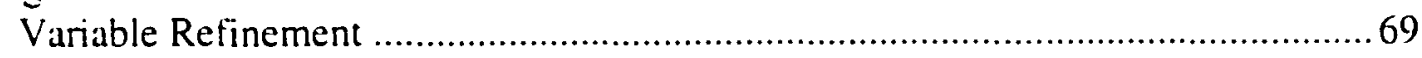

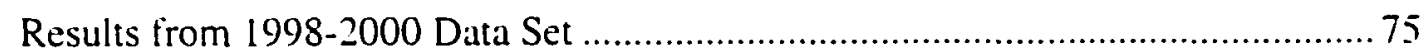

Predictions for Fall 2001 Enrollment .......................................................................85

Regression Results from Four-Year Data Set ..........................................................8

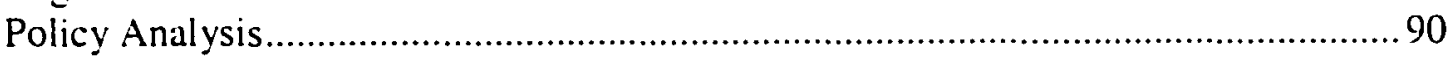

Price Sensitivity Analysis.............................................................................. 90

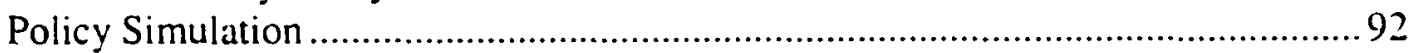

Summary and Conclusion ............................................................................... 96

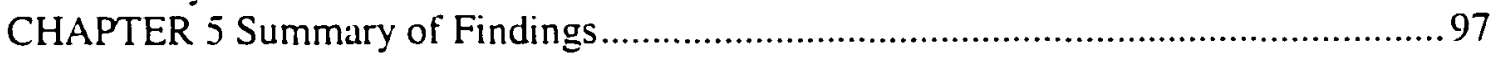

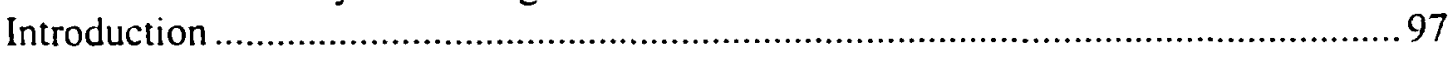

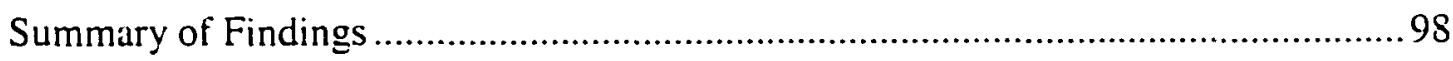

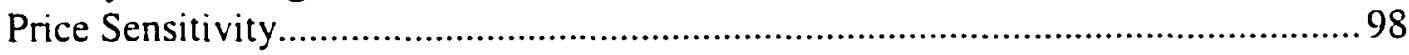

viii 
Income Sensitivity and Effects of Income on Price Sensitivity ........................ 101

Comparison of logistic and probit models ................................................... 102

Use of this Model for Institutional Policy and Practice .......................................... 105

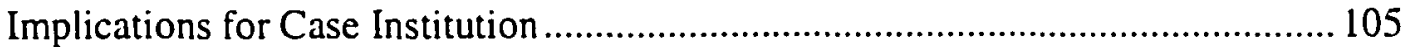

Implications for Other Institutions .......................................................... 110

Implications for Further Research ............................................................... 111

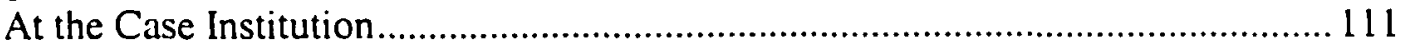

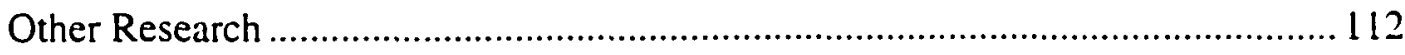

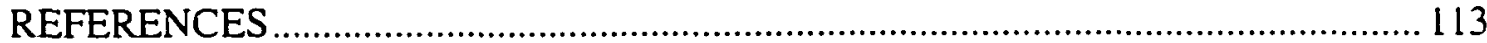

APPENDIX 1998-2001 Correlation Matrix ......................................................... 123

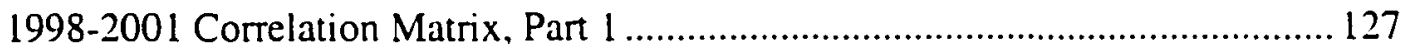

\section{LIST OF TABLES}

Table I Effects of Education on Selected Non-monetary Indicators................. I4

Table 2 Specification of Variables in the Model....................................47

Table 3 Sample Size.......................................................... 49

Table 4 Analysis of Sample Data by Year and Enrollment Decision..................61

Table 5 Admitted and Enrolled Percentages for Gender, Campus Visit, Legacy........62

Table 6 Admitted and Enrolled Percentages for Race or Ethnicity....................63

Table 7 Admitted and Enrolled Percentages for Religious Affiliation...................63

Table 8 Admitted and Enrolled Percentages for Distance from Home..................64

Table 9 Admitted and Enrolled Percentages by Need Category......................65

Table 10 Admitted and Enrolled Means for Application Rating. High School GPA.

SAT, Price........................................................66

Table 11 Percent Enrollment by Net Price Category and Demographic/

Socio-economic Category............................................ 68

Table 12 Specification of Variables in Final Model............................... 74

Table 13 Regression Results from 1998-2000 Data.............................. 76

Table 14 Likelihood Ratio Tests for Categorical Variables for 1998-2000 Data........ 83

Table 15 Classification Accuracy for 1998-2000 Data.............................. 84

Table 16 Classification Accuracy for Fall 2001 Enrollment Predictions................ 86

Table 17 Regression Results from 1998-2001 Data............................87

Table 18 Likelihood Ratio Tests for Categorical Variables for 1998-2001 Data.........89

Table 19 Classification Accuracy for 1998-2001 Data.............................89

Table 20 Price Sensitivity.................................................. 91

Table 21 Effects of Pricing Policy Changes..................................... 94

Table 22 Comparison of Price Sensitivity Estimates.............................. 101

Table 23 Income and Price Sensitivity....................................... 102

Table 24 Sample Financial Aid Decision-making Rules.......................... 109 


\section{LIST OF FIGURES}

Figure 1 Demand curves for selective and highly selective univerisities.............. 22

Figure 2 Demand curve for a selective university............................... 45

Figure 3 Linear model compared to theoretical model............................... 51

Figure 4 Comparison of logit and probit models...................................53

Figure 5 Price versus estimated probability (all else constant) $\ldots \ldots \ldots \ldots \ldots \ldots \ldots \ldots . \ldots \ldots$

Figure 6 High school GPA versus estimated probability (all else constant).............81

Figure 7 Student price sensitivity against net price.............................. 91

Figure 8 Difference between probit and logit probability plotted against net price...... 103

\section{LIST OF APPENDICES}

Appendix 1998-2001 Correlation Matrix. 


\section{CHAPTER 1}

Introduction

\section{Background}

Institutions of higher education have faced a number of admissions-related problems in the last two decades. These problems fall into two areas. The first area is the rising cost of education. The price of attending a four-year undergraduate college has increased faster than family income (The College Board, 1998a). At the same time, the federal government has shifted its pattern of financial support for higher education from grants to loans and individual tax incentives. Many niversities are forced to increase institutional grants in order to make enrollment at theirinstitution more attractive to the students they want to attract.

The second set of problems is related changing patterns in the number of schools students are applying to and in the rates of student enrollment. As the search and application processes has gotten easier for students, the number of schools each student applies to has increased. In addition, freshman enrollment rates have fluctuated over the last two decades as the lagging effect of oscillations in the U.S. birth rate. These changes cause additional competition among colleges for students and uncertainty about the size of the applicant pool. These problems create the need for each institution to be able to accurately predict student enrollment based on information about student patterns of enrollment and financial aid costs. This study presents a model for making such predictions. 
According to Hossler and Gallagher (1987), college enrollment is a three-phase process. The first phase is the predisposition phase, during which the student determines whether or not he or she would like to continue his or her education past high school.' The second or search phase consists of looking for colleges to attend and learning about the characteristics of various colleges. During this phase, the student develops a choice set, that is, the set of institutions to which he will apply. The final phase is the choice phase, when the student decides which member of the choice set to attend. At this point, the choice is narrowed to only those institutions at which the student has been accepted. Therefore. this phase represents the intersection of all prior institutional and student decisions. If the institution has made accurate predictions of enrollment from its acceptances, it will get the freshman class it was aiming for, and will do so at the predicted cost. If not, it may experience over or under enrollment. and the financial aid expense may not be in line with the budget.

There is a large body of research on the general topic of higher education enrollment. Most existing research is based on the foundation of economic theory, as it provides a strong framework for both policy analysis and the building of practical tools. According to traditional economic demand theory, the quantity demanded of a good or service is related to the price of the good or service. the income of the buyer. the prices of alternative products, and the buyer's tastes and preferences. In order to try to confirm this theory in the case of higher education. sociologists. economists, and educators have conducted numerous studies to determine how responsive students are to price.

Researchers have looked at gross tuition. grants, loans, and net tuition as price variables

\footnotetext{
'For the remainder of this paper. the pronouns he and his will be used to represent students of either gender.
} 
that affect the probability of enrollment (Heller, 1997; Leslie \& Brinkman. 1987).

Research supports the findings that reductions in net price (tuition minus grants) positively effect enrollment decisions.

More specifically, research shows that grants, as opposed to loans, are a major factor in student decisions. We have a rich history in this country of providing scholarships to "needy and deserving" students. Traditionally, colleges held limited funds for scholarships and loan, typically derived from gifts from alumni and corporations. Scholarships, however, have taken on a life of their own in the second half of the twenty century. In the 1950s, when competition for students increased, a number of colleges determined that it was not fiscally sound to use their limited financial aid funds to compete for the same students. This led to developing specific criteria for judging student financial need. The College Scholarship Service was formed to standardize financial aid offers (Hansen, 1983). With the Higher Education Act of 1965, the federal government began a series of programs to help more Americans access a college education. As Leslie \& Brinkman (1988) point out. “Expanding and equalizing student access long has been a major public policy goal, and manipulation of price has been seen as the major policy instrument for achieving this goal" (p. 182). However, federal grant programs were not able to keep pace with rising costs in education. In 1975. the maximum Pell Grant funded $85 \%$ of the tuition at a four-year public college and $38 \%$ of the tuition at a four-year private college. By 1998 , these figures had fallen to $38 \%$ and $17 \%$. respectively (The College Board. 1998b). Realizing that federal programs did little. if anything, to increase college enrollment in the 1970s, (Hansen, 1983: Jackson, 1988: Kane. 1994: St. John \& Noell, 1989). institutional grants began to take up the slack. Presently, institutionally 
funded financial aid pays for $19 \%$ of the cost of attending college (The College Board, 1998b).

This institutional aid, in addition to being used to provide access, is used in conjunction with admissions policies to attract students with specific characteristics to enroll. Financial aid is changing from assistance to those who would not be able to attend otherwise, to the amount of money necessary to enroll a particular student (Finney, 1996). According to McPherson \& Shapiro (1998), "differential treatment of students within the aid-eligible population is very common" (p. 96). Bowen and Breneman (1993) argue that student financial aid serves different purposes for different institutions. For some, financial aid is a price discount, a financial tool for increasing enrollment and net tuition revenues. For other institutions, it is an investment in the composition of the student body. In other words, less selective colleges use this tool to fill their classrooms. and the most selective colleges use it to create a diverse student body; many colleges in between do both.

\section{Statement of the Problem}

In today's higher education environment, institutions need tools to make accurate predictions about enrollment and financial aid. However. most existing research has studied the decision to enroll in college at the national level. and, when schools have been categorized, the categories have normally been limited to private and public schools or to two-year and four-year schools. Much work on the topic was based on decade-old data, and the research questions were generally related to federal policies (see Jackson \& Weathersby. 1975: Leslie \& Brinkman, 1987; Leslie \& Brinkman. 1988). Until recently, the market lacked workable predictive models. According to St. John \& Somers (1997). 
there is a "near-void" in institution-specific research regarding financial aid effects on student enrollment. Recently, some researchers have begun developing institutionspecific models to aid institution administrators. However, more refined techniques are needed. In addition, institution-specific variables need to be investigated. Past empirical research has analyzed the effects of changes in net price on students in different demographic categories such as income and race, but less attention has been paid to other factors important to universities, such as gender, religious preference, and geographic variables. Finally, because there is no general model, and because the costs involved are high, most institutions are working blindly, without a clear picture of the effectiveness of their existing financial aid strategies in simultaneously achieving enrollment and revenue goals.

\section{Purpose of the Study}

The purpose of this study was to develop and test a mathematical model of student enrollment for a private. more selective. Catholic university. The intent was to use this model as an enrollment management tool for predictive purposes, utilizing institutional data defined by historical administrative need.

The institution used in this study is a Roman Catholic university in southwest United States. It is a liberal arts institution that is dedicated to providing a values-based education. The university is classified as more selective. In 2000, it received 6.780 freshman applications for an entering class of 1.000 . Over $65 \%$ of undergraduate students receive some form of financial aid. Financial aid offers are both need-and merit-based.

When institutions set admissions and financial aid policies, two questions are asked: (1) what is the probability of enrollment for each admitted student, and, (2) is 
there any way to increase that probability in the short run? The outcome of this study is a quantitative model that can be used to answer these questions. The model is grounded in economic theory and derived using logistic regression equations. The variables in the model are those that are of policy interest to the particular institution. For each student, these are: the cost of attendance, measures of academic preparedness, gender, race or ethnicity, distance from home. and religious affiliation. The model utilizes data collected by the institution and available to it at the time the admissions and financial aid decisions are made. Specifically, this is data that comes from the admissions application and the financial aid application.

The methodology was carried out in three steps. First, an enrollment probability model was estimated using three years (1998-2000) of admissions data from the particular institution. Linear regression analysis is a logical technique for estimating most demand functions. However, the case of enrolling in an undergraduate program is different from that of typical decisions such as purchasing food or clothing. The decision to enroll in college is normally only made once. Therefore the quantity purchased is either zero or one. As with all dichotomous phenomena, several assumptions of linear regression are violated with this type of decision. In addition, although the decision for one candidate is yes or no, the accumulation of these decisions is used to determine the probabilities that certain groups of individuals will select a specific institution. This leads to the additional concern over whether or not probability relationships can be truly linear (Agresti, 1990: Greene, 1990. Crown, 1998). Because of these shortcomings of traditional linear regression, researchers have used logistic regression and probit analysis to study such phenomena as college enrollment and persistence decisions (Greene. 1990: 
Cabrera, 1994). Both methods are build to be used with dichotomous dependent variables, and are based on distributions that produce equations that do not hold marginal effects constant. The S-like shape of the equations from these models indicates that the effect of the independent variables is minimal until some threshold is reached, increases rapidly in the mid-range, and levels off again around at the top of the range (Kleinbaum, 1994). Both logistic and probit models are fairly similar theoretically (Dey \& Astin. 1993), and provide extremely similar results (Aldrich \& Nelson, 1984). The main difference between them is in the tails, or threshold areas, where the logit model approaches the probabilities of 0 and 1 less rapidly than the probit model. Since the literature strongly argues the limitations of linear regression, but provides no apparent relative strength between logistic and probit models, this research used both logit and probit models to estimate the probability model and compared the results of both estimation techniques.

The second methodological step was to validate the model against additional data. Since the purpose of developing this model was to predict enrollment in future years. a temporal validation was used. The model was tested for predictive accuracy against the admissions data for 2001. After rerunning the model for all four years, the final step in the research methodology was to simulate the effects on enrollment of various changes in the tuition and financial aid policy. such as the change in enrollment of specific target populations from a decrease in tuition. 


\section{Research Questions}

In order to develop a model that would predict with an acceptable degree of accuracy the enrollment probabilities of admitted applicants to the particular institution, the following research question guided the study.

How do the following factors combine to influence the first time enrollment probability at the case institution?

- Student price (tuition net of gift aid)

- Student preparedness (SAT score, High School GPA, institutional rating)

- Student socio-economic characteristics (race or ethnicity, family income, religious preference)

- Student demographic characteristics (distance from home. gender)

\section{Delimitations and Limitations.s}

This research focused on developing a mathematical model intended to be used as an enrollment management tool for predictive purposes. As such, it utilized institutional data defined by historical administrative needs, not data collected with theory testing in mind.

An important limitation to this study is the inability to generalize the results to other institutions. All institutions have a unique set of characteristics that influences enrollment decisions. The higher education market can best be described as monopolistically competitive. Each institution is, in fact, a quasi-monopoly. It cannot be assumed that changes in enrollment attributed to varying amounts of financial aid at one institution can be generalized to other universities, although institutions with similar characteristics can use the findings to make assumptions to start their own investigations. 
Careful construction of the research model is important in considering validity in quantitative research. This model was grounded in economic theory and derived using widely accepted statistical methodology. There may also be a question as to the reliability of the institutional quantitative data. Incentives exist for students to oversell their qualifications and overestimate their financial need. As far as qualifications are concerned, the institution has other documented sources of data, such as official SAT score reports and official school transcripts. This official data was used to measure student ability. Family financial data is usually verified by the institution through copies of IRS filing reports. This study used the same data that the institution uses for making financial aid decisions for all students.

This study used data from multiple years. To mitigate limitations regarding changes in admissions procedures and student demand over time, the data used for this study came from a four-year period where admissions procedures were fairly constant. and the selectivity ranking of the university remained constant.

\section{Significance of Study}

This study contributes to the body of empirical research regarding the factors that affect a student's decision to enroll in an undergraduate institution, with an emphasis on financial aid effects. While many studies have used national databases to examine student college demand, this study contributes to the methodologies used to examine the issues unique to given institutions. This study is useful to policy makers at private universities who are interested in enrolling a diverse student body while at the same time minimizing financial aid costs. For the case institution, this analysis helps clarify the market in which it operates, helps measure the influence of financial aid on enrollment decisions, and 
helps estimate financial costs and enrollment composition. In addition, the richness of the data collected should lead to a deeper understanding of the issues facing the case institution and to its organization environment. 


\section{CHAPTER 2 \\ Review of Literature \\ Introduction}

Researchers in the fields of economics, public policy, and sociology have studied college enrollment and student financial aid from the perspective of the student, the perspective of the institution. and the perspective of social policy. Most existing research is based on the foundation of economic theory as it provides a strong framework for both policy analysis and building practical tools. Supporting economic theories include human capital theory, utility theory, and demand theory. This chapter reviews the literature that is relevant to the purpose of this dissertation. It is organized into three sections. The first section reviews the economic theory of human capital as it relates to student decisions to attend college. and reviews empirical finding on the rates of return to investment in human capital. The next section reviews the economic theories of consumer choice. including utility theory and demand theory, and summarizes empirical finding on student price responsiveness related to changes to tuition and financial aid. The final section provides a review of relevant institutional and public policy issues regarding student financial aid.

\section{Human Capital and Rates of Retum on Investment}

\section{Human Capital Theory:}

In 1776, in what many call the seminal work in economic theory. Adam Smith briefly discussed the notion that men, while born fairly similar, begin to acquire skills and 
education that differentiates their labor productivity (Smith, 1937). This idea was mostly ignored, however, as economists during the industrial revolution assumed that labor was homogeneous in models that concentrated on the distinction between capital and labor. As we entered the information age, Gary Becker reintroduced the idea within a framework that allows for both quantitative analysis and policy discussions. According to Becker, "human capital refers to the skills, education, health. and training of individuals. It is capital because these skills or education are an integral part of us that is long lasting, in the way a machine, plant, or factory lasts" (1998, p.1). Human capital differs from physical and financial capital in that it is that capital which cannot be separated from the person. The concept of human capital has become increasingly important as world economies have moved from being labor and materials centered to being knowledge and information centered. The role of education and its effect on human capital has become an integral part of economic development models (Becker, 1998: McMahon, 1999). According to Becker (1998), as much as $80 \%$ of the capital of the United States and other developed countries is human capital.

Given that skills, knowledge, and even good health can be acquired. both individuals and companies invest in human capital. As Becker states. "Education and training are the most important investments in human capital" (p. 17). Human capital theory assumes that education raises productivity by providing knowledge. skills, and a way of analyzing problems. An alternate view. credentialism. assumes that education is a signal. In this view, a degree conveys information about underlying abilities and traits (Becker, 1993). In either case, to potential employers. education is an indicator of an individual's quantitative potential for productivity. For the individual, investment in 
human capital is a rational choice to defer current gratification for anticipated future earnings (Gray, 1995). According to Becker (1993), over a lifetime, individuals should accumulate human capital and then run it down. Earlier investments in human capital yield greater overall returns because one's life is finite.

As with other types of investments, one can analyze the rate of return on human capital investment. The private rate of return on investment, that is, the rate of return for the individual, is the rate that causes the net present value of the costs to equal the net present value of the benefits (Belfield, 2000). The costs are both the price paid (i.e. tuition and other expenses) and the foregone earnings during the time of schooling. The benefits are earnings over and above what would have been earned without the additional education. which includes both additional earnings per year, and additional earnings due to increased time in the work force (see Table 1). There are also benefits that cannot be given monetary values, such as the psychic retums to knowledge acquisition, better health, and increased longevity. Table 1 illustrates some of the non-monetary benefits of education. 
Table 1

Effects of Education on Selected Non-monetary Indicators

\begin{tabular}{|c|c|c|c|c|}
\hline & \multicolumn{4}{|c|}{ Educational Attainment } \\
\hline & $\begin{array}{l}\text { Less Than } \\
\text { High } \\
\text { School } \\
\text { Graduate }\end{array}$ & $\begin{array}{c}\text { High } \\
\text { School } \\
\text { Graduate }\end{array}$ & $\begin{array}{l}\text { Some } \\
\text { College }\end{array}$ & $\begin{array}{c}\text { Bachelor's } \\
\text { Degree or } \\
\text { Higher }\end{array}$ \\
\hline $\begin{array}{l}\text { Percent of Life Economically } \\
\text { Active from Birth } \\
\text { Male } \\
\text { Female }\end{array}$ & $\begin{array}{l}49 \% \\
29 \%\end{array}$ & \multicolumn{2}{|c|}{$\begin{array}{l}57 \% \\
39 \%\end{array}$} & $\begin{array}{l}59 \% \\
45 \%\end{array}$ \\
\hline $\begin{array}{l}\text { Deaths per } 100,000 \text { for Persons } \\
25-64 \text { Years of Age }\end{array}$ & 515.1 & 426.1 & \multicolumn{2}{|c|}{218.1} \\
\hline $\begin{array}{l}\text { Mothers Who Smoked } \\
\text { Cigarettes During Pregnancy }\end{array}$ & $31.1 \%$ & $18.0 \%$ & $10.4 \%$ & $2.6 \%$ \\
\hline $\begin{array}{l}\text { Breastfeeding by Mothers } 15-44 \\
\text { Years of Age }\end{array}$ & $43.0 \%$ & $51.2 \%$ & $65.9 \%$ & $80.6 \%$ \\
\hline Doing Volunteer Work & $29.9 \%$ & $40.4 \%$ & $56.7 \%$ & $67.2 \%$ \\
\hline Voted (1996) & $38.8 \%$ & $51.7 \%$ & $63.1 \%$ & $77.0 \%$ \\
\hline
\end{tabular}

Source: Mortenson. Postsecondary Education Opportunity, March 1999

In addition to the private rate of return. there is also a social rate of return, which compares the costs and benefits of education to society as a whole. These costs and benefits are much more difficult to measure. However, St. John and Masten`s (1990) comparison of the costs of federal student aid and the estimated increase in tax revenue reviewed later in this chapter is one such attempt at measuring this social ratc of return.

The main theoretical objections to Becker's human capital model are that it does not take into account certain structural or cultural factors that play a major role in career choice (Gray. 1995), it assumes that knowledge does not atrophy (Groot. 1998). and it assumes many constants over individuals. such as risk aversion (Belfield. 2000).

Nonetheless, the theory of human capital explains student choice in higher education well and is useful in making public policy decisions regarding access to higher education. 


\section{Estimates of the Returns to Investment in Education}

As stated above, one can estimate the return on investment in human capital. The rate of return on investment is determined by comparing the cost (tuition, forgone wages) to the expected stream of earnings, both in present value terms. Becker estimated, using ordinary least squares techniques (OLS), the rate of return on an investment in a college education by an urban, native white male who graduated from high school in 1939 to be about $13 \%$, and for one who graduated in 1949 to be about $11.5 \%$. after adjustments for different ability levels (Becker, 1993).

Other researchers have also estimated the rate of return on a college education based on Becker's theory. Hartog's (1999) review showed these estimates generally fall between $5 \%$ and $15 \%$. Card (1995a) also summarized recent studies and concluded the each additional year of schooling increases real wages by $6 \%$ to $10 \%$. This section will review four studies, three that used instrumental variable techniques and one that also estimated the retums for women.

Angrist and Krueger (1991) noted that conventional estimates that used OLS regression and measured the retums to education as the coefficient on the variable "years of schooling" could not control for unobserved factors which may be alfecting both schooling and eamings. This problem is sometimes referred to as "selectivity bias," since individuals tend to self-select their educational levels based on other factors. Because of this unobserved self-selection, the estimates using this technique may be biased. Angrist and Krueger used instrumental variable estimation to overcome this bias. As with all instrumental variables estimation, they looked for a variable to include in the estimation that was correlated with years of schooling but uncorrelated with the unobserved factors. 
and hence the error term in the equation. Due to compulsory education laws, children born later in a calendar year are required to obtain more schooling than those born earlier in the year are. (This is due to the fact that most school districts require that a child tum six by January 1 of the year he enters first grade, and the fact that most states require a student to stay in school until his sixteenth birthday.) Angrist and Krueger used the quarter of birth as their instrumental variable, since it is presumably correlated with years of schooling, but not unobserved effects. Their two-stage least squares estimates of the returns to education used a model containing the variables schooling. wages, quarter of birth. and demographic characteristics. Data was obtained from the 1960,1970 , and 1980 Census files. Their estimated returns on investment in education were from $7 \%$ to $10 \%$ for men who were aged 40 to 49 in 1960: from $6 \%$ to $8 \%$ for men aged 40 to 49 in 1970 : and from $4 \%$ to $7 \%$ for men aged 40 to 49 in 1980 . However, they also found that the estimates they obtained using OLS methods were not statistically significantly different from their instrumental variable estimates.

Card (1995b) did find significant differences in estimated returns to education using OLS and instrumental variable techniques. For his instrumental variable. he used geographic differences in the accessibility of college. arguing that the distance to the nearest postsecondary institution is correlated with years of schooling because it raises costs. but should not be correlated with unobserved effects on wages. The variables in the model were hourly wages. age. education, distance to nearest postsecondary school. certain demographic variables and certain family background characteristics. Card used a sample of individuals from the National Longitudinal Survey of Young Men (1966 through 1981). Using distance to the nearest postsecondary school as the instrumental 
variable, Card estimated the rate of retum to an additional year of schooling to be $13 \%$. Using OLS, his estimate was only $7 \%$. Therefore, Card concluded that OLS underestimates the returns to education.

Ashenfelter and Krueger's (1994) instrumental variable model took advantage of unique data. They interviewed 298 pairs of identical twins. They used the difference in each twin's education and earnings to control for unobserved family effects. They also used each twin's report of his or her sibling's education as an instrument for that sibling's own report of education, since misreports of education may be correlated with each other. but are unlikely to be correlated with unobserved effects on earnings. Angrist and Krueger estimated the returns to a year of education to be $16 \%$, and reported that their OLS estimates were biased downward.

The final study, by Kane and Rouse (1995) looked at the returns to education from both two-year and four-year institutions. They assumed that there is no difference between a credit unit at a two-year school and a credit unit at a four-year school. The variables in their returns to education model were the number of credits taken at two-year and four-year institutions, degree awarded, a measure of ability, demographic characteristics, family background characteristics. hourly wages, and average annual income. Data for their study came from the National Longitudinal Survey of the Class of 1972. which surveyed a panel of high school seniors in 1972. and periodically until 1986. Using OLS techniques, Kane and Rouse's findings were that the return to a year of schooling for men was $4 \%$ to $6 \%$. Unlike the other studies, they also estimated the returns for women, and found them to be between $6 \%$ and $8 \%$. They also found that receiving a 
degree had a greater effect on the returns to education than simply completing four years of schooling without obtaining a degree.

Two other groups of researchers looked at returns to education from different perspectives than the private rate of return on human capital investment models used in the previous studies. Pascarella and Smart (1990) studied the influence of both college grades and educational attainment on early career earnings (for the first nine years after entry into college). The results of their study showed that each grade point increased annual earnings by $\$ 432$ for African American women, $\$ 230$ for white women, $\$ 59$ for African American men, and $\$ 86$ for white men. They also found that educational attainment increased annual earnings for women, both African American and white. but had no effect on the earnings of men.

In the second study. St. John and Masten (1990) looked at a measure of the social rate of return on education. They examined the tax revenue increases attributable to federal student aid programs. They estimated gains in educational attainment attributable to federal student aid, then estimated lifetime earnings based on those attainments. and finally estimated federal income tax liabilities using then current laws. From these. St. John and Masten determined the net present value of those additional tax revenues to be \$4.30 for each student aid dollar spent on the high school class of 1972.

In summary, the human capital studies provide estimates for the rate of return to education for males that range from $4 \%$ to $16 \%$. Two of the three instrumental variable studies found that OLS estimates of the retums to education are biased downward. The Pascarella and Smart and the St. John and Masten studies also support positive earnings returns to education. In addition, the studies of both Kane and Rouse and Pascarella and 
Smart indicate that the returns to education are higher for women than for men, or at least were in the 1970s. Regardless of any downward bias in certain studies, what is clear is that the returns to the investment in education are significant and are likely one factor in maintaining the demand for higher education despite increasing prices. However, research to date has been general in nature. I found no references to returns on investment for particular undergraduate degrees or particular schools, and only two studies regarding diverse subgroups of students.

\section{Consumer Choice Theories and Price Sensitivity}

\section{Utility Theory}

While human capital theory addresses the choice to enroll in college as an investment decision, utility theory addresses that choice as a consumption decision. According to consumer behavior theory, a consumer chooses among available alternatives in a manner that maximizes his level of satisfaction. Information pertaining to his satisfaction is contained in the consumer's utility function (Henderson \& Quandt. 1971). A number of researchers have built models that hypothesize that the choice to enroll in college is the outcome of a utility-maximizing process. Willis and Rosen (1979) examined the hypothesis that high school graduates make the choice between attending college and entering the labor market by maximizing the utility associated with these two options. The utility of each option is based on the individual's unique characteristics and his or her expected lifetime earnings under each option. In particular. Willis and Rosen conjecture that some students have a comparative advantage in the occupations requiring a college education, while others have the comparative advantage in the occupations that require a high school education. Therefore, the expected lifetime earnings of each option 
would differ for individuals in each of the two groups. "Those who did not attend college (had they attended) would have earned less than measurably similar people who did attend, while those who attended college would have earned less as high school graduates than measurably similar people who stopped after high school" (p. S7). As noted before, this is often referred to as selectivity bias. Manski and Wise (1983), however, implicitly assumed that expected eamings based on college attendance are constant across individuals within a locality. In addition to ability, parental income, and high school characteristics, their utility model includes only the effects of the costs of college attendance - tuition costs, foregone earnings and financial aid-and does not include expected future earnings. Brewer and Ehrenberg (1996) extended both of these models by going one step further than Willis and Rosen to differentiate between types of colleges chosen, while incorporating the cost aspects of the Manski and Wise model. Bershadker's (1998) utility function measured the background, socioeconomic, and ability characteristics of each individual, the expected lifetime earnings of each option. the net cost of attending college, and a random component for tastes, preferences, and nonmonetary benefits of each option.

There are a number of rationales for looking at college enrollment in terms of consumer utility rather than simply as an investment in order to increase future earnings. In reality, individuals also attend college to broaden their horizons, have new experiences, and become more well rounded (Bershadker, 1998). Haveman and Wolfe (1984) also point out that acquiring education has non-market (yet utility maximizing) outcomes such as health status. marriage. fertility, and criminality. In addition, looking at college enrollment from an investment point of view may be unrealistic because some 
students do not bear the full burden of cost and others may not be able to borrow the up front costs due to imperfect capital markets, even with the help of federal student loan programs (Bershadker, 1998). ${ }^{2}$ Utility theory can account for the additional consumption benefits and imperfect investment information.

\section{Demand Theory}

Demand theory follows analytically from utility maximizing theory. The demand for a particular commodity can be derived by maximizing the consumer's utility function across all commodities simultaneously (Henderson \& Quandt, 1971). Based on this, the quantity demanded of a good or service is related to the price of the good or service, the income of the buyer, the prices of alternative products, and the buyer's tastes and preferences. In the case of demand for particular institutions of higher education. theory maintains that students respond inversely to net tuition (Breneman, 1994; Hopkins \& Massy, 1981) and directly with income. and the prices of alternative goods. All else constant. as the price of attending a specific college decreases. more students will desire enrollment. Figure 1 illustrates a typical downward sloping demand curve for a selective university $\left(D_{S}\right)$, with the able and willing students arranged in order of how much they are willing to pay. The demand curve is downward sloping because it is assumed that each college is a price-discriminating monopolist. Each college can be viewed as a monopolist because it offers a unique education and experience. which is made up of a particular combination of history, religious affiliation, course and major offerings, and prestige not found anywhere else (Breneman, 1994).

\footnotetext{
'See the section Institutional and Public Policies Issues Regarding Financial Aid for more discussion about the availability of information on student financial aid programs.
} 


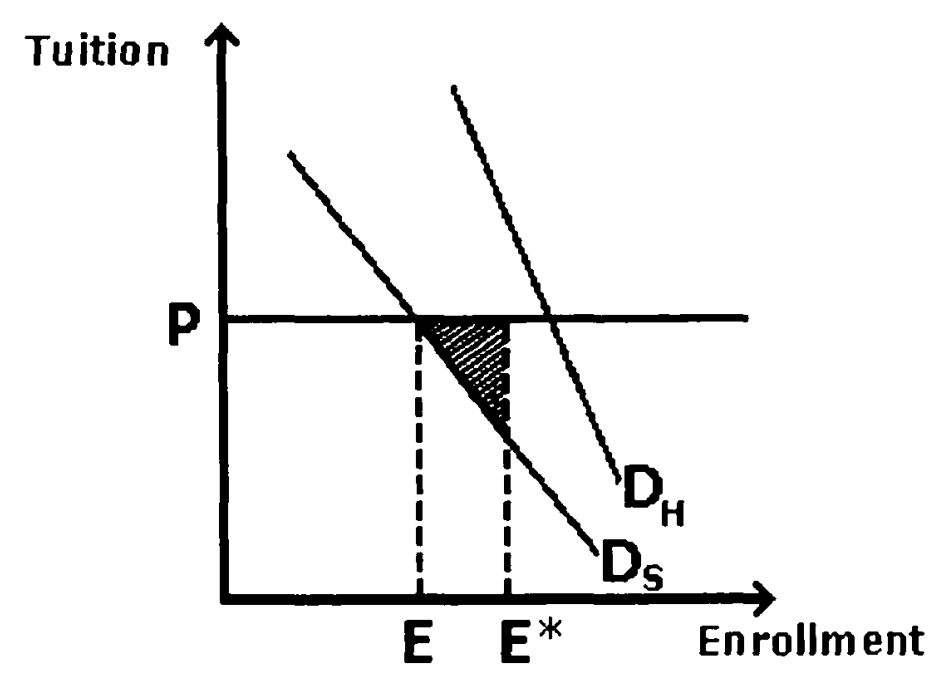

Figure 1 . Demand curves for selective and highly selective universities.

The tuition that a university charges, $\mathrm{P}$. is determined by optimizing the level of educational resources (Hopkins \& Massy, 1981), or, as observed by Breneman (1994). by optimizing the level of enrollment and resources. This tuition must also be in line with the tuition charged by the institutions it sees as its competitors. In Figure 1. P illustrates that price, and $E^{*}$ is the optimal enroliment level. At many colleges, the optimal enrollment cannot be reached at the optimal tuition $\mathrm{P}$. The shaded area represents the cost of financial aid, as each student between $E$ and $E^{*}$ receives a larger financial aid package to induce him to attend. This illustrates the price discriminating aspect of the model. since students face different net prices. For a few of the most highly selective universities. the demand curve is actually far enough to the right that total enrollment could be met at full price (demand curve $D_{H}$ in Figure 1). However, these schools choose to incur the opportunity cost of providing financial aid in order to invest in the quality and diversity of the student body (Breneman, 1994, Bowen \& Breneman. 1993). 
In addition to the relative position of the demand curve, another factor that is important in demand theory is the slope of the demand curve. The slope illustrates the extent to which enrollment demand responds to changes in price. This price sensitivity is called the elasticity of demand and is affected by a number of things. ${ }^{3}$ The ease of substitution of other goods is a primary factor. For example, if a student regards several universities as more or less desirable for the satisfaction of his education needs, the demand for each school will be highly elastic. However. if a particular school has some quality. such as prestige or a unique major that cannot be found at another institution, the demand for that school will be highly inelastic. Other factors that affect elasticity are the prices at other institutions, expectations about future prices, and family income. In addition to this measure of price responsiveness. some authors (Jackson \& Weathersby, 1977: Leslie \& Brinkman. 1987) have calculated a student price response coefficient (SPRC). The SPRC reports the change in college enrollment for a group as a result of a $\$ 100$ (or $\$ 1,000)$ price increase.

Demand theory provides a simple, workable model for analyzing public and private policy questions regarding such things as stimulating enrollment and providing access to college for underrepresented groups. School administrators and government policymakers can control price through both the actual price of tuition and the amount of financial aid. If the elasticity of demand is different for different subgroups of students. then enrollment proportions can be modified by manipulating the price.

\footnotetext{
"In mathematical terms, the price elasticity is equal to the percentage change in quantity demanded divided by the percentage change in price (Henderson \& Quandt. 1971).
} 


\section{Price and Financial Aid Effects on College Enrollment Decisions}

Researchers have been studying the economic factors that affect student college enrollment, and, in particular, the effects of changes in price and financial aid, for twentyfive years. There are two main reasons for this. First, as Leslie and Brinkman (1988) point out, "Expanding and equalizing student access long has been a major public policy goal, and manipulation of price has been seen as the major policy instrument for achieving this goal" (p. 182). Researchers have been interested in substantiating the fact that federal and state governments can increase access to college for underrepresented groups by lowering the net price paid. In addition to access, student choice among institutions has become an issue not only for government, but also for private institutions that are trying to optimally manage their enrollment. The theoretical foundation for most of these studies has been either utility theory or demand theory. A number of authors have produced reviews and meta-analyses of the published research findings, starting with the earliest works from the 1960s. For this literature review. I will summarize the research through the review articles of Jackson and Weathersby (1975), Leslie and Brinkman (1987), and Heller (1997), and follow with more recent research in the area.

The seminal work in the area of meta-analysis of price effects on enrollment in higher education is that of Jackson and Weathersby (1975). They reviewed seven empirical studies that were conducted between 1967 and 1975. The studies used a number of approaches. Five of them utilized traditional demand theory as the basis for regression analysis. The other two used utility theory as the basis for their maximum likelihood estimations. In a demand study, the options are to enroll or not enroll, either in higher education in general or at a particular institution. The utility of other options in not 
factored in. Using a utility model, the value of the alternatives, usually viewed as entering the job market, are taken into account.

Jackson and Weathersby compared the results from these seven studies by calculating what they labeled a student price response coefficient (SPRC). This SPRC converted all results to a common set of values for family income, base year and base tuition. The SPRCs that they calculated were for a hypothetical first-time student from a family earning $\$ 12.000$ in 1974 and facing a college cost of $\$ 2,000$ per year. Their calculations resulted in SPRCs that ranged from $-0.05 \%$ to $-1.46 \%$ change in the enrollment rate for each $\$ 100$ increase in price, with a mean of $-1.06 \%$. These numbers need to be converted further. Since the higher education participation rate was $29.5 \%$ in 1973, a SPRC of $-1.06 \%$ means that participation would drop by about $2.5 \%$, or to $27 \%$, if tuitions increased by $\$ 100$. Jackson and Weathersby also noted a consistent fact across the studies: the absolute magnitude of the price responsiveness increases as income decreases. that as, potential students from low-income families are more affected by price changes than those from high-income families. In addition, it should be noted that a $\$ 100$ change in tuition would have had a much smaller impact on students planning to attend a private college, with the average tuition of $\$ 6.671$ in 1974 . than on students planning to attend a public college, with the average tuition of $\$ 1,361$ in 1974 (The College Board. 1998a).

Of particular interest for the present research is the study done by Spies (1973). Spies divided institutions of higher education into cost-quality categories. roughly related to selectivity categories, and students into groups by family income and academic ability. This resulted in 650 college-type/student-type groupings, which were used as 
observations in a multiple regression analysis. Variables in the analysis were annual family income, student's combined SAT score, college's median combined SAT score, cost of attending that college divided by family income, the square of the difference between the student's combined SAT score and the college's median combined SAT score, and the number of schools in the category. Spies' results were a 6.72 percentage point decrease in the likelihood of applying to a college for every unit increase in the ratio of college cost to father's income. However, the sample used had a family income $\$ 3.000$ higher than the national average at the time. This would probably cause an underestimation of the effect. since higher income families are less sensitive to price changes. In addition, applications were used instead of enrollments, and this would also likely cause an underestimation of the effect of price changes, since students often apply to colleges more expensive than they plan to attend.

A number of authors found fault in the methods Jackson and Weathersby used to equate the finds of the studies. Chisholm and Cohen (1982) showed that, due to the mathematical properties of elasticity, comparisons across studies could produce errors. especially in the case of time series data. Leslie and Brinkman (1987) also noted that Jackson and Weathersby deflated price levels twice in their analysis and made some inconsistent assumptions about the student base. However, they also concluded "that Jackson and Weathersby's errors often cancel out" (p. 186), therefore providing an estimate of sensitivity that may be fairly accurate.

In 1987 Leslie and Brinkman conducted another meta-analysis of the price responsiveness in higher education enrollment. They analyzed twenty-five higher education demand studies published between 1967 and 1982. including both time series 
(20) and cross-sectional (5) analyses, and including models based on both traditional demand theory and utility theory. Their goal was not only to thoroughly and systematically examine the literature, but also to standardize the findings so that a definitive conclusion might be reached. Results of each study were adjusted three ways. First, each result was transformed to a common measure of student response to change in price. Second, each was corrected to reflect consistent price levels. Finally, the data was converted to a common student age base. As in the Jackson and Weathersby analysis, a student price response coefficient (SPRC) was calculated. The final SPRCs reported were the change in participation in higher education for $18-24$ year olds as a result of a $\$ 100$ price increase. in the base school year 1982-83.

The results of all studies reviewed were in the expected direction, that is. enrollment increases when prices go down. The calculated SPRCs ranged from $-0.2 \%$ to $-2.4 \%$, the mean response was $-0.7 \%$, and the mode was $-0.6 \%$, which they suggested as the "best estimate for public policy purposes" (p. 189). This is slightly lower than Jackson and Weathersby's average of $-1.06 \%$. The modal response of $-0.6 \%$ is interpreted as follows: for every $\$ 100$ increase in tuition price against the average tuition in $1982-83$ of $\$ 3.420$, the participation rate of $18-24$ year olds would drop $-0.6 \%$. Since the higher education participation rate was $33 \%$ for $18-24$ year olds in 1982 , this means that participation would drop by about $2 \%$, or to $31 \%$ if tuitions increased by $\$ 100$.

Results tended to be higher for community colleges and public institutions, and lower for data that covered private institutions only, as one would expect. Overall. SPRCs at two-year public colleges appear to be at least two or three times larger than at private colleges. This is presumably due in part to the higher average family income and the 
higher base price of tuition at private colleges. Of the three private college studies reviewed, Knudsen and Servelle's (1978) results for moderately selective, private colleges were at the mode for all public and private schools $(-0.6 \%)$, which is higher than expected for private colleges alone. A number of regressions were run in the study, using combinations of the following explanatory variables: tuition and fees or tuition and fees minus student aid: state personal income per capita; average tuition and fees at competing public institutions or average tuition and fees minus student aid at competing public institutions; average tuition and fees at competing private institutions or average tuition and fees minus student aid at competing private institutions. However, they used net tuition as the price variable when calculating price elasticities. and a net price increase of $\$ 100$ could equate to a "list price" increase of as much as $\$ 200$.

Three studies investigated income effects. Radner and Miller (1970) used 1966 data for California and Illinois high school seniors. Using the explanatory variables ability, income selectivity or quality of alternative schools, and out of pocket costs. they found student responsiveness inversely related to family income. Hoenack (1968) studied the effect of income using 1965 high school seniors applying to California state colleges and junior colleges. Explanatory variables in his model were the cost of attendance, the average unemployment rate in the region. the average wages in the region. the median family income in the region. and an interaction variable between cost and income. The results of this study also verified an inverse relationship between income and college enrollment. In contrast, Corazzini et. al. (1972) showed a pattern of the highest responsiveness demonstrated by the top two income quartiles at private institutions (presumably implying a switch to public schools) and the bottom two quartiles at public 
institutions (presumably implying a switch to two-year institutions or a decision to not attend college). These results were based on an early 1960 s national sample of 4,000 high school seniors, using the variables tuition, state average production worker wages and employment, average level of father's education in state, and average performance on achievement test in state. The sample was stratified by income, and separate regressions were run for each quartile. None of the studies in the Leslie and Brinkman analysis compared rates between the genders.

In 1988, Leslie and Brinkman examined the literature on the effects of student financial aid on college enrollment. They examined studies that had used three types of approaches to the problem: econometric analyses of enrollment behavior. surveys of student opinions on the impact of financial aid, and calculations of the aggregate enrollment in higher education, or participation rates. Unlike their 1987 review of demand studies based on tuition only, they did not conduct a formal meta-analysis. This was not only due to the fact that there were three different approaches to the issue, but was also due to the fact that methodology varied widely within the general approaches. They reported their findings in terms of the effects of financial aid on access. choice. and persistence (which will not be reviewed).

A major public policy question regarding financial aid is whether or not it is responsible for some students attending college at all. in other words. does it improve access to higher education for students who could otherwise not afford to attend. Leslie and Brinkman reviewed nine econometric studies, six opinion-survey studies. and twelve studies that calculated participation rates. The results of most of the studies indicated that financial aid. at least in the form of grants, increases the enrollment of low-income 
individuals. They estimated from the econometric studies that $20 \%$ to $40 \%$ of the enrollment of lower-income students, and $13 \%$ of the enrollment of middle-income students, was due to grant aid. Aggregating these numbers for 1982, their conclusion was that $16 \%$ of the full-time enrollment in college was due to the existence of need-based grants.

However, one of the most controversial findings was that of Hansen (1983). He used data from the Current Population Survey to analyze the effects of the Basic Educational Opportunity Grants (BEOG) program established in $1972 .{ }^{+}$Comparing enrollment rates before and after the implementation of the BEOG program (1971/72 and 1978/79), he found little improvement in the enrollment rates of lower-income students. He confirmed this finding using the High School and Beyond Surveys of 1972 and 1980. Hansen offered four possible explanations for these findings: (1) the program did not target aid enough towards lower-income students: (2) the size of the grants and the overall volume was not enough to change aggregate behavior: (3) because of changing tuition prices, the enrollment might have actually decreased during the time period if the grants were not available; (4) the findings might have methodological problems.

A second public policy question regarding financial aid is whether it opens up the possibilities of choosing from the full range of institutions. At the institutional level. administrators want to know how effective changes in financial aid awards are in attracting students to enroll. Leslie and Brinkman analyzed over 30 studies addressing one or the other of these choice questions. Their conclusions for the effect of financial aid on choice of institution is not as clear as their results for access. Nonetheless, the evidence in the research did indicate that institutions can improve their ability to recruit 
students by using financial aid and that financial aid has had a beneficial effect on student choice.

The literature showed conflicting results concerning the effects of Pell Grants on college choice. Based on four of the econometric studies, Leslie and Brinkman calculated the effect of a $\$ 100$ decrease in the net price difference between competing institutions. They estimated that the higher cost institution would obtain a $1.8 \%$ increase in lowerincome enrollments if they increased aid by $\$ 100$ ( $18 \%$ for a $\$ 1,000$ increase in aid).

Heller (1997) updated the comparison analyses of Leslie and Brinkman in order to capture the effects of the significant increases in real tuition prices during the 1980 s and 1990s. His review included both effects of tuition changes and financial aid, as the significance of aid gained during the time period. In addition, he also analyzed the data in relation to comparisons between students of different incomes and of different races and ethnicities. Again, there was no comparison of students of different genders.

With regard to the price of tuition and college enrollment. Heller reviewed nine recent studies. All the studies found that increases in tuition will result in decreases in enrollment. The exact size of the effect differed depending on the methodology and data set used, and depending on the student characteristics and institution characteristics. In general. the studies indicated that an increase of $\$ 100$ in tuition would result in a decrease in enrollment in the range of $0.5 \%$ to $1.0 \%$, results consistent with Jackson and Weathersby (1975) and Leslie and Brinkman (1987).

Savoca's (1990) theoretical model deserves particular note. She argued that "by treating the application decision as exøgenous. [most studies] are likely to understate the true price effects, for they ignore the possibility that a change in tuition may affect

\footnotetext{
4 As an historical note. Pell Grants replaced Basic Educational Opportunity Grants in 1973.
} 
enrollments through its effect on the decision to apply to college" (p. 123). Savoca reexamined the same data set that was used by Fuller, Manski, and Wise (1982). Her model used the explanatory variables combined SAT score, race, unemployment rate in state, average hourly earnings in state, father's education, mother's education, annual cost of attendance of institution, average combined SAT score for institution, geographic region of residence, parent's annual income. Where Fuller, Manski, and Wise s had found an SPRC of $-0.23 \%$ for those students who applied, Savoca estimated an SPRC of $0.26 \%$ for the decision to apply. Assuming that a school's tuition policy and admission policy are set independently, she argued that the true price sensitivity was the sum of these, or $-0.49 \%$. Heller noted that a flaw in this analysis is that rising tuition prices may force institutions to lower their admissions requirements, violating Savoca's assumption of independent policy decisions. However. Heller's concern neglects the fact that there are both student and institutional decisions, and tuition increases do affect individual decisions to apply to college. An alternative approach might be to take Savoca's two effects and subtract out the students who enrolled after a price increase who would not have been accepted anywhere unless admissions standards had changed.

Heller also reviewed articles covering the relationship between student financial aid and college enrollment. Although one might assume that students should react similarly to dollar for dollar changes in tuition and financial aid. the research shows that this is not the case. One reason is that there are many forms of financial aid: grants. subsidized loans, unsubsidized loans, tuition remission, and work study. Students do not tend to do the mental gymnastics that economists do to equate the net present value of these. and so do not make decisions on the same basis. Students also seem to have the 
largest reaction to the "sticker price," possibly from not being aware of all of the financial aid opportunities, or not believing that they would qualify for them.

Evidence of this can be seen in the twelve studies reviewed by Heller. Kane (1994) tested the conclusions of Hansen (1983) discussed above. His analysis confirmed Hansen's findings that enrollment rates of lower-income students did not increase due to the BEOG program. He offered another explanation for this: that only the students who were already college-bound had the time and incentive to "solve the mystery of eligibility" (p.8). McPherson and Schapiro (1991a) performed a time series analysis of the CPS data (1974 to 1984), including more years than Hansen (who used only two points in time), but only looking at white students. Explanatory variables in their model were time trend, gender, net cost. dummy variables for medium and high income, and interaction terms between cost and income, time and income, and gender and income. They reported that the effect on lower-income white students of a $\$ 100$ increase in financial aid from the BEOG program would be an increase in enrollment of 0.07 percentage points.

Other research reviewed by Heller analyzed the effects on enrollment of different types of financial aid. Moore. Studenmund. and Slobko (1991) examined one institution. Occidental College. They modeled the decision to enroll by considering the choice between this college and another selective college. The explanatory variables in the model were student's academic rating (given by Occidental admission's staff), gender. race. legacy (whether parents, siblings or grandparents attended Occidental), region of residence, parent's discretionary income, average SAT at other college, region of other college. and cost variables (in one version Occidental cost variables minus the cost at the 
other college, and in the other two versions Occidental costs and the other college costs entered separately). They found that a $\$ 1,000$ increase in grants would increase the probability of student enrollment by $7.8 \%$. When comparing other types of financial aid, however, they reported that "scholarships affect the probability of enrollment of financial aid applicants, but loans and work-study have no significant effect" (p. 311 ). St John (1990) found that enrollment was sensitive to changes in loans and work study. He examined the HSB survey data, and used the variables region, ethnicity, mother's education, family income, ability/achievement, high school experience, post-secondary aspirations, tuition, and student aid in his model. He estimated that a $\$ 1.000$ increase in grants increased the probability of enrollment by 4.3 percentage points. a $\$ 1,000$ increase in loans increased the probability of enrollment by 3.8 percentage points, and a $\$ 1.000$ increase in work study increased the probability of enrollment by 4.6 percentage points. In general, those researchers who conducted cross-sectional analyses tended to find that students were sensitive to financial aid awards.

Heller also examined the research with a focus on students of different incomes and races. Kane (1995), McPherson and Schapiro (1989), and St. John (1990) all found that sensitivity to changes in tuition and financial aid differed by income level, with generally the lower-income groups being more sensitive. McPherson and Schapiro (1994) specifically examined data from the American Freshman Survey for evidence of the middle income melt-the suspicion that middle income students are most severely affected by rising tuition. Their analysis of 1980. 1989, and 1993 survey data indicated that middle-income student enrollment declined over the period. but they attended private and public institutions in the same proportions. It could not be discerned from the data 
whether this was due to changes in national income distributions or differential changes in enrollment rates. St. John and Noell (1989), Jackson (1989), Kane (1991), and Heller (1994) found consistently that white students were the least sensitive to changes in tuition and financial, although differences in sensitivity between Hispanic and African American students fluctuated in the findings.

Heller's summary shows that the findings regarding financial aid effects are much more complex than those of tuition effects. Those researchers who used cross-sectional data and who analyzed the types of aid separately concluded that at least grants had a effect on enrollment. Those researchers who used time series data to analyze the BEOG program reached conflicting conclusions. Heller concludes that "more time-series research is needed to determine whether the effects of financial aid are consistent over longer periods of time, and are not just an artifact of the periods studied in the crosssectional analyses" (p.637-8).

Some other recent work has brought additional insight into student college choice between private and public institutions by adding measures of student willingness to pay into their models. The lack of inclusion of variables related to students' subjective preference and expectations had limited research (Manski, 1993). Hu and Hossler (2000) analyzed data from a longitudinal survey of Indiana high school students. where students and parents were interviewed 10 times between their freshman and senior years (19861990). Besides background characteristics (gender, race and ethnicity, father's and mother's education, and parental income), and student academic characteristics (high school GPA and education expectations). they added student sensitivity to tuition and to financial aid variables. Stepwise logistic regression was used to estimate the model. The 
results of the study suggest that student and family characteristics alone do not explain student preference for type of institution. Students who are less concerned about the price of tuition are more likely to have a preference for private institutions. Students who feel financial aid availability is more important are also more likely to have a preference for private institutions. Hossler, Hu, and Schmidt (1999), using the same data set, found family income reduces student sensitivity to both the price of tuition and the importance of the availability of financial aid. This helps explain why much research indicates that family income has little bearing on preference for private institutions.

Finally, Somers (1991) and Sinha (1997) provide recent research on enrollment prediction models at the institution level. Somers analyzed first-time attendance, withinyear persistence, and year-to-year persistence at an urban, public university. With regard to first-time attendance, the model included the factors background (race or ethnicity, gender, age, independence status, and income), achievement (ACT category and National Merit Finalist status), and financial aid (receipt of aid, amount of aid, type of aid, and package). Somers found financial aid had a positive effect on enrollment. calculating a SPRC of 6.2 percentage points per $\$ 1.000$ in aid. Sinha used a market demography perspective to develop a predictive model for student enrollment at a private, highlyselective, national university. Data used was for the three-year period 1994-1996. and consisted of only non-ethnic-minority. admitted first-time freshmen in the School of Engineering. Variables included demonstrated need, gender, high school GPA. financial aid award, and residence status (in-state or out-of-state). Results of the logistic regression sensitivity analysis predicted total enrollment of 317 . compared to the actual enrollment of 327 (3.1\% difference). 
With the price of higher education increasing over the last two decades, why hasn't enrollment fallen? Leslie and Brinkman (1987) cite three price-related factors. First, educational costs lagged behind inflation in the 1970s, so this catch up has not caused a significant rise in relative prices. Second, individual students have been able to avoid the price increase by attending a lower-cost institution. Third, need-based aid at the institutional level has increased, lowering the actual price. In addition, the assumption of all else constant does not hold. McPherson and Schapiro (1998) note that the returns to education have increased. Tastes and preferences are changing, for example, with more women pursuing schooling beyond high school. Finally, the product itself is changing. with universities offering more variety in programs.

Institutional and Public Policies Issues Regarding Financial Aid

As the research in the previous section shows, financial aid is a factor in student decisions to attend college. especially for lower-income students. Here in the United States. we have historically had two competing philosophies on who should pay for college. The first perspective is that higher education enhances the lives of those who receive the education, and the recipients should pay for it. The early private and religious colleges founded in the seventeenth and eighteenth centuries were funded from tuition. Fortunately, we have a long history in this country of philanthropy that provides scholarships to "needy and deserving" students. These scholarships came mostly from wealthy donors and were either provided directly to students or were funneled through institutions of higher education. The second perspective is that higher education, just like $\mathrm{K}-12$ education, provides benefits to society in general. Because of this, the costs of higher education should be funded or at least subsidized by the government. Working 
within this perspective, state governments began erecting public universities and colleges in the nineteenth century. The federal government involved itself through the passage of the Morrill Acts of 1862 and 1890, which created land-grant colleges specializing in agriculture and engineering. Through this perspective emerged the state college systems of the twentieth century. In $1998,44 \%$ of the cost of a public institution education was funded by the state and local government (The College Board, 1998b).

After World War II, two new trends began in the financing of higher education. With many veterans returning to the United States, the federal government sought to both reward those veterans and control their entry into the labor market. The Serviceman's Readjustment Act of 1944 (the GI Bill) was passed, which provided fixed stipends to the veterans and direct payments to institutions for tuition. This started the trend of the federal government providing financial aid benefits directly to individuals. The Higher Education Act of 1965 instituted programs to equalize access to college for all qualified students. These programs included grants, college work study and guaranteed student loans provided based on individual need. This act has been reauthored a number of times since 1965 , with the balance shifting from the provision of grants to the provision of loans (Gladieux \& Hauptman. 1994). Because of this shift. federal grant programs have not kept pace with rising costs in education. In 1975, the maximum Pell Grant funded $85 \%$ of the tuition at a four-year public college and $38 \%$ of the tuition at a four-year private college. By 1985 , these figures had fallen to $60 \%$ and $25 \%$, respectively. They are now $38 \%$ and $17 \%$, respectively (The College Board, 1998b).

The second trend is increased competition for students. By the mid-1950s, there were fewer and fewer returning servicemen to take advantage of the GI Bill. Colleges 
began bidding for students by offering better and better institutional financial aid packages. The College Scholarship Service (CSS) was formed in 1954 as an offshoot to the College Entrance Examination Board, which already had the mission to foster cooperative admissions policies between high schools and colleges. The mission of CSS was to develop a method for objectively determining a family's ability to pay for higher education. The methodology took into account family income, assets, and obligations. The gap between the total cost of education and the family's ability to pay was calculated. CSS helped colleges develop aid-packaging methodologies. These aid packages included grants, loans and work. CSS encouraged colleges to cooperate in determining their aid-packaging methodologies. One of CSS's principles was that students should only receive aid up to their demonstrated need. This principle could more appropriately be termed a "vision" or even an "ideology." The hope was that institutions of higher education, with the support of the government, could achieve equal educational opportunity by making the commitment to meet the full financial need of all admitted students (McPherson \& Schapiro, 1998). However, there were incentives for institutions to cheat on the agreement to enroll more students from the common pool. In reality, most institutions were never financially able to embrace this concept without the help of federal grants. As was mentioned above. federal government support did not maintain pace with the rapidly rising tuitions of the 1980s and 1990s. Despite budgetary struggles, institutional grants are taking up the slack. Presently, institutionally funded financial aid pays for $19 \%$ of the cost of attending college (The College Board. 1998b). 
Taken together, these two trends leave both prospective students and policymakers confused. Mumper (1996) summarizes the dilemma that policymakers are facing in seeking to lower the cost of education for needy students:

A plan that may look good in an economics class may prove counterproductive in the real world of college finance. In this view, lower-income students are likely to become discouraged by rapid increases in the "sticker price" of higher education. This occurs because information about tuition levels is much more widely known and available than is information about financial aid programs. (p. 45)

These new forms of government and institutional aid led many policy analysts to question whether student aid was actually a major factor in the rapid rise of tuitions. With respect to federal aid, the argument was that these funds are simply "appropriated by the universities and colleges" (Baldi \& Pearson, 1998: Hauptman, 1990). With respect to institutional aid, the argument was that tuition for full-pay students had to rise in order to generate the funds necessary for institutional grants. Baldi and Pearson (1998) reported that, as of that date. net tuition (after institutional grants) was about $80-85 \%$ of gross tuition. This practice has, in tum, created a debate related to distributive fairness, as rising tuitions pushed affordability of college for middle-class students to a top priority for federal policy makers (Reindl \& Redd, 1999). However, others contended that competition between colleges necessitated expenditures on programs, and that these expenditures were the cause of rising tuitions (Reynolds. 1997: St. Johns, 1994). Empirical research by McPherson and Schapiro (1991a and 1991b) showed that increases 
in federal aid did not have an impact on tuition levels at private colleges and universities, but institutional aid did increase with increases in federal aid. According to a more recent Coopers \& Lybrand, LLP report (1997), federal aid had the effect of reducing tuition levels, and increases in institutional aid accompanied substantial increases in tuition. In their 1998 work, McPherson and Schapiro analyzed institutional finances during the period 1987 to 1994 . They found that the real annual growth rate of institutional aid at private schools increased in the range of $8 \%$ to $9 \%$ for different groups from 1987 to 1991 , and then increased by $8 \%$ to $12 \%$ from 1991 to 1994 . During that time, a considerable gap developed between gross tuition and net tuition, making tuition hikes not fiscally productive. However, none of these methodologies provide any information about causation. McPherson and Schapiro did note that increases in institutional aid caused a reduction in expenditures in other categories. most notably operations and maintenance, suggesting intergenerational transfers of costs, with deferred maintenance costs moving to future years. Not satisfied with these regression-based studies, which simply correlated the time series trends. Baldi and Pearson (1998) have outlined a causal structural equation model for estimating the relationship between financial aid and tuition. $^{5}$

One of the reasons it is difficult to sort through the chicken and the egg controversy regarding financial aid and tuitions is that financial aid, and particularly institutional aid, is used differently at different private institutions. Institutions of higher education, especially those that are concerned with their selectivity rating, have admissions criteria related both to measures of probability of success and to other purposes of the university, such as diversity in the student body (Quann, 1979). There is a

\footnotetext{
${ }^{5}$ Baldi and Pearson have not published results using this model with existing data sets.
} 
large research base devoted to optimal admissions criteria (see for example Lay, Maguire, \& Litten, 1982, and Peacock, 1993). However, admitting the right students is only the first step, since these students must also matriculate. Because of this, institutional grants, in addition to being used to provide access, are also used in conjunction with admissions policies to attract specific students to enroll. According to McPherson and Schapiro (1998), while few institutions are willing to admit to it, "differential treatment of students within the aid-eligible population is very common" (p. 96). Even at schools that preach no-merit, need-only financial aid, it is common for some students to be offered packages containing more grants and less loans. Institutions use this financial aid packaging as a competitive tool, along with the natural competitive tools of programs, faculty prestige. etc. Shea (1996) reports cases of institutions offering "desirable" students various financial incentives while still advertising need-blind polices. Bowen and Breneman (1993) also argue that student financial aid serves different purposes for different institutions. For some, financial aid is a price discount. a financial tool for increasing enrollment in general and, therefore, net tuition revenues. For other institutions, it is an investment in the composition of the student body. In other words, less selective colleges use this tool to fill their classrooms, and the most selective colleges use it to attract the best students and to create a diverse student body: many colleges in between the extremes use aid to do both.

\section{Conclusion}

Theory and research to date suggest the following points regarding student demand for higher education in the United States:

- There is a positive rate of return to higher education: 
- The rate of return differs between groups, and is higher for women than men:

- Most students are sensitive to changes in the price of tuition, with enrollment demand decreasing as tuition increases, all else constant;

- Lower income students are more price sensitive that other income groups;

- Student price sensitivity measures are lower for private institutions than for public institutions;

- Students from lower-income groups are sensitive to changes in student financial aid, at least in the form of grants;

- Information regarding financial aid is less than adequate for obtaining the full potential impact of government financial aid policies:

- Institutions use financial aid to increase enrollment and to invest in the diversity of the student body:

- Institutions use differential packaging to attract certain groups of students. The present research will expand upon these findings to date by investigating particular subcategories of students and institutional types. 


\section{CHAPTER 3}

\section{Methodology}

\section{The Theoretical Model}

The purpose of this study was to develop a mathematical model of the decision to enroll in a private, more selective, Catholic university. In addition. the intent was to use this model as an enrollment management tool for predictive purposes, utilizing institutional data defined by historical administrative need. Specifically, then, the goal of the present research was to fit the best predictive model for the data collected by the institution and available to it at the time the admissions and financial aid decisions are made.

According to Hossler and Gallagher (1987), college enrollment is a three-phase process. The first phase is the predisposition phase, during which the student determines whether or not he would like to continue his education past high school. The second or search phase consists of looking looks for colleges to attend and learning about the characteristics of various colleges. During this phase, the student develops a choice set. the set of institutions to which he will apply. The final phase is the choice phase, deciding which member of the choice set to attend. This research focused on the third phase of college choice-the decision of which college to attend once admissions decisions have been made. As discussed in the review of literature. economics provides a number of theories that lay the foundation for modeling student enrollment decisions. When examining the enrollment decision for a particular university at this stage. demand 
theory provides the best theoretical basis. Theory states that the demand for a particular institution of higher education is a function of the price of the institution, income, the price of competitors, and the student's tastes and preferences. Each institution is a pricediscriminating monopolist, and faces a downward sloping demand curve relative to price. All else constant, as the price of attending a specific college decreases, more students will desire enrollment. Figure 2 illustrates a typical downward sloping demand curve for a selective university $\left(D_{S}\right)$, with the able and willing students arranged in order of how much they are willing to pay.

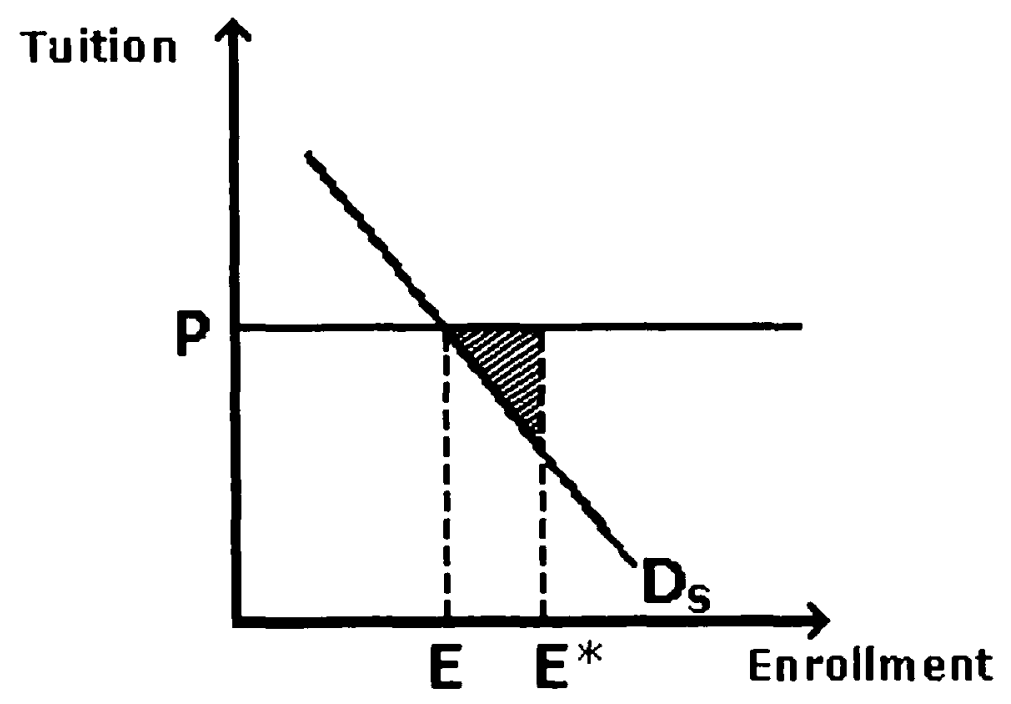

Figure 2. Demand curve for a selective university.

The tuition that a university charges. $P$. is determined by optimizing the level of enrollment and resources. This tuition must also be in line with the tuition charged by the institutions it sees as its competitors. In Figure 2. P illustrates that price. and $E^{*}$ is the optimal enrollment level. At most colleges in the selective category, the optimal enrollment cannot be reached at the optimal tuition P. The shaded area represents the cost 
of financial aid, as each student between $E$ and $E^{*}$ receives a larger financial aid package to induce him to attend. This illustrates the price discriminating aspect of the model, since students face different net prices.

Unfortunately, the institution neither sees this demand curve, nor knows each student's willingness to pay. Yet it needs to estimate the yield from its admissions and financial aid decisions. And in this short run period of time, the information it has with which to make its estimate is from the admissions and financial aid applications. At the time admissions and financial aid decisions are made, the institution does not have information about other colleges the student may have applied to, nor information about the financial aid packages from those colleges. It also does not have information about tastes and preference. The institution can only make generalizations about demand based on the student characteristics it knows. From the viewpoint of the institution. each student's demand, that is. the probability that he or she will enroll if admitted, is a function of the price the student faces (which, because of financial aid, differs for each student), his or her academic and other preparedness, and certain socio-economic and demographic characteristics:

$$
\begin{gathered}
P(\text { Enrollment })=f(\text { price }, \text { preparedness, socio-economic characteristics, } \\
\text { demographic characteristics })
\end{gathered}
$$

The goal of this study was to develop the best predictive model based on the information available to the school at the time the admissions and financial aid decisions are made. Since equation (1) contains only that information. it was used for the purpose of this research. 


\section{Operationalizing the Model}

Equation (1) was operationalized by identifying specific variables of interest, the source of the data for those variables, and the functional form that was be used for estimating the coefficients of each variable. The variables used in this study are defined in the following table.

Table 2

Specification of Variables in the Model

\begin{tabular}{|c|c|}
\hline Variable & Description and Coding \\
\hline Enrolled & $\begin{array}{l}0 \text { if the admitted student did not enroll, } I \text { if the student enrolled - dependent } \\
\text { variable }\end{array}$ \\
\hline Net Price & $\begin{array}{l}\text { Net tuition after all grant aid (institutional. governmental, private): does not } \\
\text { include loans; figures converted to base year } 1998 \text { and represented in } \$ 1.000 \text { s }\end{array}$ \\
\hline No need & 0 if other. $I$ if no need \\
\hline Low need & 0 if other. 1 if low need \\
\hline High need & 0 if other. $l$ if high need \\
\hline Early Decision & 0 if other, 1 if applicant applied for early decision \\
\hline HS GPA & High school GPA \\
\hline App. Rating & $\begin{array}{l}\text { Application Rating. Rating given to each application by admissions staff as a } \\
\text { measure of overall preparedness; } 0 \text { to } 9 \text { scale }\end{array}$ \\
\hline SAT Verbal & Sat Verbal score \\
\hline SAT Math & Sat Math score \\
\hline Gender & 0 if temale. 1 if male \\
\hline Catholic & 0 if other, 1 if Catholic \\
\hline Protestant & 0 if other. 1 if Protestant \\
\hline Jewish & 0 if other. 1 if Jewish \\
\hline Other religion & 0 if other. 1 if Other Religion \\
\hline African American & 0 if other. 1 if African American \\
\hline Asian & 0 if other. 1 if Asian: Asian American: Pacific Islander \\
\hline Caucasian & 0 if other. 1 if Caucasian \\
\hline Filipino & 0 if other. 1 if Filipino \\
\hline Hispanic & 0 if uther. 1 if Hispanic: Chicano: Latin/Central American; Puerto Rican \\
\hline Native American & 0 if other. 1 if Native American: Eskimo \\
\hline Other ethnicity & 0 if other. 1 if Other ethnicity \\
\hline Within state & 0 if other. 1 if residence is within state \\
\hline Less than 1000 & 0 if other. 1 if residence is outside state. but less than 1.000 miles from school \\
\hline 1000 to 2000 & 0 if other. 1 if residence is between 1000 and 2000 miles trom school \\
\hline Over 2000 miles & 0 if other. 1 if residence is over 2000 miles from school \\
\hline International & 0 if other. 1 if an international student \\
\hline Legacy & 0 if other. 1 if parent, sibling. or other relative attended school \\
\hline Visit & 0 if other, 1 if applicant visited campus \\
\hline 1998 & 0 if other. 1 if 1998 \\
\hline 1999 & 0 if other. 1 if 1999 \\
\hline 2000 & 0 if other. 1 if 2000 \\
\hline 2001 & 0 if other. 1 if 2001 - omitted from $1998-2000$ model \\
\hline
\end{tabular}


The dependant variable is the dichotomous variable Enrolled, whether or not the admitted student enrolled in the institution. Net Price is tuition net of all grant aid, but not loan aid. Dollars for all years were converted into the base year 1998. The variables related to student ability and preparedness are GPA, SAT Verbal, SAT Math, and App. Rating. App. rating is a holistic score assigned to each application by the admissions staff $^{6}$. The demographic variables in the equation are gender, race or ethnicity, religious preference, and distance from home. Race or ethnicity is represented by the seven dummy variables African American, Asian, Caucasian, Filipino, Hispanic, Native American, and other, with Caucasian being the omitted variable. Religious preference is represented by the four dummy variables Catholic. Protestant, Jewish. and other, with Other religion being the omitted variable. Distance from home is represented by the dummy variables Within state, Less than 1000 miles, 1000 to 2000 miles. over 2000 miles, and International. with Within state being the omitted variable. Financial need is used in this model as a measure of ability to pay for college. Some models have used income rather than a financial need to measure this. It is assumed that financial need is highly correlated with income. One advantage of using financial need is that it is possible to make assumptions about need for nonapplicants for financial aid, specifically that they have no need. However. it is difficult to make intuitive assumptions about income for nonapplicants. In addition. if need were measured as the amount of demonstrated need (either the institutional formula or the federal formula). Need would be perfectly correlated or highly correlated with Net Price. Therefore, in this study. I used the Need variable suggested by St. John (1992). which is the set of dummy variables No need. Low

\footnotetext{
${ }^{6}$ The application rating is the sum of scores for GPA. SAT. strength of academic program. leadership. community service. talent, and personel attributes. All students are placed along a continum, which is
} 
need, and High need, with No need being omitted variable. The variables for Year were included to test for significant differences between the years, due to changes in relative price compared to competitors, for example. Finally, Legacy and Visit are variables of specific interest to the specific institution. Legacy measures the ties that the student may have to the school based on a close relative attending the university. Visit measures the interest level of the student, the visit itself showing enough interest to make the trip, and the act of applying after the visit reflecting a positive experience.

\section{Data Source}

Data for this study came from a private, selective, Catholic university. For estimating the model, admitted student admissions and financial aid data for 1998, 1999. and 2000 were used. The estimated model was validated using 2001 data. and then rerun using all four years of data to produce policy simulations.

Table 3
Sample Size
\begin{tabular}{|ccc|}
\hline Year & Admitted & Enrolled \\
\hline 1998 & 3.285 & 1.031 \\
1999 & 3.286 & 991 \\
2000 & 3.365 & 1.026 \\
\hline $1998-2000$ & 9.936 & 3.048 \\
\hline 2001 & 3.378 & 1.004 \\
\hline $1998-2001$ & 13.314 & 4.052 \\
\hline
\end{tabular}

divided into deciles, and assigned a code 0 to 9. 


\section{Statistical Methodology}

Linear regression analysis is a logical technique for estimating most demand functions. However, the case of enrolling in an undergraduate program is different from that of typical decisions such as purchasing food or clothing. The decision to enroll in college is normally only made once. Therefore the quantity purchased is either zero or one. As with all dichotomous phenomena, several assumptions of linear regression are violated with this type of decision. This can lead to biased estimates (Dey and Astin, 1993). One assumption of OLS is that of constant variance of the error terms (homoskedasticity). With a dichotomous dependent variable, observations with predictions close to 1 when the actual value is 1 , or close to 0 when the actual value is 0 will have relatively small errors. but those with predictions close to 0.5 will have relatively large variances. Greene (1990), argues, however, that this is a "minor complication" since there are many robust estimation techniques now available (p. 663). Another assumption of OLS is a normally distributed error term. However, when the dependent variable is dichotomous, the error term is also dichotomous. If $y_{i}=1$. $e_{i}=1-p_{i}$; if $y_{i}=0, e_{i}=-p_{i}$. This issue would not have caused a problem in this study with a large sample size. The central limit theorem guarantees that the regression coefficients would be normally distributed. even if the error terms are not (Greene. 1990).

However, there are two technical shortcomings of OLS that lead to countertheoretical results. Since the assumption of a continuous dependent variable is violated. linear models often predict values that have no meaning, such as values below zero or above one. Another limitation with using the OLS model is that it implies a linear probability model. Although the decision for one candidate is yes or no, the accumulation 
of these decisions is used to determine the probabilities that certain groups of individuals will select a specific institution. The assumption of linearity implies that the marginal effect on the probability of a one-unit change in an independent variable is constant. However, this probably does not hold true for the probability of college enrollment. For example, there may be threshold effects at both ends of the price scale. A change in tuition from $\$ 30,000$ to $\$ 29,000$ may have little effect on the probability of enrollment, with both being close to zero. A change in tuition from $\$ 1.000$ to $\$ 2,000$ may also have little effect on the probability of enrollment, with both being close to 1 . But in the competitive environment, a change in net tuition from $\$ 15,000$ to $\$ 14,000$ may have a significant effect on the probability of enrollment. Figure 3 illustrates this concept.

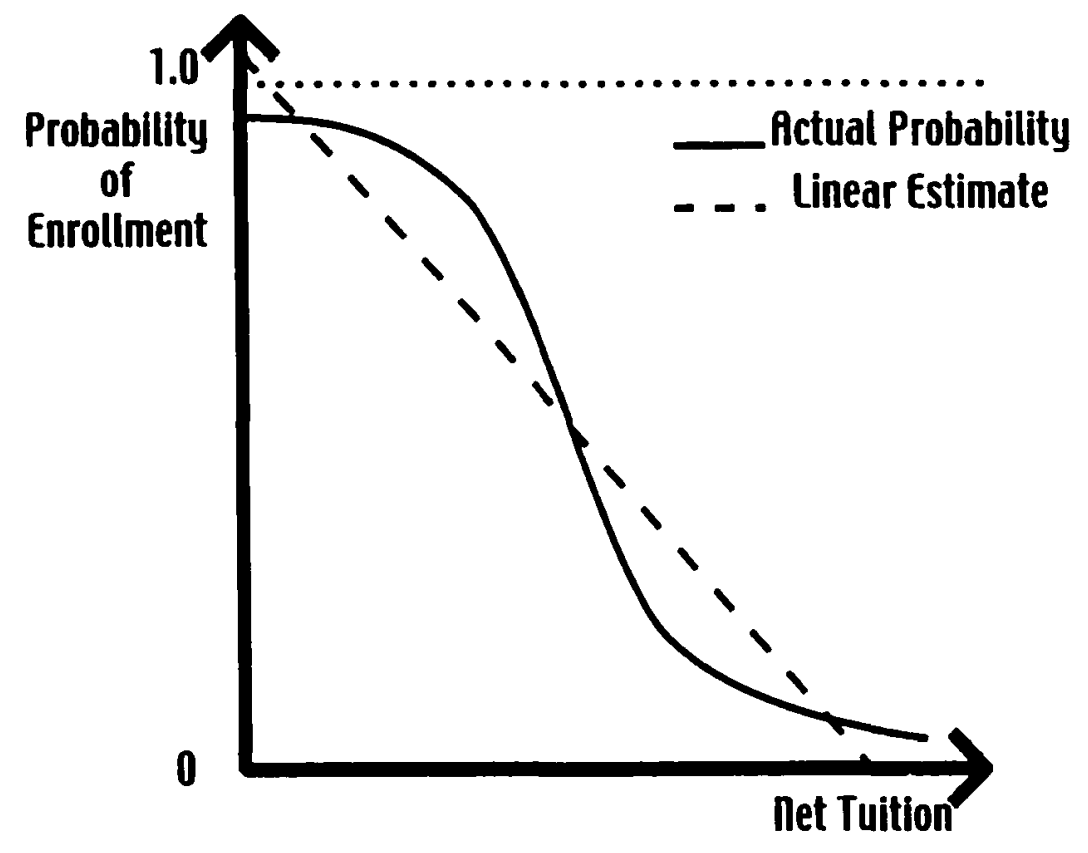

Figure 3. Linear model compared to theoretical probability.

The linear probability model is specified as

$$
\mathrm{p}=\mathrm{X} \beta \text {. }
$$

where $p$ is the $n^{*} 1$ vector of probabilities, $X$ is the $n^{*} k$ matrix of observations, and $\beta$ is 
the $k^{*} 1$ vector of coefficients. In order to overcome the four issues discussed, this model can be respecified as

$$
p=\Phi(X \beta)
$$

where $\Phi$ is the cumulative distribution function assumed for the event.

Researchers have used two different cumulative distribution functions for the probability of events. The first is the cumulative logistic probability distribution, defined as

$$
\delta(z)=1 /\left(1+e^{-z}\right)
$$

Substituting equation (4) into equation (3), the ith observation is

$$
p_{i}=1 /\left(1+e^{-x_{i}^{\beta} \beta}\right) .
$$

Rearranging the terms and taking the natural log yields

$$
\ln \left(\mathrm{p}_{\mathrm{i}} /\left(1-\mathrm{p}_{\mathrm{i}}\right)\right)=\mathrm{X}^{\prime} \beta
$$

The term $\ln \left(\mathrm{p}_{i} /\left(1-\mathrm{p}_{\mathrm{i}}\right)\right)$ is the natural log of the odds that $y_{i}$ is one rather than zero. This log-odds specification eliminates the four issues discussed regarding the linear model. This model is called the logistic or logit model.

$\Phi$ can also replaced with the standardized cumulative multivariate normal distribution. This model is called the probit model. Logit and probit models yield very similar estimates of the probability of events. Figure 4 compares the logit, probit, and linear probability models. Logit and probit both produce S-shaped functions. The main difference between them is in the tails of the distribution. The logit model has fatter tails. while the probit model approaches 0 and 1 more quickly. Therefore. at each end of the range. the probit model will predict values closer to 0 and 1 . respectively. 


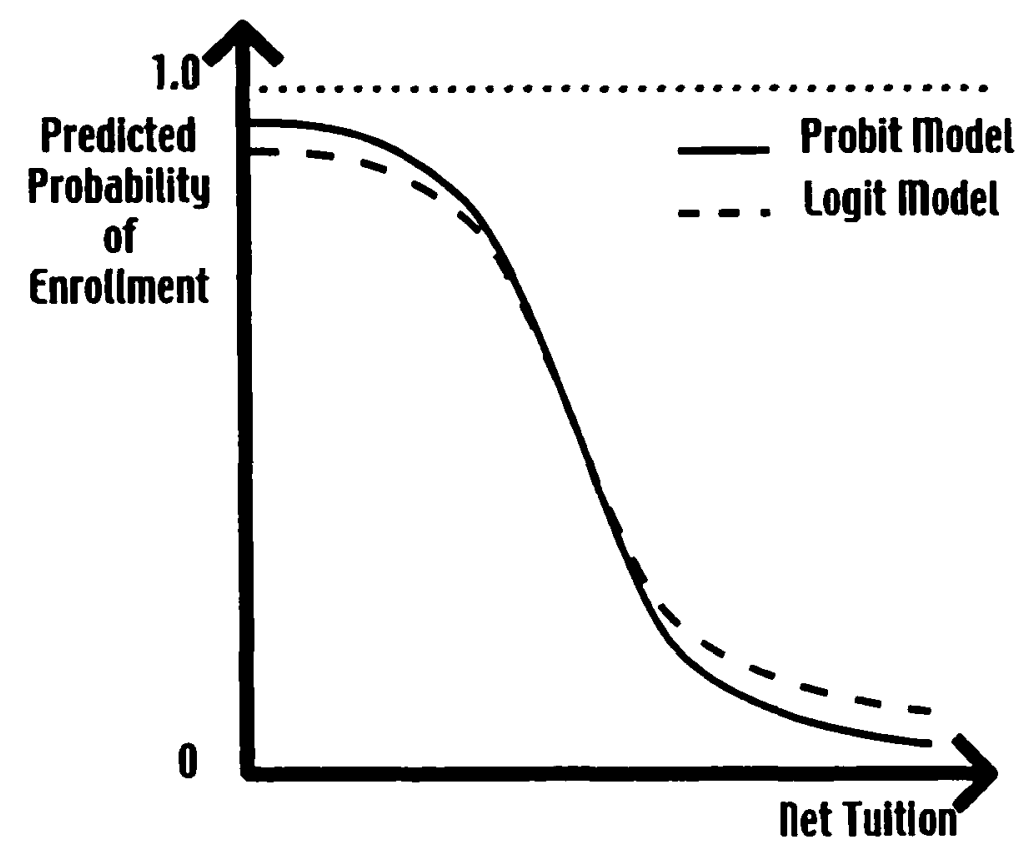

Figure 4. Comparison of logit and probit models

Marimum likelihood estimation. Both logit and probit analysis use maximum likelihood estimation techniques. The objective with this technique is to estimate those population parameters that would most likely generate the observed sample (Crown. 1998). To generate these coefficients, the derivatives of the log odds function is taken with respect to the coefficients of each variable and the constant term. yielding $k+1$ equations in $k+1$ unknowns. A common procedure for solving for the maximum likelihood coefficients of this system of equations is to start with the coefficient estimates from the linear model. and then make small changes in the coefficient values and observe the effects on the likelihood function. The maximum likelihood values for the coefficients are those coefficient values for which the value of the likelihood function cannot be increased.

Interpreting output and price sensitiviț: Logit and probit coefficients are. themselves, interpreted like regression coefficients. A problem. however. is that the 
dependent variable is the log of the odds of the event. Therefore, each coefficient represents the change in the "log odds" associated with a one-unit change in an independent variable. Since the log odds moves in the same direction as the probability of the event, the sign of the coefficient is easily recognizable as the direction of the relationship between the independent variable and the probability of the event. However, if the interest is in determining the magnitude of the effect, the coefficients have to be manipulated.

One way to do this is to calculate the partial derivative with respect to each independent variable. With linear probability, this is very easy, as the coefficient itself is the partial derivative. In the logit model, the partial derivative is a function of both the coefficient and the probabilities themselves, and can be written as

$$
\partial \mathrm{P}_{\mathrm{i}} / \partial \mathrm{X}_{\mathrm{k}}=\mathrm{b}_{\mathrm{k}} \mathrm{P}_{\mathrm{i}}\left(1-\mathrm{P}_{\mathrm{i}}\right)
$$

Since the derivative is different for each individual, a summary value must be calculated. The best way to do this is to calculate the derivative for each individual and take the mean. Crown (1998) notes that many researchers take the derivative for the mean of the observations of the variable, which can lead to very high-and erroneous-values of the magnitude of the effect. See Crown for an illustration of this effect.

As seen in Chapter 2. one way that educational researchers have reported the magnitude of effect of the net price variable is with the Student Price Response Coefficient (SPRC). The SPRC denotes the change in probability of enrollment based on a one-unit change in price, usually $\$ 100$ or $\$ 1,000$. The SPRC can be compared to the price elasticity reported in economic research. Elasticity, $\alpha$, is calculated as follows: 
$\alpha=$ $\frac{\Delta(\mathrm{E} / \mathrm{T}) / \mathrm{E} / \mathrm{T}}{\Delta(\mathrm{P}) / \mathrm{P}}$

where $E=$ enrollment, $T=$ total eligible or admitted population, and $P=$ Net Price. From this, the SPRC is calculated:

$$
\mathrm{SPRC}=\Delta(\mathrm{E} / \mathrm{T})=\alpha(\Delta(\mathrm{P}) / \mathrm{P})(\mathrm{E} / \mathrm{T})
$$

Comparing the two, we see that the SPRC measures the absolute change in probability before and after the change in price, not the relative change as the original elasticity does. Another method for finding the magnitude of the effects of the independent variables such as net price is to calculate the delta $\mathrm{P}$ values using the following specification:

$$
\text { delta } P=\frac{\operatorname{Exp}\left(L_{1}\right)}{1+\exp \left(L_{1}\right)}-\frac{\operatorname{Exp}\left(L_{0}\right)}{1+\exp \left(L_{0}\right)}
$$

where $L_{0}$ is the logit score before the change in $X_{i}$, and $L_{1}=L_{0}+\beta_{i}$. the logit score after the unit change in $X_{i}$ (Petersen. 1984. St. John, 1992). The delta $P$ is the same as a student price response coefficient (SPRC) (Leslie and Brinkman, 1938). It. too, denotes the absolute change in probability for a unit change in price. For example. a delta $\mathrm{P}$ of 0.07 for an increase in financial aid from $\$ 4.000$ to $\$ 5,000$ indicates that the probability of enrollment will increase by $7 \%$ for a $\$ 1,000$ increase in financial aid.

Note that most researchers report the change in probability, including delta Ps. using the sample mean (Petersen. 1984). However, as noted by Crown above. this can lead to very high and erroneous estimates of sensitivity. If the data consists of many cases at the extreme and few at the mean. the change in probability at the mean may be much higher than the mean of the change in probability, since the slope of the logit and probit curves is steepest at the mean, and flat at the extremes. Therefore, for this research, the 
probability deltas were calculated for each student, and the mean and range of these deltas were provided.

Another note concerning the reporting of price sensitivities in that of the relative magnitude of the change. For instance, a delta $P$ of .02 for a student whose initial probability of enrolling is .20 (to .22) can be interpreted as meaning that that student is $10 \%(.02 / .22)$ more likely to enroll with the net price reduction. For a student whose initial probability of enrolling is .70 , a delta-p of .02 (to .72 ) means that the student is only $3 \%(.02 / .70)$ more likely to enroll. Reporting in terms of relative magnitude is more consistent with sensitivities reported in economics, such as the elasticity of demand. which divides the absolute change by the starting point. However, to remain consistent with recent educational research, this study will report mean and the range of the following absolute $\Delta \mathrm{s}$ for both the logit and probit models:

Probability $\Delta_{j}=P_{1 j}-P_{0 j}$,

where $\quad \mathrm{P}_{0 \mathrm{j}}=$ estimated probability calculated with actual net price for the $\mathrm{jth}$ student.

and $\quad P_{1 j}=$ estimated probability calculated with actual net price $-\$ 1.000$ for the jth student.

Finally, in trying to interpret probabilities of enrollment, it is useful to look at particular cases of interest. Once the model was estimated, the predicted probabilities of enroliment were calculated for students possessing certain combinations of characteristics. along with changes in probability as financial aid changes. For example. the probability of a student who is male. from within state. Hispanic. Catholic. with above average ability, and with a financial aid offer of $\$ 6.000$ versus $\$ 7.000$ was calculated. This was done for representative cases of interest. using both logit and probit coefficient estimates. 
Tests of statistical significance. For linear regression models, goodness of fit is determined using $\mathrm{R}^{2}$. However, for maximum likelihood models, the goodness of fit is based on improving the likelihood of obtaining the given sample based on the estimated coefficients. The measure most often used compares the initial value of the likelihood function (where all coefficients equal zero) to the maximum value. Most software applications provide a goodness of fit statistic $\mathrm{G}=-2\left(\ln \mathrm{L}_{0}-\ln \mathrm{L}_{\max }\right)$, which can be shown to have a $\chi^{2}$ distribution. Crown (1998) suggests care in interpreting these statistics from various software packages, and Aldrich and Nelson (1984) note that none of the $\mathrm{R}^{2}$ proxies have good theoretical bases. The likelihood ratio test can also be used to test the significance of subsets of variables. In this application, the likelihood ratio test compares the unrestricted model with a restricted model with the variables in question removed.

Hosmer and Lemeshow (1989) devised another test for the goodness of fit. It involves dividing the observations into deciles by probability. For each decile, the observed and expected counts of enrolls are compared, and the chi-square test is used to test the null hypothesis of no difference in the counts.

To test the significance of each independent variable. a standard t-test was used.

Model validation. In addition to goodness of fit and tests of significance of variables. the model in this study was validated against a more recent data set. Since the purpose of this study is to develop a model with good predictive capability. this was an important step. One approach is to use cross-validation, which entails dividing the data randomly into two sets, one for model development and one for model validation. However. since the purpose of developing this model is to predict enrollment in future years, a temporal validation strategy was used. Specifically, the model was developed 
using data for the years 1998,1999 , and 2000 , and was validated against the data from 2001 when it became available. One measure of a well-calibrated model is if the sum of the predicted probabilities approximately equals the total number of positive outcomes (Hosmer and Lemeshow, 1989). The goodness of fit for the validation data set will also be calculated using the approach suggested by Hosmer and Lemeshow (1989). After the 1998-2000 model was validated against the 2001 data, the model was rerun using all four years. In Chapter 5, the model is compared to other similar models from the literature reviewed. Recommendations for additional data collection are made based on these comparisons.

Simulation. The final step in the research methodology was to simulate the effects of a change in financial aid on student enrollment probability. The following are three examples of scenarios that were simulated with the estimated model.

(1) What would be the change in the probability of enrollment from a $\$ 1.000$ increase in financial aid for a Caucasian, Protestant male with average ability, from within state, with no financial need?

(2) What would be the change in the probability of enrollment from a $\$ 1.000$ increase in financial aid for an African American. Protestant female, with above average ability, from within state, with high financial need?

(3) What would be the change in probability of enrollment from a $\$ 1,000$ decrease in tuition for an Hispanic. Catholic male with average ability from over 1,000 miles away, with low financial need? 


\section{CHAPTER 4}

Results

\section{Introduction}

The purpose of this study was to develop and test a mathematical model of student enrollment for an individual institution, utilizing institutional data defined by historical administrative need. In order to develop a model that could predict with an acceptable degree of accuracy the enrollment probabilities of admitted applicants to the particular institution, the study was guided by the following research question:

How do the following factors combine to influence the first time enrollment probability at the case institution?

- Student price (tuition net of gift aid)

- Student preparedness (SAT score, High School GPA, institutional rating)

- Student socio-economic characteristics (race or ethnicity, family income. religious preference)

- Student demographic characteristics (geographic area. gender)

Cnapter 3 described a three-step methodology for answering this question. First. an enrollment probability model was estimated using three years (1998-2000) of admissions data from the particular institution using both logistic regression and probit techniques. Both methods are build to be used with dichotomous dependent variables. and are based on distributions that produce equations that do not hold marginal effects constant. Since the literature strongly argues the limitations of linear regression in 
probability analysis, but provides no apparent relative strength between them, both techniques were used and the results compared. The second methodological step was to validate the model against additional data. Since the purpose of developing this model was to predict enrollment in future years, a temporal validation was used by testing for predictive accuracy against the admissions data for 2001. After re-estimating the model using all four years, 1998-2001, of data, the final step in the research methodology was to simulate the effects that various changes in the tuition and financial aid policy would have on student enrollment decisions.

This chapter begins with a description of the data. Included are descriptive statistics, including cross tabulation summaries, which helped guide the empirical modeling process. The second section provides the regression results for the 1998-2000 data set. Included in this section is a discussion of analysis involved in final variable selection. The third section summarizes the results of using the 1998-2000 model to predict 2001 enrollment. The fourth section provides the regression results for the 1998 2001 data set. Section five examines the results of the final step in the methodology, the effects of policy changes on student enrollment decisions. The final section is a chapter summary.

\section{Description of the Data}

Data for this study came from a private. more selective. Catholic university. Data covered the four-year period for students enrolling as freshmen in fall 1998. 1999. 2000. and 2001. Table 4 provides information on admissions and enrollment for each year, and for the two data sets used for modeling. 1998-2000 and 1998-2001. Yield refers to the percent of the admitted population that decided to enroll for the following fall semester. 
Note that the yield for the period of this study averaged slightly over $30 \%$, that is, about $30 \%$ of the students admitted made the decision to enroll in the university.

Table 4

Analysis of Sample Data by Year and Enrollment Decision

\begin{tabular}{|cccc|}
\hline Year & Admitted & Enrolled & Yield \\
\hline 1998 & 3.285 & 1.031 & $31.4 \%$ \\
1999 & 3.286 & 991 & $30.2 \%$ \\
2000 & 3.365 & 1.026 & $30.5 \%$ \\
\hline $1998-2000$ & 9.936 & 3.048 & $30.7 \%$ \\
\hline 2001 & 3.378 & 1.004 & $29.7 \%$ \\
\hline $1998-2001$ & 13.314 & 4.052 & $30.4 \%$ \\
\hline
\end{tabular}

The data was first analyzed with respect to the variables discussed in Chapter 3 that were to be used in creating the predictive model. Tables $5-10$ provide comparisons between those students that enrolled and the total admitted population with regard to the independent variables in the model. These tables highlight many of the enrollment challenges facing the institution. All monetary figures are adjusted to the base year 1998 .

Table 5 provides the percentage breakdowns for gender (male only). students who visited campus, and students that had a legacy with the university (a parent. sibling. or other relative who attended the university). For each year, the proportion of males that enrolled is greater than the proportion in the total admitted population. indicating that male admitted students enrolled at a slightly higher rate than fermales. However, the data indicates that the percentage of males enrolling has been declining, and is significantly 
less than half. For the years available, the data shows that visiting campus and having a legacy with the university increases the likelihood of enrolling.

Table 5

Admitted and Enrolled Percentages for Gender, Campus Visit, Legacy

\begin{tabular}{|c|c|c|c|}
\hline & \multicolumn{3}{|c|}{ Percent } \\
\cline { 2 - 4 } & Male & Visited Campus & Legacy \\
\hline 1998 & & & \\
Admitted & $38.8 \%$ & $45.5 \%$ & $11.6 \%$ \\
Enrolled & $40.3 \%$ & $52.5 \%$ & $16.1 \%$ \\
\hline 1999 & & $50.8 \%$ & $10.6 \%$ \\
Admitted & $36.6 \%$ & $62.1 \%$ & $15.3 \%$ \\
Enrolled & $37.3 \%$ & Data incomplete & $9.6 \%$ \\
\hline 2000 & & & $14.9 \%$ \\
Admitted & $35.3 \%$ & & \\
Enrolled & $37.2 \%$ & Data incomplete & $10.2 \%$ \\
\hline 2001 & & & $16.6 \%$ \\
Admitted & $33.4 \%$ & \\
Enrolled & $35.7 \%$ & &
\end{tabular}

Table 6 presents the proportional breakdowns of admits and enrolls according to race or ethnicity. The only ethnicities which show a consistent pattern across the years are Asian, for which the enrolled proportions are all less than the admitted proportions. and Hispanic, for which the enrolled proportions are all greater than the admitted proportions. The data also illustrates that all races and ethnicities other than Caucasian are underrepresented by both local and national figures. They are. however. consistent with the original application pools for the university. 
Table 6

Admitted and Enrolled Percentages for Race or Ethnicity

\begin{tabular}{|c|c|c|c|c|c|c|c|}
\hline & \multicolumn{7}{|c|}{ Percent } \\
\cline { 2 - 8 } & $\begin{array}{c}\text { African } \\
\text { Amer. }\end{array}$ & Asian & $\begin{array}{c}\text { Cau- } \\
\text { casian }\end{array}$ & Filipino & $\begin{array}{c}\text { His- } \\
\text { panic }\end{array}$ & $\begin{array}{c}\text { Native } \\
\text { Amer. }\end{array}$ & $\begin{array}{c}\text { Other/ } \\
\text { Unkn. }\end{array}$ \\
\hline $\begin{array}{c}1998 \\
\text { Admitted } \\
\text { Enrolled }\end{array}$ & $2.2 \%$ & $5.8 \%$ & $70.5 \%$ & $2.5 \%$ & $12.2 \%$ & $1.8 \%$ & $4.9 \%$ \\
1999 & $4.8 \%$ & $69.9 \%$ & $1.6 \%$ & $14.5 \%$ & $1.9 \%$ & $4.9 \%$ \\
Admitted & $1.9 \%$ & $6.3 \%$ & $71.3 \%$ & $2.6 \%$ & $11.7 \%$ & $1.6 \%$ & $4.6 \%$ \\
Enrolled & $1.7 \%$ & $4.5 \%$ & $73.3 \%$ & $1.8 \%$ & $12.3 \%$ & $1.8 \%$ & $4.5 \%$ \\
\hline 2000 & & & & & & & \\
Admitted & $2.2 \%$ & $7.8 \%$ & $69.6 \%$ & $2.8 \%$ & $12.9 \%$ & $1.2 \%$ & $3.4 \%$ \\
Enrolled & $1.6 \%$ & $5.8 \%$ & $73.1 \%$ & $2.3 \%$ & $13.0 \%$ & $1.1 \%$ & $3.1 \%$ \\
\hline 2001 & & & & & & & \\
Admitted & $2.3 \%$ & $8.4 \%$ & $68.4 \%$ & $3.2 \%$ & $13.5 \%$ & $1.5 \%$ & $2.7 \%$ \\
Enrolled & $2.8 \%$ & $5.8 \%$ & $67.3 \%$ & $2.8 \%$ & $16.7 \%$ & $1.8 \%$ & $2.8 \%$ \\
\hline
\end{tabular}

Table 7 gives the percentage breakdowns according to religios affiliation.

Being a Catholic university. it is no surprise that over half the students who are admitted and enroll are Catholic. The data indicates that the proportion of Jewish students has declined over the four-year period.

Table 7

Admitted and Enrolled Percentages for Religious Affiliation

\begin{tabular}{|c|c|c|c|c|}
\hline & \multicolumn{4}{|c|}{ Percent } \\
\hline & Catholic & Protestant & Jewish & $\begin{array}{c}\text { Other/ } \\
\text { Unknown }\end{array}$ \\
\hline \multicolumn{5}{|l|}{1998} \\
\hline Admitted & $54.3 \%$ & $32.6 \%$ & $2.6 \%$ & $10.4 \%$ \\
\hline Enrolled & $55.2 \%$ & $32.9 \%$ & $2.2 \%$ & $9.7 \%$ \\
\hline \multicolumn{5}{|l|}{1999} \\
\hline Admitted & $54.0 \%$ & $30.9 \%$ & $1.6 \%$ & $13.5 \%$ \\
\hline Enrolled & $55.4 \%$ & $31.4 \%$ & $1.4 \%$ & $11.8 \%$ \\
\hline \multicolumn{5}{|l|}{2000} \\
\hline Admitted & $52.7 \%$ & $31.7 \%$ & $2.1 \%$ & $13.4 \%$ \\
\hline Enrolled & $53.5 \%$ & $32.5 \%$ & $1.6 \%$ & $12.5 \%$ \\
\hline \multicolumn{5}{|l|}{2001} \\
\hline Admitted & $54.6 \%$ & $31.5 \%$ & $1.4 \%$ & $12.5 \%$ \\
\hline Enrolled & $57.9 \%$ & $30.8 \%$ & $1.0 \%$ & $10.4 \%$ \\
\hline
\end{tabular}


Table 8 provides information on the distance the students would have to travel from home to attend the university. Although the institution is private, and not a state school, the majority of students admitted and enrolled are from within the state. There are no consistent pattems across the years regarding the proportions of enrolled students versus the proportions of admitted students in any of the distance categories. However, as would be expected, the percentages decrease with distance.

Table 8 Admitted and Enrolled Percentages for Distance from Home

\begin{tabular}{|c|c|c|c|c|c|}
\hline & \multicolumn{5}{|c|}{ Percent } \\
\hline & $\begin{array}{l}\text { Within } \\
\text { state }\end{array}$ & $\begin{array}{c}\text { Less than } \\
1000 \\
\text { miles* }\end{array}$ & $\begin{array}{c}\text { Betwcen } \\
1000 \text { and } \\
2000 \text { miles }\end{array}$ & $\begin{array}{c}\text { Greater } \\
\text { than } 2000 \\
\text { miles }\end{array}$ & $\begin{array}{c}\text { Inter- } \\
\text { national }\end{array}$ \\
\hline 1998 & & & & & \\
\hline Admitted & $59.2 \%$ & $16.1 \%$ & $15.6 \%$ & $7.6 \%$ & $1.4 \%$ \\
\hline Enrolled & $57.9 \%$ & $17.0 \%$ & $15.9 \%$ & $7.5 \%$ & $1.7 \%$ \\
\hline 1999 & & & & & \\
\hline Admitted & $58.1 \%$ & $16.6 \%$ & $16.3 \%$ & $7.4 \%$ & $1.5 \%$ \\
\hline Enrolled & $58.2 \%$ & $18.1 \%$ & $16.0 \%$ & $6.6 \%$ & $1.2 \%$ \\
\hline 2000 & & & & & \\
\hline Admitted & $57.6 \%$ & $16.9 \%$ & $15.6 \%$ & $7.7 \%$ & $2.1 \%$ \\
\hline Enrolled & $56.5 \%$ & $18.6 \%$ & $14.5 \%$ & $8.4 \%$ & $2.0 \%$ \\
\hline 2001 & & & & & \\
\hline Admitted & $56.1 \%$ & $16.2 \%$ & $16.1 \%$ & $9.8 \%$ & $1.8 \%$ \\
\hline Enrolled & $54.0 \%$ & $19.7 \%$ & $14.5 \%$ & $10.4 \%$ & $1 .+\%$ \\
\hline
\end{tabular}

* Less than 1000 , but outside the state in which the university is located 
Table 9 provides the percentage breakdowns in the three financial need categories. The need categories were created as follows: No Need (did not apply for financial need, or the federal formula indicated no financial need): Low Need (the federal formula indicated financial need above 0 and less than or equal to $\$ 12,000$ ); and High Need (the federal formula indicated financial need above $\$ 12.000$ ). Note the large variation between the percentages of admitted and enrolled student in the categories no need and high need, with the percentage of students with no need who enrolled being significantly less than the percentage who were admitted, and the percentage of students with high need who enrolled being significantly more than the percentage who were admitted. Depending on whether the need was met and the source of the aid, this could indicate a substantial budgetary concern for the institution.

Table 9

Admitted and Enrolled Percentages by Need Category

\begin{tabular}{|c|c|c|c|}
\hline & \multicolumn{3}{|c|}{ Percent } \\
\cline { 2 - 4 } & No Need & Low Need & High Need \\
\hline 1998 & & & $27.7 \%$ \\
Admitted & $63.5 \%$ & $8.8 \%$ & $41.4 \%$ \\
Enrolled & $47.3 \%$ & $11.3 \%$ & \\
\hline 1999 & & & $27.3 \%$ \\
Admitted & $63.7 \%$ & $9.0 \%$ & $+1.5 \%$ \\
Enrolled & $48.5 \%$ & $10.0 \%$ & $25.4 \%$ \\
\hline 2000 & & & $40.0 \%$ \\
Admitted & $65.9 \%$ & $8.8 \%$ & \\
Enrolled & $50.1 \%$ & $9.9 \%$ & $24.4 \%$ \\
\hline 2001 & & & $43.0 \%$ \\
Admitted & $68.0 \%$ & $7.6 \%$ & $7.9 \%$ \\
Enrolled & $49.1 \%$ & & \\
\hline
\end{tabular}

Table 10 supplies the averages for the variables application rating. combined SAT. high school GPA, and price. Average SAT scores and GPAs have gone up. In both cases, the average for the enrolling students is less than the average for all admitted students. Since the application rating is an internal number. per year differences cannot 
be given meaning. However, as with SAT scores and GPAs, the average for the enrolling students each year is less than the average for all admitted students. The price variable is the cost of tuition, fees, room and board, and other estimated expenses minus the amount of institutional grant aid, adjusted to 1998 dollars. Outside aid was not subtracted, as it can be used by the student at any institution, and therefore does not affect his enrollment decision. Therefore price can be thought of as the Net Discounted Price offered by the institution to each individual student (see Figure $I$ and discussion on page 22). The data shows that price has gone up more than inflation. It also shows that price does matter, with the mean for those students who chose to enroll being less than for the total admitted population.

Table 10 Admitted and Enrolled Means for Application Rating. High School GPA. SAT. Price

\begin{tabular}{|c|c|c|c|c|}
\hline & \multicolumn{4}{|c|}{ Mean } \\
\hline & $\begin{array}{c}\text { Application } \\
\text { Rating }\end{array}$ & $\begin{array}{c}\text { High School } \\
\text { GPA }\end{array}$ & $\begin{array}{c}\text { Combined } \\
\text { SAT }^{*}\end{array}$ & $\begin{array}{l}\text { Adjusted } \\
\text { Net Price }\end{array}$ \\
\hline \multicolumn{5}{|l|}{1998} \\
\hline Admitted & 5.69 & 3.70 & 1152 & $\$ 23,015$ \\
\hline Enrolled & 5.48 & 3.66 & 1139 & $\$ 22,003$ \\
\hline \multicolumn{5}{|l|}{1999} \\
\hline Admitted & 5.17 & 3.79 & 1168 & $\$ 24.523$ \\
\hline Enrolled & 4.87 & 3.76 & 1148 & $\$ 22.818$ \\
\hline \multicolumn{5}{|l|}{2000} \\
\hline Admitted & 5.50 & 3.77 & 1187 & $\$ 24.609$ \\
\hline Enrolled & 5.04 & 3.72 & 1163 & $\$ 23,259$ \\
\hline \multicolumn{5}{|l|}{2001} \\
\hline Admitted & 5.97 & 3.78 & 1191 & $\$ 25.055$ \\
\hline Enrolled & 5.55 & 3.73 & 1159 & $\$ 23.412$ \\
\hline
\end{tabular}

* Combined SAT score or ACT score converted to SAT combined scale 
Of particular interest to this study, and all demand models, is the effect of the price faced by the consumer. Because of financial aid, prospective students face different prices. For Table 11, the range of adjusted net price was divided into six categories. Table 11 provides the percent of admitted students that made the decision to enroll for each price category. This information is provided for the total sample and for various demographic and socio-economic variables. Note that for the total sample, the percentage of students enrolling decreases as price increases until the last category, where it increases. This effect is particularly pronounced for males. Also note that for Catholic. Asian. Hispanic, and Filipino students, the percent enrolling is higher for the category $\$ 0$ to $\$ 5,000$ than for $\$ 5,000.01$ to $\$ 10,000$. These anomalies will be discussed further below in the section Functional form. 
Table 11

Percent Enrollment by Net Price Category and Demographic/Socio-ecomomic Category

\begin{tabular}{|c|c|c|c|c|c|c|c|}
\hline \multirow[b]{2}{*}{$\begin{array}{l}\text { Demographic/ } \\
\text { Socio-economic } \\
\text { Category }\end{array}$} & \multicolumn{7}{|c|}{ Net Price Category } \\
\hline & $\begin{array}{c}\$ 0- \\
\$ 5,000\end{array}$ & $\begin{array}{c}\$ 5,000.01- \\
\$ 10,000\end{array}$ & $\begin{array}{c}\$ 10,000.01- \\
\$ 15,000\end{array}$ & $\begin{array}{l}\$ 15,000.01- \\
\$ 20,000\end{array}$ & $\begin{array}{c}\$ 20,000.01- \\
\$ 25,000\end{array}$ & $\begin{array}{c}\$ 25,000.01- \\
\$ 30,000\end{array}$ & Total \\
\hline Male & $77.3 \%$ & $66.8 \%$ & $62.1 \%$ & $31.1 \%$ & $20.6 \%$ & $26.3 \%$ & $31.8 \%$ \\
\hline Female & $68.7 \%$ & $67.7 \%$ & $61.5 \%$ & $31.7 \%$ & $21.8 \%$ & $22.9 \%$ & $29.6 \%$ \\
\hline Catholic & $66.9 \%$ & $70.6 \%$ & $63.8 \%$ & $31.7 \%$ & $22.2 \%$ & $24.8 \%$ & $31.3 \%$ \\
\hline Protestant & $80.6 \%$ & $62.8 \%$ & $58.1 \%$ & $31.6 \%$ & $21.4 \%$ & $25.4 \%$ & $30.6 \%$ \\
\hline Jewish & - & $62.5 \%$ & $58.3 \%$ & $26.7 \%$ & $17.4 \%$ & $21.7 \%$ & $24.5 \%$ \\
\hline Other Rel. & $66.7 \%$ & $64.6 \%$ & $61.4 \%$ & $30.9 \%$ & $18.0 \%$ & $19.2 \%$ & $27.1 \%$ \\
\hline Afr. Am. & $78.6 \%$ & $63.6 \%$ & $68.8 \%$ & $23.5 \%$ & $15.0 \%$ & $4.2 \%$ & $2.93 \%$ \\
\hline Asian & $56.5 \%$ & $60.0 \%$ & $64.1 \%$ & $22.2 \%$ & $11.6 \%$ & $15.4 \%$ & $22.5 \%$ \\
\hline Caucasian & $80.0 \%$ & $67.0 \%$ & $60.2 \%$ & $31.0 \%$ & $23.3 \%$ & $26.9 \%$ & $30.9 \%$ \\
\hline Filipino & $40.0 \%$ & $71.4 \%$ & $67.7 \%$ & $21.4 \%$ & $19.4 \%$ & $10.8 \%$ & $23.4 \%$ \\
\hline Hispanic & $60.2 \%$ & $70.9 \%$ & $65.8 \%$ & $41.0 \%$ & $16.3 \%$ & $18.2 \%$ & $34.2 \%$ \\
\hline Native Am. & $80.0 \%$ & $64.3 \%$ & $63.3 \%$ & $24.1 \%$ & $21.9 \%$ & $18.9 \%$ & $32.7 \%$ \\
\hline Other Eth. & $100.0 \%$ & $65.4 \%$ & $48.7 \%$ & $34.4 \%$ & $22.7 \%$ & $24.0 \%$ & $30.1 \%$ \\
\hline Within State & $66.3 \%$ & $66.9 \%$ & $62.9 \%$ & $30.9 \%$ & $19.5 \%$ & $22.6 \%$ & $29.9 \%$ \\
\hline$<1000$ Miles & $100.0 \%$ & $69.1 \%$ & $63.5 \%$ & $33.2 \%$ & $26.4 \%$ & $28.8 \%$ & $33.9 \%$ \\
\hline $1000<$ miles $<2000$ & $83.3 \%$ & $64.3 \%$ & $54.0 \%$ & $31.4 \%$ & $21.8 \%$ & $25.8 \%$ & $29.1 \%$ \\
\hline Over 2000 miles & $100.0 \%$ & $71.4 \%$ & $63.5 \%$ & $33.1 \%$ & $24.3 \%$ & $21.7 \%$ & $30.7 \%$ \\
\hline International & - & $100.0 \%$ & - & $23.1 \%$ & $3.0 \%$ & $30.0 \%$ & $26.5 \%$ \\
\hline Total & $71.7 \%$ & $67.4 \%$ & $61.7 \%$ & $31.5 \%$ & $21.4 \%$ & $24.2 \%$ & $30.4 \%$ \\
\hline
\end{tabular}




\section{Regression Results from Three-Year Data Set}

\section{Variable Refinement}

Although preliminarily variables were selected for inclusion in the model based upon theoretical considerations and results of previous empirical work, various model refinements were tested with the institution-provided data for 1998-2000.

Net price. Two versions of the net price variable were tested. The first version of net price was defined as CPI adjusted full price minus all grants (institutional and outside). The rationale for this price was discussed extensively in Chapters 2 and 3 . The second version consisted of the CPI adjusted full price minus CPI adjusted institutional grants. The rationale for testing this variable was that outside grants can be used at all institutions. Therefore students would compare the price minus institutional grants of the various institutions when making a decision. While this second version of the variable was significant, the model containing CPI adjusted full price minus all grants had higher tests of overall model significance and better predictive accuracy. It can be argued that this overall price plays a larger role in the decision-making process because the ratio of prices is more important than the difference in prices. This distinction is especially significant when students are comparing private and public schools, which have large differences in costs. Outside grants can reduce the cost of a public education to a few thousand dollars per year. Other research by the author for the case institution in $200 \mathrm{I}$ found that the state public institutions were its leading competitors.

Functional form. The distinctions between logit and probit models and linear regression models were discussed in Chapter 3 . Although the logit and probit models are non-linear estimations of probability, normal entry of an independent variable into the 
regression assumes linearity of the logit, that is, linearity of that variable with respect to the log-odds of enrolling. ${ }^{7}$ This is equivalent to assuming a linear relationship in ordinary least squares analysis. The functional forms of the continuous variables High School GPA, SAT Combined, and Application Rating were tested by entering the squared and cubed forms of these variables into preliminary regressions. Analysis showed that the cubic version of GPA $\left(\beta_{8} \mathrm{GPA}+\beta_{9} \mathrm{GPA}^{2}+\beta_{10} \mathrm{GPA}^{3}\right)$ produced higher tests of overall model significance and better predictive accuracy. This is consistent with the findings of other empirical models (Sinha, 1998). It is reasonable to assume that, for a more selective institution (one in the middle of the selectivity categories), that the probability is neither constantly increasing nor constantly decreasing with respect to GPA. but rather that there is maximum value within the relevant range from which the probability decreases in both directions. Neither quadratic nor cubic forms of the other two variables were significant. The functional form of the net price variable was of particular importance to this study. since price is the major factor in demand. and price sensitivity analysis is a major factor in enrollment management policy analysis. In preliminary models. the t-statistic for this variable entered in linear form was in the range of 24 . Analysis of the enrollment yield by the six price categories (Table 11 ) provided some interesting findings. As already noted. the percent enrollment (yield) increased between the second highest and highest categories, indicating that the students in the highest price category are actually more likely to enroll. In addition. for some demographic categories, the yield increased between the first and second categories. These finding indicate that the relationship between net price and enrollment might be quadratic or cubic.

\footnotetext{
${ }^{7}$ Note that in equation (3) the original linear matrix is substituted into the cumulative probability distribution function.
} 
A number of tests were performed. In the first test, the data was divided into six categories by net price, and six separate regressions were run to determine if separate models for each category might better explain enrollment patterns. ${ }^{8}$ The explanatory power of this modei was not as powerful as the combined model. However, it did provide additional evidence of possible non-linearity in the price variable.

In the second test, the net price variable was added to the equation in quadratic and cubic form. Results are footnoted below. ${ }^{9}$ Based on these results, net price was entered in cubic form $\left(\beta_{1}\right.$ NetPrice $+\beta_{2}$ NetPrice $^{2}+\beta_{3}$ NetPrice $\left.^{3}\right)$ in the final model.

Multicollinearity. The logistic and probit programs do not provide multicollinearity analysis. Effects of multicollinearity can be seen through traditional measures, including the correlation coefficients and change in significance of variables when other variables are added. In addition, formal measures such as tolerance and Variance Inflation Factors can be obtained by running a linear regression. since the functional form of the model with respect to the dependent variable does not matter when determining collinearity (Menard, 1995). The original proposal called for using SAT Verbal and Math scores separately. The correlation between these two variables was .831 (see the Appendix for full correlation table). In the preliminary models. SAT Math was significant when entered alone. but became non-significant when SAT Verbal was added (with SAT Verbal significant). Model significance increased. and predictive accuracy increase with SAT Combined. This provided evidence that multicollinearity was a

\footnotetext{
${ }^{8}$ In the multiple price group model, the net price coefticient was positive. although not significantly different from zero. in the $\$ 0-\$ 5.000$. and $\$ 5.000-\$ 10.000$ categories. It was negative in the others, although not significant in the $\$ 20.000-\$ 25.000$ category.

${ }^{9}$ In the quadratic net price model. net price was signficant and net price squared was not. The statistic

-2loglikelihood was 14051 in the linear model and 14051 in the quadratic model. showing no signiticant
} 
problem in the original regression. As another consideration, $3.5 \%$ of the admitted students had only taken the ACT. ACT scores can be converted to SAT Combined scores, but cannot be separated into verbal and math scores. By using SAT Combined scores with ACT conversions when necessary, the model would be more useful to the institution in the future. Therefore Combined SAT was used in the final model. Multicollinearity in this and other areas of the model was also tested for by running linear regressions and comparing tolerance and VIF. The only other variables that showed high numbers on these measures were the three GPA variables (GPA, GPA ${ }^{2}$, and $G A^{3}$ ) and the three Net Price variables (NetPrice, NetPrice' and NetPrice ${ }^{3}$ ). This is normal when such functional forms are added to the model.

Interaction effects. It can be theoretically argued that a number of interaction effects play significant rolls in college enrollment. As examples, a Catholic student might be more likely to travel farther from home to attend a Catholic institution than a nonCatholic student, or a female may have difference preferences than a male with the same GPA or SAT score. All major interaction effect variables were tested in the model. None of the interaction variables were significant at the .05 level (although GPA*Asian was significant at $p=.09)$, nor added to model significance or predictive accuracy. Since no interaction variables were significant at the chosen level. and the major goal of the research was to provide a workable model for the case institution to use in enrollment management, these variables were not included in the final model.

Other variable considerations. The original intension was to include the variable campus visit as an explanatory variable. As indicated in Table 5. however, this variable 13980. which was a signiticant difference from 14051 at $\mathrm{p}<.001$. 
was not available for all four years. To determine whether the variable would have significant explanatory power, the model was run for the two years data was available (1998-1999). ${ }^{10}$ The results show that it would be valuable for the institution to resume recording complete information on this variable in the future.

As indicated in Chapter 3. dummy variables for the years were added to the model to test for other significant phenomena each year that were not accounted for. Although these variables were not significant in the 1998-2000 model, two of the three-year variables were significant in the 1998-2001 model. Therefore. they were not removed from the model.

Final variable list. Table 12 provides the full list of variables included in the final model, with descriptions of each variable.

\footnotetext{
${ }^{10}$ The results were that the coefficient on campus visit was significant $(t=7 .+$ in both logit and probit models). and the likelihood ratio test was significant at $p<.00$. Classification accuracy increased only slightly, from $69.6 \%$ to $70.0 \%$.
} 
Table 12

Specification of Variables in Final Model

\begin{tabular}{|c|c|}
\hline Variable & Description and Coding \\
\hline Enrolled & $\begin{array}{l}0 \text { if the admitted student did not enroll, } 1 \text { if the student enrolled - dependent } \\
\text { variable }\end{array}$ \\
\hline Net Price & $\begin{array}{l}\text { Net tuition after all grant aid (institutional, governmental, private); does not } \\
\text { include loans; figures converted to base year } 1998 \text { and represented in } \$ 1.000 \text { s }\end{array}$ \\
\hline (Net Price) $^{2}$ & Net price squared \\
\hline$(\text { Net Price) })^{3}$ & Net price cubed \\
\hline No need & 0 if other, 1 if no need - omitted variable \\
\hline Low need & 0 if other. 1 if low need $-\$ 1-\$ 12.000$ using federal formula ${ }^{n}$ \\
\hline High need & 0 if other. 1 if high need - over $\$ 12.000$ using federal formula \\
\hline Early Decision & 0 if other, 1 if applicant applied for early decision \\
\hline HS GPA & High school GPA \\
\hline (HS GPA) $^{2}$ & High school GPA squared \\
\hline$(\mathrm{HS} \mathrm{GPA})^{3}$ & High school GPA cubed \\
\hline App. Rating & $\begin{array}{l}\text { Application Rating. Rating given to each application by admissions staff as a } \\
\text { measure of overall preparedness; } 0 \text { to } 9 \text { scale }\end{array}$ \\
\hline Combined SAT & Combined SAT score or ACT converted to SAT combined scale \\
\hline Gender & 0 if female, 1 if male \\
\hline Catholic & 0 if other, 1 if Catholic \\
\hline Protestant & 0 if other. 1 if Protestant - omitted variable \\
\hline Jewish & 0 if other. 1 if Jewish \\
\hline Other religion & 0 if other. 1 if Other Religion \\
\hline African American & 0 if other. 1 if African American \\
\hline Asian & 0 if other, 1 if Asian; Asian American; Pacitic Islander \\
\hline Caucasian & 0 if other, 1 if Caucasian - omitted variable \\
\hline Filipino & 0 if other. 1 if Filipino \\
\hline Hispanic & 0 if other, I if Hispanic; Chicano: Latin/Central American: Puerto Rican \\
\hline Native American & 0 if other. I if Native American: Eskimo \\
\hline Other ethnicity & 0 if other. 1 if Other ethnicity \\
\hline Within state & 0 if other. $I$ if residence is within state - omitted variable \\
\hline Less than 1000 & 0 if other. 1 if residence is outside state. but less than 1.000 miles from school \\
\hline 1000 to 2000 & 0 if other. 1 if residence is between 1000 and 2000 miles trom school \\
\hline Over 2000 miles & 0 if other. 1 if residence is over 2000 miles from school \\
\hline International & 0 if other. 1 if an international student \\
\hline Legacy & 0 if other. $I$ if parent. sibling. or other relative attended school \\
\hline 1998 & 0 if other. 1 if 1998 - omitted variable \\
\hline 1999 & 0 if other. 1 if 1999 \\
\hline 2000 & 0 if other. 1 if 2000 \\
\hline 2001 & 0 if other, 1 if 2001 - omitted from 1998-2000 model \\
\hline
\end{tabular}

"The cut off of $\$ 12.000$ between low and high need was used in this study. This tigure is approximately half of the required costs of attending the university. With this cut off. $26 \%$ of the admitted students were placed in the high need category. By comparison. the cut off of $\$ 15.000$ would have put 2\$\% of the students into the high need category. There was no significant variation in the model results when run using these two figures. 
Results from 1998-2000 Data Set

The model was estimated using SPSS. SPSS provides two separate programs for running binary regressions: binary logistic and probit. The probit program estimates both probit and logit models. The logit variation of the probit program provides the same estimate as the binary logistic program. However, there are major differences in the statistical outputs of these two programs. The probit program provides only the Pearson Goodness-of-Fit test. The binary logistic program provides the Hosmer and Lemeshow Goodness-of-Fit test, the model chi-squares, the log likelihood figure for model comparisons, and two "psuedo-R ${ }^{2 *}$ tests, the Cox and Snell and the Nagelkerke. In order to obtain the Pearson Goodness-of-Fit test for both models (and coefficients with a higher degree of precision), the logit model was run using both programs. Table 13 summarizes the results from these regressions. 
Table 13

Regression Results from 1998-2000 Data

\begin{tabular}{|c|c|c|c|c|c|c|c|c|}
\hline \multirow[b]{2}{*}{ Variable } & \multicolumn{4}{|c|}{ Logit } & \multicolumn{4}{|c|}{ Probit } \\
\hline & B & & $\begin{array}{c}\text { Standard } \\
\text { Error }\end{array}$ & i-statistic & $\bar{B}$ & & $\begin{array}{c}\text { Standard } \\
\text { Error }\end{array}$ & t-statistic \\
\hline Net Price & .16928 & $* *$ & .05882 & 2.87784 & $.098+4$ & $* *$ & .03520 & 2.79671 \\
\hline (Net Price) : & -.08167 & $* *$ & .00381 & -5.69335 & -.01287 & ** & .00227 & -5.67300 \\
\hline (Net Price) $^{3}$ & .00043 & $* *$ & .00007 & 5.89010 & .00026 & ** & $.0000 t$ & 5.92052 \\
\hline Low need & $.596+3$ & ** & $.082+1$ & 7.23689 & $.3588+$ & $* *$ & $.0+9+8$ & 7.25249 \\
\hline High need & -.15473 & * & .08246 & $-1.876+7$ & -.07516 & & .04766 & -1.57702 \\
\hline Early Action & .65958 & ** & .05739 & $11 .+9307$ & .39165 & $* *$ & $.03+31$ & $11 .+1381$ \\
\hline App. Rating & -.17426 & $* *$ & .01950 & -8.93485 & -.10276 & $* *$ & .01150 & $-8.93+91$ \\
\hline HS GPA & 1.77655 & $*$ & 1.07818 & 1.64773 & 1.00905 & & .66755 & 1.51157 \\
\hline (HS GPA)' & -.78113 & $* *$ & .36830 & -2.12093 & -.4648 & ** & $.22+48$ & -1.98898 \\
\hline$(H S G P A)^{3}$ & .08650 & $* *$ & .04065 & 2.12785 & 04921 & ** & $.02+55$ & $2.00+16$ \\
\hline Combined SAT & -.00125 & $* *$ & .00027 & $+4.62+11$ & -.00075 & $* *$ & .00016 & -4.71835 \\
\hline Gender (male) & $.030+1$ & & .05120 & .59400 & $.0180 !$ & & .03008 & .59850 \\
\hline Catholic & -.07877 & & .05506 & $-1 .+3065$ & .04576 & & .03239 & $-1 .+1275$ \\
\hline Jewish & -.23395 & & .17733 & $\cdot 1.31922$ & -.12728 & & .10202 & -1.24766 \\
\hline Other religion & -11455 & & $.08+49$ & -1.35580 & -.06735 & & .04950 & -1.36056 \\
\hline African American & .88403 & $* *$ & .18952 & -1.66459 & .55245 & ** & .11183 & -4.94020 \\
\hline Asian & $-.5+196$ & $* *$ & .11252 & -4.81650 & -.31139 & ** & $.06+28$ & $-4.8+429$ \\
\hline Filipino & -.53615 & $* *$ & $.1686 t$ & -3.17929 & -.32673 & ** & .09772 & -3.34300 \\
\hline Hispanic & -.25978 & $* *$ & .08110 & -3.20311 & .15639 & $* *$ & .04740 & -3.29916 \\
\hline Native American & $\cdot .36583$ & * & .20260 & -1.80570 & -.22601 & * & .11934 & -1.89376 \\
\hline Other cthnicily & -12513 & & .12263 & -1.02041 & .07116 & & .0714 & -.99615 \\
\hline Less than 1000 & $300+2$ & $*$ & .06671 & +.50313 & 18051 & $* *$ & .03933 & +.58927 \\
\hline 1000 to 2000 & 19274 & $* *$ & .06866 & 2.80703 & 11565 & ** & .04032 & 2.80829 \\
\hline Over 2000 miles & .14852 & & .09536 & 1.55740 & $08+87$ & & .05602 & 151486 \\
\hline International & $.605+4$ & $* *$ & .18015 & 3.36078 & $3522 \mathrm{~S}$ & ** & .10623 & 3.31623 \\
\hline Legacy & .65504 & $* *$ & .07319 & 8.95852 & .39156 & ** & $.0+410$ & $\$ .87909$ \\
\hline 1999 & 05368 & & .06363 & 84369 & 03300 & & .03749 & 88030 \\
\hline 2000 & $.08+99$ & & .06467 & $1.31+28$ & 05290 & & .03801 & 1.39187 \\
\hline Constant & 3.13832 & $* *$ & 1.11754 & 2.50823 & 1.91837 & $* *$ & 70404 & $2.72+58$ \\
\hline
\end{tabular}

* Significant at 10 level

** Significant at 05 level

$n=9935$

\section{Model Significance}

$\underline{\text { Logit }}$

Pearson Goodness-ot-Fit

Hosmer and Lemeshow

Model Chi-square

-2Log likelihood

Cox \& Snell R:

Nagelkerke $R^{2}$
9863.253

17.398

1682.701

10567.383

.156

.220 $\underline{\text { Probit }}$

of 9906 Sig. $.618 \quad 9891.518$ df 9906 Sig. $\quad .539$

df 8 Sig. .026

df $28 \quad$ Sig. .000 
Measures of overall model significance. Goodness-of-fit tests compare observed

and expected number of responses within cells that are defined by grouping the dependent variable. The null hypothesis for these tests is that there is no difference between the number of observed and the number of expected responses. High p-values suggest that this hypothesis cannot be rejected, that is, that there is no difference between the two. Therefore high p-values indicate that the model fits the data well. The Pearson Goodness-of-Fit p-values were .618 for the logit model and .539 for the probit model. These indicate that the null hypothesis cannot be rejected and that the model fits the data well. The Hosmer and Lemeshow Goodness-of-Fit chi-square was significant $(p=.026)$. There is a significant difference in the two goodness-of-fit statistics. The Pearson Goodness-of-Fit statistic groups the residual prediction errors, with the number of groups determined by the number of covariate patterns. while the Hosmer-Lemeshow Goodnessof-Fit statistic groups the predictions themselves in a predetermined number of groups, in the case of SPSS. 10. The literature suggests that the use of the Pearson statistic is not advised when the number of covariate patterns approaches the number of observations, which is presumably not the case with the present study. Recent work also has suggested that the Hosmer-Lemeshow statistic is limited by its grouping strategy and can hide difficulties when the estimated cell probabilities approach either zero or one (Pigeon \& Heyse. 1999). An additional note is that the Hosmer-Lemeshow statistic was not stable as variables were entered into the model, whereas the Pearson statistic increased as significant variables were entered.

The likelihood statistic (-2 log likelihood) was used for comparing preliminary results for variable selection. As indicated in the section above, the final model was 
chosen by using the likelihood ratio to test for significant increase in the explanatory value of the models. (Overall predictive accuracy was also considered in choosing the final model.)

The Cox and Snell $R^{2}$ and the Nagelkerke $R^{2}$ are pseudo- $R^{2}$ measures. They have been devised to give a measure of the explanatory value of the model. These statistics are defined as $\left(1-L_{1}\right) / L_{0}$, where $L_{0}$ is the $\log$ likelihood for the constant only model and $L_{1}$ is the log likelihood for the full model. However, the literature suggests that the interpretation of these measures is difficult. In addition, they tend to be lower that expected. even for successful models. These measures for the present research (.156 and .220) are consistent with other recent results of similar models (Sinha, 1998: Somers. 1991).

Analy:ing individual variable coefficients. There are two things to look for with regard to each independent variable coefficient: the sign of the coefficient, and whether or not it is significantly different from zero. Magnitudes of the coefficients cannot be interpreted directly in logit and probit models, since the $X \beta$ matrix is then inserted in the logistic or standard normal distribution.

Net price (in $\$ 1.000 \mathrm{~s})$ was entered in the equation in cubic form $\left(\beta_{1}\right.$ NetPrice + $\left.\beta_{2} \mathrm{NetPrice}^{2}+\beta_{3} \mathrm{NetPrice}^{3}\right)$. All three coefficients are significant at $\mathrm{p}<.001$ in both models. Interpretation of the coefficients of these variables is difficult given both the cubic functional form and the fact that it is entered within another function (the probability functions). Figure 5 shows the relationship between net price and the predicted probability of enrollment. all else constant. Note that the shape is similar to the actual enrollment rates by price category presented in Table 11. The fact that the upward 
effect is exaggerated in the figure can be explained by the fact that this figure only illustrates the relationship between price and probability, with all other variable held constant. When those other variables are not held constant, they account for fact that the overall percentage yield does not go up in the lower price range.

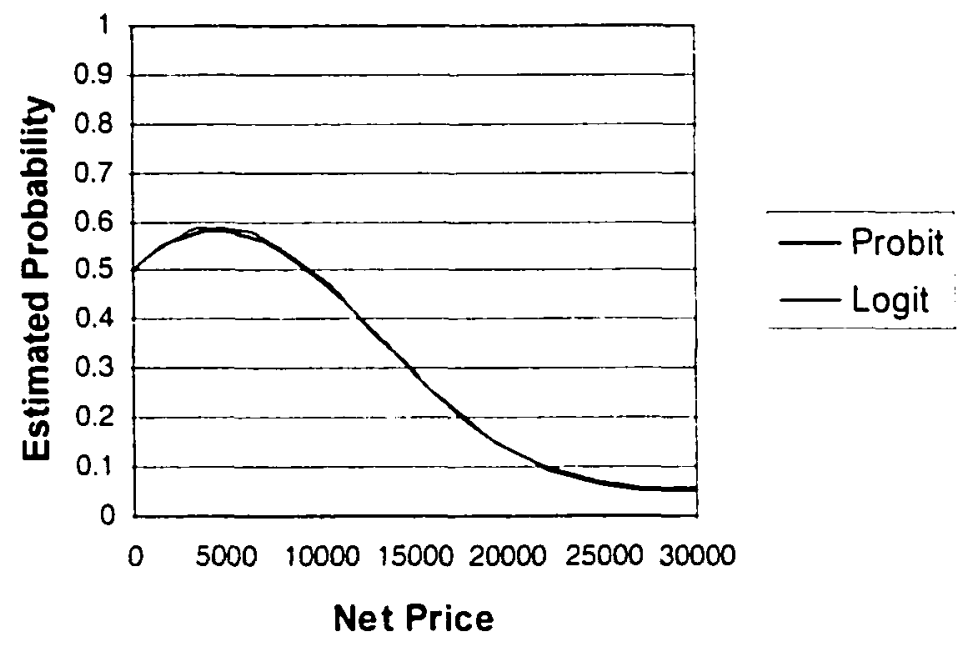

Figure 5. Price versus estimated probability (all else constant).

Need was divided into three categories - no need, low need, and high need, with the cut off between low and high need at $\$ 12,000$. The variable no need was omitted from the equation to avoid perfect collinearity. The signs of the coefficients of the other two variables are interpreted as the difference in the initial value of the dependent variable (intercept) compared to what it would be for the omitted variable. The sign of the low need variable is positive. indicating that. all else equal. a low need candidate will have a higher probability of enrolling than a no need candidate. and was significant at the .05 level. This may seem counter-intuitive at first, but there are a number of factors that would cause this. The no need student may have applied to more schools. reducing the probability of enrolling in any one school. In addition, if the low need candidate's need is 
met at this institution, it could increase the probability of enrollment (especially if it was not met at the other institution). A final consideration is that the no need category includes applicants who had no demonstrated need or who did not apply for financial aid. It can be argued that many candidates with need do not apply for aid. The sign of the high need variable is negative, indicating that, all else equal, the high need candidate will have a lower probability of enrolling than a no need candidate. Since the case institution does not guarantee to meet total demonstrated need. as only a handful of institutions due, is this a logical outcome. However, the coefficient of this variable was significant at the .10 level of significance in the logit model and not significant in the probit model.

The effect of being an early admissions candidate was positive and was significant at the .05 level. For any given set of other characteristics, the early admissions applicant has a higher probability of enrollment than the regular admissions applicant.

High school GPA was entered in cubic form $\left(\beta_{8} \mathrm{GPA}+\beta_{9} \mathrm{GPA}^{2}+\beta_{10} \mathrm{GPA}^{3}\right)$. GPA was significant at .10 in the logit model, but not in the probit. GPA ${ }^{2}$ and GPA ${ }^{3}$ were significant at the .05 level in both models. The signs of these coefficients are more difficult to interpret because they are part of a cubic equation. The cubic function defines a relationship where the probability of enrollment peaks at a GPA of 1.5 , and decreases after that. In other words, for GPAs less than 1.5, the probability of enrollment increases as GPA increases: for GPAs greater than 1.5, the probability of enrollment increases as GPA increases. Figure 6 illustrates the relationship between GPA and estimated probability, all else held constant. 


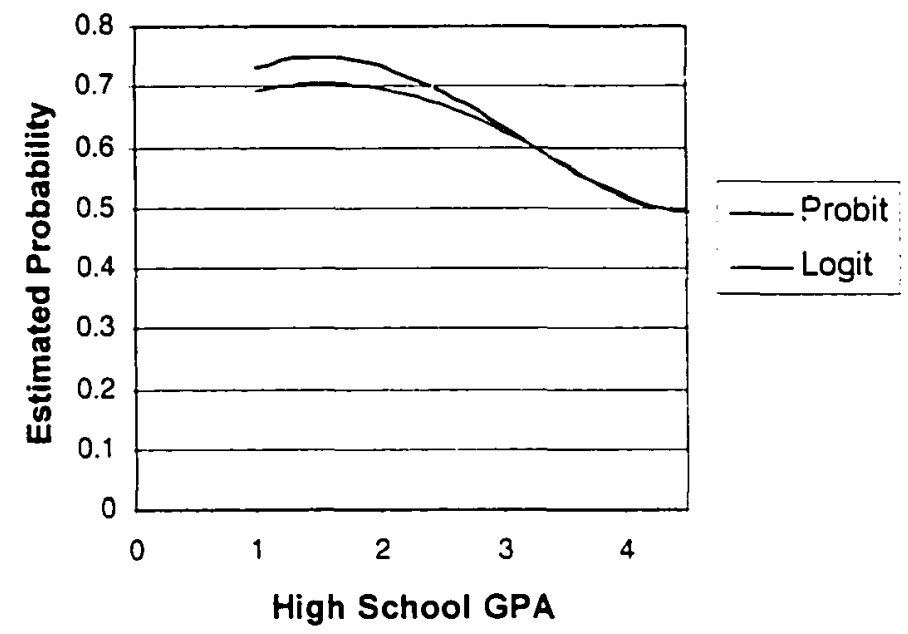

Figure 6. High school GPA versus estimated probability (all else constant).

The sign of combined SAT is negative, indicating that, as the SAT score increases, the probability of enrollment decreases. Combined SAT is significant at the .05 level.

The sign of the gender variable (with 1 being male) is positive, indicating that. all else constant, a male is more likely to enroll than a female. This is consistent with the cross tabulation results that. once admitted, the percentage of enrollment is slightly higher for males than females. However, the coefficient is not significantly different from zero.

Religion was divided into four categories-Catholic. Protestant. Jewish. and Other. The Protestant variable was omitted. The signs of the other three variables were all negative, indicating that. all else equal, the Protestant candidate would have the highest probability of enrollment. However, none of the coefficients were significantly different from zero.

Race or ethnicity was divided into seven categories - African American. Asian. Caucasian, Filipino. Hispanic, Native American, and Other. The Caucasian variable was omitted from the equation. The signs of the other six variables were all negative. 
indicating that, all else equal, the Caucasian candidate would have the highest probability of enrollment. The coefficients of the African American, Asian, Filipino, and Hispanic variables were significant at the .05 level. The coefficient of the Native American variable was significant at the .10 level. The coefficient of the Other Ethnicity variable was not significant.

Distance from home was divided into five categories - within state, out of state but less than 1,000 from home, from 1,000 to 2,000 miles from home. greater than 2,000 from home, and intemational students. The within state variable was omitted from the equation. The signs of the other four variables were all positive, indicating that. all else equal. the within state candidate would have the lowest probability of enrollment. This seems counter-intuitive. There are a number of possible reasons why these results occurred. First, as noted previously, the state institutions are this institution's leading competitors. Within state students are also applying to these schools, which have a lower price. Secondly, out of states students that apply would be expected to have a higher interest level on average, since it takes more effort to research and visit the institution. Three of the four coefficients were significant at the .05 level.

The sign of the legacy variable was positive. indicating that. all else equal. a candidate with a relative who had attended the institution has a higher probability of enrollment. The coefficient of this variable was significantly different from zero at the .05 level.

Three dummy variables for the year were created - 1998. 1999. and 2000. The year 1998 was omitted from the equation. The signs of the other two variables were positive, indicating that over the time period of analysis. the probability of enrollment 
increased due to factors not in the model. This indicates that other factors not in the model were changing. However, neither coefficient was significantly different from zero at the .05 level.

Significance of groups of variables. Since sets of dummy variables were used to estimate the effects of need, race or ethnicity, religion, and distance from home, the significance of the groups of dummy variables were tested in each case. Likelihood ratio tests were performed. The likelihood ratio test is performed by running the full model (unrestricted) and running a restricted model with the variable group omitted. The difference in the statistics -2 Log likelihood for the two models is calculated, the difference in the degrees of freedom is calculated, and the results are compared to the chisquare distribution. The results of these tests are in Table 14.

Table 14 Likelihood Ratio Tests for Categorical Variables for 1998-2000 Data

\begin{tabular}{|l|c|c|c|c|c|}
\hline $\begin{array}{c}\text { Variable } \\
\text { Group }\end{array}$ & $\begin{array}{c}-2 \log \\
\text { likelihood }\end{array}$ & $\mathrm{L}_{\mathrm{R}}-\mathrm{L}_{\mathrm{U}}$ & $\mathrm{df}$ & $\begin{array}{c}\text { Critical } \\
\chi^{2}\end{array}$ & Significance \\
\hline Need & 10630.675 & 63.292 & 2 & 5.991 & .000 \\
\hline Religion & 10571.243 & 3.860 & 3 & 7.815 & -.300 \\
\hline Race or ethnicity & 10624.397 & 57.014 & 6 & 12.592 & .000 \\
\hline Distance & 10598.685 & 31.302 & 4 & 9.488 & .000 \\
\hline
\end{tabular}

Need. race or ethnicity, and distance each have a significant effect on the probability of enrollment. Religion was not shown to have a significant effect on the probability of enrollment.

Classification Accuracy. Another measure of the goodness-of-fit of the model is how well it classifies the dependent variable. The observed values of the dependent variable. enrolled, are either 0 or 1 . The model provides a probability estimate between 0 and 1 based on the independent variables. To test classification accuracy. a cut score is 
determined for the probability, below which the student is classified as not enrolling and above which the student is classified as enrolling. For the $1998-2000$ data set, $30.7 \%$ of the admitted students enrolled in the institution (see Table 4). This historical percentage is the best information regarding the probability of enrollment. Therefore the cut score of .31 (the interface for the logistic model only provides two decimal places) was used to test classification accuracy. The probit model does not provide this procedure. To test classification accuracy of the probit model, the probabilities were calculated using the regression coefficients and then categorized. (See the Predictions for Fall 2001 Enrollment section below for a complete description of this process.) Table 15 provides the results of this test.

Table 15

Classification Accuracy for 1998-2000 Data

\begin{tabular}{|l|c|c|}
\hline & Logit & Probit \\
\hline Enrolled & $61.6 \%$ & $65.9 \%$ \\
\hline Did Not Enroll & $74.5 \%$ & $70.3 \%$ \\
\hline Overall & $70.6 \%$ & $69.0 \%$ \\
\hline
\end{tabular}

Cut score $=.31$

The logit model classified those students who did not enroll with more accuracy than the probit model. and the probit model classified those that did enroll with more accuracy. However, the overall classification accuracy was similar, with the logit accuracy slightly higher, and in the range consistent with other recent research (Sinha. 1998). 


\section{Predictions for Fall 2001 Enrollment}

Once the model was estimated for the 1998-2000 data using logit and probit techniques, the results were used to predict the enrollment from the admitted students for fall 2001 . This was done by calculating the $\mathrm{j}^{\text {th }}$ student's probability of enrollment using the model coefficients to obtain the logit or probit, and then substituting into the respective probability distribution.

$$
\begin{aligned}
P_{\text {logit }}= & \operatorname{EXP}\left(x_{j} \beta_{\text {logit }}\right) /\left(1+\operatorname{EXP}\left(x_{j} \beta_{\text {logit }}\right)\right) \\
P_{\text {probit }}= & 0.5+(1 / 2.5066)^{*}\left(\left(\left(x_{j} \beta_{\text {probit }}\right)^{\wedge} 3 / 6\right)+\left(\left(x_{j} \beta_{\text {probit }}\right)^{\wedge} 5 / 40\right)+\right. \\
& \left.\left.\left(\left(x_{j} \beta_{\text {probit }}\right)^{\wedge} 7 / 388\right)\right)\right)
\end{aligned}
$$

An additional refinement was necessary for the 2001 predictions. Although the year variables were not significant, there was the concern that, as time passed, there would be some significant variation in the enrollment probability that would not be captured by the other variables. So logit and probit coefficients for 2001 were estimated from the patterns over time for the year variables ${ }^{12}$. The coefficient .13 was used for the logit model and .08 for the probit model. Note that when the full 1998-2001 data set was run, the actual coefficients were .22016 and .12994 , respectively, and were both significant. These values were not used. however. since when making predictions of enrollment for a given year, the institution would not have this information and could only use the best information at hand at the time of prediction. which is the historical pattern in these variables. Table 16 provides the prediction classification accuracy based on the historical probability of enrollment of .307 .

\footnotetext{
12 The logit coefficient was .053 for 1999 and $.08+$ for 2000. The coefficient increased (from 0 for 1998) an average of $0+2$ for the two years. It was assumed that the coefficient would increase by $0+2$ to .126 for 2001 .
} 
Table 16

Classification Accuracy for Fall 2001 Enrollment Predictions

\begin{tabular}{|l|c|c|}
\hline & Logit & Probit \\
\hline Enrolled & $58.5 \%$ & $64.7 \%$ \\
\hline Did Not Enroll & $80.4 \%$ & $75.4 \%$ \\
\hline Overall & $73.9 \%$ & $72.2 \%$ \\
\hline
\end{tabular}

Cut score $=.31$

The probit model predicted both enrolls and not enrolls more accurately than it classified the 1998-2000 data. The logit model predicted enrolls less accurately than it classified the 1998-2000 data, although it predicted not enrolls more accurately, and overall accuracy was higher as well. The logit model predicted 1051 enrollments. compared to the actual enrollment of 1003 . The probit model predicted 1232 .

\section{Regression Results from Four-Year Data Set}

After model validation against the 2001 data, regressions were rerun using all four years of data. Results of the logistic and probit procedures are given in Table 17. 
Table 17

Regression Results from 1998-2001 Data

\begin{tabular}{|c|c|c|c|c|c|c|c|c|}
\hline \multirow[b]{2}{*}{ Variable } & \multicolumn{4}{|c|}{ Logit } & \multicolumn{4}{|c|}{ Probit } \\
\hline & B & & $\begin{array}{l}\text { Standard } \\
\text { Entor }\end{array}$ & l-statistic & $\mathbf{B}$ & & $\begin{array}{c}\text { Standard } \\
\text { Error }\end{array}$ & l-statistic \\
\hline Net Price & .23356 & ** & .04689 & 4.98085 & .13821 & $* *$ & .02792 & 4.95041 \\
\hline (Net Price) : & .02518 & ** & .00302 & -8.32892 & .01505 & $* *$ & .00179 & -8.39388 \\
\hline (Net Price) $^{3}$ & .00049 & $* *$ & .00006 & 8.47969 & .00029 & $* *$ & .00003 & 8.60805 \\
\hline Low need & .56528 & ** & .07285 & 7.75945 & .33875 & *** & .04359 & 7.77080 \\
\hline High need & -.15014 & $* *$ & .07358 & -2.04047 & -.07351 & * & $042+2$ & $\cdot 1.73292$ \\
\hline Early Action & .63915 & $* *$ & .04954 & 12.90240 & .37909 & $* *$ & .02954 & 12.83191 \\
\hline App. Rating & -.17018 & $* *$ & .01719 & -9.89946 & -.10045 & ** & .01014 & -9.91065 \\
\hline HS GPA & 2.40551 & $* *$ & $.967+1$ & 2.48654 & 1.39413 & $* *$ & .60097 & 2.31979 \\
\hline (HS GPA): & -.98133 & $* *$ & .33265 & -2.95008 & $-.568+3$ & $* *$ & .20308 & -2.79899 \\
\hline$(H S \text { GPA) })^{3}$ & .10564 & $* *$ & .03693 & 2.86080 & .06085 & $* *$ & .02232 & 2.72602 \\
\hline Combined SAT & .00150 & $* *$ & .00024 & -6.32150 & -.00088 & ** & .00014 & .6 .38922 \\
\hline Gender (male) & .05148 & & $.0+481$ & 1.14883 & .03008 & & .02626 & 1.14561 \\
\hline Catholic & -.04562 & & .04803 & -.94978 & .02699 & & .02812 & -.95984 \\
\hline Jewish & -.24680 & & .16127 & -1.53037 & -.14009 & & .09275 & .1 .51045 \\
\hline Other Religion & -.13907 & $*$ & .07379 & $-1.88+455$ & -.08127 & $*$ & $.0+300$ & -1.89020 \\
\hline African American & -.79529 & $* *$ & .16109 & $-\$ .93686$ & -.49271 & $* *$ & .09507 & -5.18262 \\
\hline Asian & -.52134 & $* *$ & .09546 & -5.46125 & -.30263 & $* *$ & $.05+46$ & -5.55737 \\
\hline Filipino & -.48201 & $* *$ & $.1+1+6$ & -3.40743 & -.28909 & $* *$ & .08161 & $-3.5+259$ \\
\hline Hispanic & -.23809 & $* *$ & .07012 & -3.39564 & .14280 & ** & 04093 & -3.48862 \\
\hline Native American & -.26330 & & $.17+32$ & $-1.510+2$ & $\cdot .16320$ & & .10256 & -1.59124 \\
\hline Other ethnicity & .06850 & & .11121 & -.61602 & $.037+8$ & & $.06+64$ &. .57993 \\
\hline Less than 1000 & .35931 & $* *$ & .05803 & 0.19226 & .21546 & $* *$ & $.03+13$ & 6.31342 \\
\hline 1000 to 2000 & $.200+3$ & $* *$ & .05995 & 3.34304 & .11921 & $* *$ & 03506 & 3.40032 \\
\hline Over 2000 miles & .17431 & $* *$ & .08076 & 2.15848 & 10216 & $* *$ & 04733 & 2.15846 \\
\hline International & .50857 & $* *$ & .15850 & 3.20871 & 29377 & $* *$ & .09265 & 3.17091 \\
\hline Legacy & .68281 & ** & .06380 & 10.70263 & .40774 & $* *$ & $.038+1$ & 10.61465 \\
\hline 1999 & .07823 & & .06243 & 1.25304 & .04733 & & .03670 & 1.28953 \\
\hline 2000 & .11241 & * & .06495 & 1.75521 & .06871 & * & 03693 & 1.86039 \\
\hline 2001 & .22016 & ** & .04954 & 3.38946 & 12994 & ** & 03811 & 3.40997 \\
\hline Constant & 2.48329 & ** & .99179 & 2.50385 & 1.49672 & *** & 62852 & 2.38132 \\
\hline
\end{tabular}

* Significant at . 10 level

** Significant at .05 level

$n=13308$

\section{Model Significance}

Logit

Pearson Goodness-of-Fit Hosmer and Lemeshow Model Chi-square

-2Log likelihood

Cox \& Snell R

Nagelkerke $\mathrm{R}^{\text {: }}$
13218.186

17.492

2376.558

13980.284

.164

.231
Probit

df $1327 \mathrm{~S}$ Sig. $642 \quad 13261.094$ df 13278 Sig. .540 df 8 Sig. .025

df $29 \quad$ Sig. .000 
Comparison of model significance between 1998-2000 and 1998-2001 data sets.

The measures of goodness-of-fit were similar using the full data set. The Pearson Goodness-of-Fit chi-square was not significant again with the complete data set, indicating that the model fit the data well. The Hosmer and Lemeshow Goodness-of-Fit chi-square was significant at the .05 level with the full model $(p=.025)$, as in the 1998 2000 model. The Cox and Snell $\mathrm{R}^{2}$ and the Nagelkerke $\mathrm{R}^{2}$ were both higher with the complete data set.

Comparison of variable coefficient signs and significance between $1998-2000$ and 1998-2001 data sets. The signs of all of the coefficients were the same for the estimates from both the 1998-2000 and 1998-2001 data sets. The significance levels of the coefficients were the same for most variables. However. significance did change for a few of variables. High need rose in significance in both the logit and probit models. High school GPA and over 2,000 miles from home became significant at the .05 level. Other religion became significant at the .10 level. Native American went from being significant at the .10 to being not significant with the complete data set $(p=.14)$. The year 2000 variable became significant at the .10 level, and the new variable, year 2001 was significant at the .05 level.

Comparison of significance of calegorical variables. Table 18 provides the likelihood ratio test results for the categorical variables. 
Table 18

Likelihood Ratio Tests for Categorical Variables for 1998-2001 Data

\begin{tabular}{|l|c|c|c|c|c|}
\hline $\begin{array}{c}\text { Variable } \\
\text { Group }\end{array}$ & $\begin{array}{c}-2 \log \\
\text { likelihood }\end{array}$ & $\mathrm{L}_{\mathrm{R}}-\mathrm{L}_{\mathrm{U}}$ & $\mathrm{df}$ & $\begin{array}{c}\text { Critical } \\
\chi^{2}\end{array}$ & Significance \\
\hline Need & 14052.948 & 72.664 & 2 & 5.991 & .000 \\
\hline Religion & 13985.623 & 5.339 & 3 & 7.815 & -.150 \\
\hline Race or ethnicity & 14045.965 & 65.681 & 6 & 12.592 & .000 \\
\hline Distance & 14028.572 & 48.228 & 4 & 9.488 & .000 \\
\hline
\end{tabular}

As in the model estimated with 1998-2000 data, need, race or ethnicity, and distance all have significant effects on the probability of enrollment. As with the 19982000 data, religion was not shown to have a significant effect on the probability of enrollment.

Classification Accuracy. Classification accuracy was calculated for the 1998-2001 data set. The results are provided in Table 19.

Table 19

Classification Accuracy for 1998-2001 Data

\begin{tabular}{|l|l|l|}
\hline & \multicolumn{1}{|c|}{ Logit } & Probit \\
\hline Enrolled & $63.0 \%$ & $60.9 \%$ \\
\hline Did Not Enroll & $74.2 \%$ & $76.4 \%$ \\
\hline Overall & $70.8 \%$ & $71.6 \%$ \\
\hline
\end{tabular}

Cut score $=.30$

The probability cut score was changed from .31. which was used with the 19982000 data, to .30 for the 1998-2001 data set. This is because the overall percentage of enrollment was $30.7 \%$ for $1998-2000$ and was $30.4 \%$ for $1998-2001$. The classification accuracy was very similar between the 1998-2000 and the 1998-2001 data sets for the logit model. The classification accuracy changed more for the probit model between the two data sets. with the dispersion between classification accuracy of enrolls and not enrolls being much greater for the 1998-2001 data. 


\section{Policy Analysis}

The final step in the analysis was to examine the effects of various pricing policy changes. The full four-year data model results were used for this purpose. This analysis was performed using two procedures. The first is a price sensitivity analysis on the total data set. The second is the creation of policy simulations of particular interest to the institution.

\section{Price Sensitivity Analysis}

This research used logit and probit regression techniques rather than linear regression. Therefore, the sensitivity to price is not constant in the model. In fact, the price sensitivity is different for each student (Crown, 1998). Just as Crown noted that taking the derivative of the mean value might produce an inflated summary figure, calculating any change statistic at the mean might also inflate the price sensitivity for the same reason. Therefore in this research, sensitivity to a $\$ 1,000$ decrease in price was calculated for each student, and then the mean was calculated. The following formula presented in Chapter 3 was used with both the logit and probit output:

$$
\begin{aligned}
& \text { Probability } \Delta_{j}=P_{1 j}-P_{0 j} \text {. } \\
& \text { where } \quad P_{0 j}=\text { estimated probability calculated with actual net price } \\
& \text { for the jth student. } \\
& \text { and } \quad P_{1 j}=\text { estimated probability calculated with actual net price }-\$ 1.000 \\
& \text { for the jth student. }
\end{aligned}
$$

The mean sensitivity to a $\$ 1,000$ decrease in net price was .02 for both the logit and probit models. The range was -.07 to .05 for the logit model and -.06 to .05 for the probit model. That is. a $\$ 1.000$ decrease in net price increased the probability of enrollment by $2 \%$, for example, from .30 to .32 . However, again because of the shape of the probability distribution, there is a wide variation in the change in the probabilities as 
price changes. Table 20 shows the mean changes in probability by net price group. The sensitivity to change is strongest in the $\$ 15,000$ to $\$ 20,000$ price range.

Table 20

Price Sensitivity

\begin{tabular}{|l|c|c|}
\hline & \multicolumn{2}{|c|}{ Mean Change in Probability } \\
\hline Net Price Group & Logit & Probit \\
\hline$\$ 0-\$ 5,000$ & -.02 & -.02 \\
\hline$\$ 5,000-\$ 10,000$ & .01 & .01 \\
\hline$\$ 10,000-\$ 15,000$ & .03 & .03 \\
\hline$\$ 15,000-\$ 20,000$ & .04 & .04 \\
\hline$\$ 20,000-\$ 25,000$ & .03 & .03 \\
\hline$\$ 25,000-\$ 30,000$ & .02 & .02 \\
\hline Total & .02 & .02 \\
\hline
\end{tabular}

Figure 7 provides the same information discretely for all students in the sample.

Note the very definite quadratic relationship between the maximum sensitivities and net price.

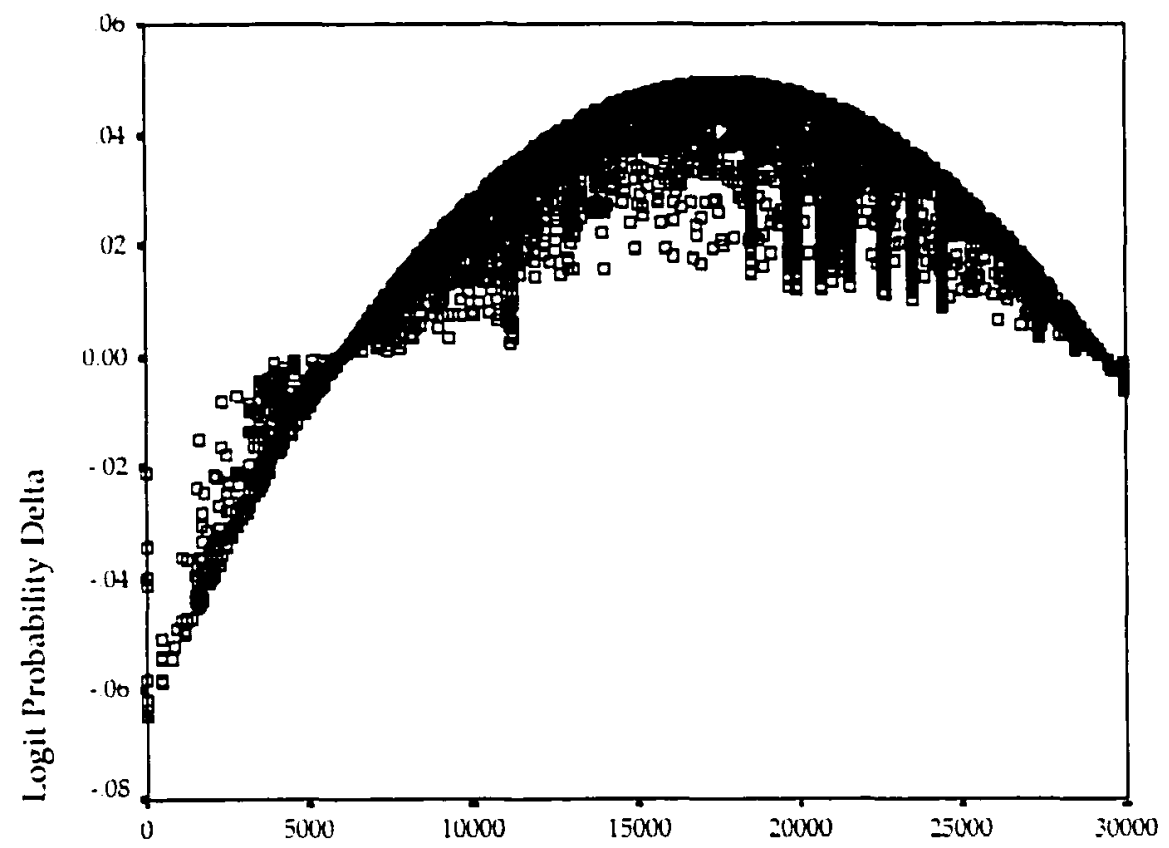

Net Price

Figure 7. Student price sensitivity against net price. 
When comparing these results to SPRCs and delta Ps reported in other research, it must be noted that the results reported here do not have the overestimation bias associated with calculating only one estimate at the mean. As will be discussed in Chapter 5, the present results are lower than most other recent research.

Note that the average change was negative between $\$ 0$ and $\$ 5,000$. This is consistent with the findings in Figure 5. This effect is uncovered because the net price variable was not constrained to be linear. This effect was also observed for certain demographic groups in Table 11 , and in the price-group model reported on page 72.

As previously mentioned in Chapter 3, another caveat with the price sensitivity reporting practices is that absolute probability changes fail to uncover the power of the $\$ 1.000$ change at difference points in the function. For example, for a student whose initial probability of enrolling was .20 . a change of .02 to .22 means he is $10 \%$ more likely to enroll. For a student whose initial probability of enrolling was .70 , a change of .02 to .72 means he is only $3 \%$ more likely to enroll.

\section{Policy Simulation}

Eight scenarios of interest to the institution were created. Each of these scenarios simulates a $\$ 1,000$ decrease in the net price variable. For example, the first scenario simulates a $\$ 1.000$ increase in financial aid for a Caucasian. Protestant male, with average ability, from within state. with no financial need, no legacy. and who applied for regular admission. For each scenario, the initial probability of enrollment is estimated. the probability of enrollment after the net price decrease is estimated. and the change in probability is calculated. The changes in probability were calculated using formula (11) above. It is also noted whether or not the $\$ 1,000$ decrease in price resulted in a predicted 
change in the enrollment decision. This was based on whether the estimated probability changed from below to above the cut score of .30 .

The eight scenarios are divided into four pairs so that the effects of changes in other variables can be analyzed as well. For example, scenarios $1 \mathrm{a}$ and $\mathrm{lb}$ are the same, except that the student in la applied under regular admissions and the student in Ib applied for early admission. The single variable that differs between the " $a$ " and " $b$ " cases are in bold.

Table 21 provides the results of these scenarios. 
Table 21

Effects of Pricing Policy Changes

\begin{tabular}{|c|c|c|c|c|}
\hline Scenario & $\begin{array}{c}\text { Initial } \\
\text { Probability }\end{array}$ & $\begin{array}{c}\text { New } \\
\text { Probability }\end{array}$ & $\begin{array}{l}\text { Probability } \\
\text { Delta }\end{array}$ & $\begin{array}{c}\text { Enrollment } \\
\text { Decision } \\
\text { Change } \\
\end{array}$ \\
\hline $\begin{array}{l}\text { 1a. } \$ 1.000 \text { increase in financial aid for a } \\
\text { Caucasian. Protestant male, with average } \\
\text { ability, from within state, with no financial } \\
\text { need (initial net price }=\$ 29.908 \text { ). regular } \\
\text { admission, no legacy }\end{array}$ & $\begin{array}{l}.15 \\
.13\end{array}$ & $\begin{array}{l}.15 \\
.13\end{array}$ & $\begin{array}{l}0 \% \\
0 \%\end{array}$ & $\begin{array}{l}\text { No } \\
\text { No }\end{array}$ \\
\hline $\begin{array}{l}\text { Ib. } \$ 1.000 \text { increase in financial aid for a } \\
\text { Caucasian. Protestant male, with average } \\
\text { ability, from within state, with no financial } \\
\text { need (initial net price }=\$ 29.908 \text { ), early } \\
\text { admission. no legacy }\end{array}$ & $\begin{array}{l}.26 \\
.23\end{array}$ & $.23^{\mathrm{P}}$ & $\begin{array}{r}-1 \% \\
0 \%\end{array}$ & $\begin{array}{l}\text { No } \\
\text { No }\end{array}$ \\
\hline $\begin{array}{l}\text { 2a. } \$ 1.000 \text { increase in financial aid for an } \\
\text { African American. Protestant female, with } \\
\text { above average ability, from within state, with } \\
\text { high financial need (initial net price = } \\
\text { \$12.000). regular admission, no legacy }\end{array}$ & $\begin{array}{l}.28 \\
.29\end{array}$ & $.32^{\mathrm{p}}$ & $\begin{array}{l}4 \% \\
3 \%\end{array}$ & $\begin{array}{l}\text { Yes } \\
\text { Yes }\end{array}$ \\
\hline $\begin{array}{l}\text { 2b. } \$ 1.000 \text { increase in financial aid for an } \\
\text { African American. Protestant female. with } \\
\text { above average ability, from within state, with } \\
\text { low financial need (initial net price }=\$ 20.000 \text { ), } \\
\text { regular admission, no legacy }\end{array}$ & $\begin{array}{l}.18 \\
.17\end{array}$ & $\begin{array}{l}.21 \\
.20\end{array}$ & $\begin{array}{l}3 \% \\
3 \%\end{array}$ & $\begin{array}{l}\text { No } \\
\text { No }\end{array}$ \\
\hline $\begin{array}{l}\text { 3a. } \$ 1.000 \text { decrease in tuition for an Hispanic. } \\
\text { Catholic male. with above average ability, from } \\
\text { within state away, with low financial need } \\
\text { (initial net price }=\$ 20.000 \text { ), regular admission. } \\
\text { no legacy }\end{array}$ & $\begin{array}{l}.28 \\
.27\end{array}$ & $\begin{array}{l}.32 \\
.31\end{array}$ & $\begin{array}{l}4 \% \\
4 \%\end{array}$ & $\begin{array}{l}\text { Yes } \\
\text { Yes }\end{array}$ \\
\hline $\begin{array}{l}\text { 3b. } \$ 1.000 \text { decrease in tuition for an Hispanic. } \\
\text { Catholic male, with above average ability. from } \\
\text { over } 2000 \text { miles away, with low financial need } \\
\text { (initial net price }=\$ 20.000 \text { ). regular admission. } \\
\text { no legacy }\end{array}$ & $\begin{array}{l}.32 \\
.31\end{array}$ & $\begin{array}{l}.36 \\
.35\end{array}$ & $\begin{array}{l}4 \% \\
+\%\end{array}$ & $\begin{array}{l}\text { No } \\
\text { No }\end{array}$ \\
\hline $\begin{array}{l}\text { ta. } \$ 1.000 \text { increase in financial aid for a } \\
\text { Caucasian. Catholic female. with below } \\
\text { average ability. from } \mathbf{1 0 0 0 - 2 0 0 0} \text { miles away. } \\
\text { with low financial need (initial net price }= \\
\$ 20.000 \text { ). regular admission, with a legacy }\end{array}$ & $\begin{array}{l}.72 \\
.69\end{array}$ & $\begin{array}{l}.75 \\
.73\end{array}$ & $\begin{array}{l}3 \% \\
+\%\end{array}$ & $\begin{array}{l}\text { No } \\
\text { No }\end{array}$ \\
\hline $\begin{array}{l}\text { 4b. } \$ 1.000 \text { increase in financial aid for a } \\
\text { Caucasian. Catholic female, with below } \\
\text { average ability. from less than } 1000 \text { miles } \\
\text { away. with low financial need (initial net price } \\
=\$ 20.000 \text {. regular admission. with a legacy }\end{array}$ & $\begin{array}{l}.75 \\
.73\end{array}$ & $\begin{array}{l}.78 \\
.76\end{array}$ & $3 \pi$ & $\begin{array}{l}\text { No } \\
\text { No }\end{array}$ \\
\hline
\end{tabular}

Above average ability was coded as GPA $=4.0$. SAT $=1350$. Application Rating $=8$.

Average ability was coded as GPA $=3.75$. SAT $=1200$. Application Rating $=6$.

Below average ability was coded as GPA $=3.0$. SAT $=1050$. Application Rating $=4$.

These codings were based on the central tendency and dispersion of the three variables within the data set. 
The changes in probability from a $\$ 1,000$ decrease in net price ranged from $-1 \%$ to $4 \%$ in the logit model, and from $0 \%$ to $4 \%$ in the probit model. In two cases. (2a and 3a) the admissions decision was affected by the decrease in net price, as these students were near but below the cut score of .30 before the decrease.

Cases $\mathrm{la}$ and $\mathrm{lb}$ illustrate the effects of early decision on the probabilities of enrollment. For students with this set of characteristics, the early admissions candidate was approximately $75 \%$ more likely to enroll. In both cases, the $\$ 1.000$ decrease was not enough. however, to change the admissions decision.

Cases $2 a$ and $2 b$ illustrate the effect of the differences in need categories. For students with the given set of characteristics, the high need candidate was over $50 \%$ more likely to enroll. The enrollment decision did change for the high need candidate with a $\$ 1.000$ increase in aid. An additional assumption of these two cases was that the need was met for both the low need and high need candidates. Therefore the differences in the probabilities between case $2 \mathrm{a}$ and case $2 \mathrm{~b}$ illustrate both a difference in need and $\mathrm{a}$ difference in financial aid. and hence net price.

Cases $3 a$ and $3 b$ and $4 a$ and $4 b$ illustrate the effects of the distance for an above average ability Hispanic male and a below average ability Caucasian female. In cases $3 a$ and $3 \mathrm{~b}$, the within state candidate was about $15 \%$ less likely to enroll that the candidate from over 2000 miles away. In cases $4 a$ and $4 b$. the candidate from less than 1000 miles away (out of state) was about $5 \%$ more likely to enroll than the candidate from 1000 to 2000 miles away.

Many addition policy simulations could be illustrated. Using this model. the institution will be able to determine the effects of various financial aid policies on 
students with different demographic, socio-economic, and degree of preparation characteristics.

\section{Summary and Conclusion}

Using the methodology described in Chapter 3, logit and probit estimates of the theoretical model were estimated. Various refinements to the variables were tested (functional form, interaction effects, modifications due to multicollinearity, etc.). These refinements resulted in the final form of the model presented in Tables 13 and 17.

The signs of most of the coefficients were as expected. Those that differed from expectations were those for low need and for all the distance from home variables. Gender and religion were not significant although they were expected to be.

Classification accuracy was near $70 \%$ for all models. Although it was hoped to be higher, this percentage is consistent with other models that use admissions and financial aid data.

The results of the policy simulations were generally as expected. Decreases in net price produced changes in the probability of enrollment within the range expected based on previous research. The model estimated will provide the institution with a tool that will help with enrollment and financial aid management. 


\section{CHAPTER 5 \\ Summary of Findings \\ Introduction}

In today's higher education environment, institutions face many issues related to admissions and financial aid. Some issues are market-wide, and some are institutionspecific. All institutions face the problems associated with maintaining or improving selectivity rankings, the declining value of federal subsidy programs and increasing need for institutional aid. fluctuating enrollment rates, and the increasing competition between schools. Each institution also faces a set of unique enrollment management issues. For the institution used in this research. these issues include the desire to maintain the enrollment level of Catholic students while developing an ethnically and culturally diverse campus community.

Institutions of higher education need tools that can help them address these enrollment management issues. With technological innovations that allow institutions to collect more data. they are now in the position to develop and use more sophisticated tools. The purpose of this research was to develop a tool for one institution that would answer the following questions: (1) what is the probability of enrollment for each admitted student, and (2) how would changes in the financial aid package affect this probability? This tool will help the institution make more informed policy decisions.

This chapter will review the findings from this research, compare those findings to previous studies, discuss the potential use of this research in institutional policy- 
making processes and practices, and discuss how the results of this study might direct future research.

\section{Summany of Findings}

The model used in this research was based on both economic theory and the results of other empirical work, and was refined through statistical analysis. Its main goal was to develop the best predictive model using the data collected by the institution and available to it at the time the admissions and financial aid decisions are made. Other goals included applying the most appropriate statistical techniques, while maintaining usability of the model.

\section{Price Sensitivity}

Economic theory states that the quantity demanded of a good is negatively related to the price of the good. One of the general conclusions from past empirical research was, in fact, that most students are sensitive to changes in the price of tuition. with enrollment demand decreasing as tuition increases. The results of this study, for the most part. confirmed economic theory and general empirical findings. The unique finding was that a linear, constantly decreasing functional form was not the best fit for the data. Rather, a cubic relationship between net price and enrollment probability provided a better fit. The slope of the graph of net price (tuition, room. board, and other expenses minus all grant aid) was negative in all but the lowest price level. indicating that as the price decreased. the student was more likely to enroll. (See Figure 5.) An interpretation of the anomaly of a positive relationship in the lower price range (which was also observed in the descriptive analysis) is that when price is relatively low, other variables have a greater effect on the enrollment decision than net price. The results of the grouped model 
analysis (see footnote 8 ) also bears out the conjecture that price is not as important when it is very low, as the coefficient on net price was positive, but not significant, in the $\$ 0$ $\$ 5,000$ and $\$ 5,000-\$ 10,000$ price groups.

This research used logit and probit regression techniques rather than linear regression. Therefore, the sensitivity to price is not constant in the model. In fact, price sensitivity is different for each student (Crown, 1998). Because of this, sensitivity to a $\$ 1,000$ decrease in price was calculated for each student. The mean sensitivity to a $\$ 1,000$ decrease in net price was .02 for both the logit and probit models. That is, on average, a $\$ 1,000$ decrease in net price increased the probability of enrollment by $2 \%$, for example. from .20 to .22.

Direct comparisons of these results to the literature are difficult for a number of reasons. First, researchers use a number of measures of sensitivity. Some authors report SPRCs (Student Price Response Coefficients), some delta Ps, and others neither of these. As discussed before, there is an inherent overestimation concern with these measures. ${ }^{13}$ For the present study, the change in probability for a $\$ 1.000$ change in price was calculated by finding each student's initial estimated probability, subtracting $\$ 1,000$ from each student's actual price and recalculating the probability, finding the difference, and then taking the average across all students.

The second issue confounding comparisons is the value of a dollar. Tuition has skyrocketed in the last three decades. Jackson and Weathersby calculated SPRCs on a

\footnotetext{
${ }^{13}$ SPRCs are calculations of the absolute change in enrollment for a $\$ 100$ or $\$ 1.000$ change in price. Delta Ps also report the absolute change in enrollment for a $\$ 1.000$ change in price (given that price is entered in $\$ 1.000$ s. which is the practice of researchers who report delta Ps). However. they also reflect the change in probability at the mean, rather than the mean of the changes in probability. If the data consists of many cases at the extreme and few at the mean. the change in probability at the mean may be much higher than the mean of the change in probability. since the slope of the logit and probit curves is steepest at the mean. and flat at the extremes (Crown. 1998).
} 
$\$ 100$ change for a base year when the average tuition was $\$ 2.000$, which is a $5 \%$ change in tuition. This study uses a $\$ 1,000$ change for a base year when the total price was $\$ 27,360$, which is a $5.9 \%$ change in price. These are fairly comparable proportional changes. Studies done in the time interval between the Jackson and Weathersby study and this study also used either $\$ 100$ or $\$ 1000$ as the amount of the change in price. However, the base prices were constantly changing. Therefore, the proportional change represented by a $\$ 100$ or $\$ 1,000$ change in price could not be expected to the same across studies.

The third issue that makes comparisons difficult is the fact that there are two types of studies-national and institution specific. Studies that used institution-specific data tend to report higher price sensitivities. This makes sense because. when looking at choice rather than access models. a student may not enroll in the specific institution being studied, but may still enroll in college.

A final difficulty lies in the difference between absolute and relative change. SPRCs and delta Ps both calculate absolute change. It is general practice in fields such as economics to report relative change by dividing the absolute change by the starting value. Although the relative change provides a more precise level of comparison, the present research reported absolute change to remain comparable with existing research in the field of education.

To mitigate the effects of the first three of these issues. Table 22 compares the results of a number of the more recent studies, using the authors ${ }^{\circ}$ translation of the change statistic he or she calculated into percent change in probability language. 
Table 22

Comparison of Price Sensitivity Estimates

\begin{tabular}{|l|c|l|}
\hline \multicolumn{1}{|c|}{ Study } & \multicolumn{1}{|c|}{ Type } & Change in Probability \\
\hline St. John (1990) & National & $\begin{array}{l}4.3 \% \text { increase for } \$ 1,000 \\
\text { increase in grant aid }\end{array}$ \\
\hline $\begin{array}{l}\text { Moore, Studenmund, \& } \\
\text { Slobko (1991) }\end{array}$ & Private institution & $\begin{array}{l}7.8 \% \text { increase for } \$ 1,000 \\
\text { increase in grants }\end{array}$ \\
\hline Somers (1991) & Public institution & $\begin{array}{l}6.2 \% \text { increase for } \$ 1.000 \\
\text { increase in aid }\end{array}$ \\
\hline Heller (1997) review & Both & $\begin{array}{l}0.5 \% \text { to } 1.0 \% \text { decrease for } \\
\$ 100 \text { increase in price }\end{array}$ \\
\hline Present study (2001) & Private institution & $\begin{array}{l}\text { Mean 2\% increase for } \\
\$ 1.000 \text { decrease in price }\end{array}$ \\
\hline
\end{tabular}

The fact that the results from the present study are lower than the rest is consistent with the warnings that statistics calculated only at the mean can overestimate sensitivity. The implication for policy makers is that they need to look at specific students. or groups of similar students. when estimating the effect of policy decisions. and not rely solely on one average estimate. This study also provided this type of information in the policy scenarios in Table 21.

Income Sensitivity and Effects of Income on Price Sensitivity

Economic theory states that consumption is positively related to income. This is difficult to translate to enrollment in higher education. since you can ${ }^{\circ}$ consume discrete quantities of undergraduate education. In addition, income not only affects your ability to pay but also your tastes and preferences for education in general and for specific institutions. Therefore income variables measure multiple characteristics of the student.

In this study, financial need was used as a proxy for income. This was done because income information was only available for financial aid applicants. Need was categorized as no need. low need and high need. As a proxy for income. these would translate to high income, moderate income, and low income. Theory would suggest that 
the probability of enrollment would decrease between these categories. In fact, the sign of the coefficient on low need was positive, indicating that a moderate income student was more likely to enroll than a high income student was. As discussed in Chapter 4 , two potential reasons for this are the fact that some students with actual need do not apply for it, and the likelihood that no need students apply to more institutions, thereby lowering their probability of enrolling in any particular institution. The coefficient on high need was negative as expected.

The empirical work reviewed in the literature also showed inconsistency of results with regard to the effect income has on price sensitivity. Radner and Miller (1970), Hoenack (1968), St. John (1990), and Moore, Studenmund \& Slobko (1991) all showed an inverse relationship between income and price sensitivity. In contrast. Corazzini et. al. (1972) showed highest price responsiveness in the highest income categories and in the lowest income categories. The results from this study related to price sensitivity and income are presented in Table 23 .

Table 23

Income and Price Sensitivity

\begin{tabular}{|l|c|c|}
\hline \multicolumn{1}{|c|}{ Need Category } & $\begin{array}{c}\text { Logit Price } \\
\text { Sensitivity }\end{array}$ & $\begin{array}{c}\text { Probit Price } \\
\text { Sensitivity }\end{array}$ \\
\hline No need & .0128 & .0109 \\
\hline Low need & .0257 & .0243 \\
\hline High need & .0263 & .0255 \\
\hline
\end{tabular}

The results from this study show price sensitivity increasing with need. therefore decreasing with income, which is consistent with all the findings except Corazzini et. al. Comparison of logistic and probit models

Previous research has shown that logistic regression and probit models provide similar results (Aldrich \& Nelson, 1984). The results from this study concur with 
previous findings. The signs of the coefficients, the significance of the coefficients, and the relative magnitudes of the coefficients were the same between the two techniques. The actual values of the coefficients cannot be compared because the resulting matrices are then entered into either the logistic distribution (logit model) or the standard normal distribution (probit model). The comparison point is the actual probabilities for each student after this is done. The difference between the probabilities was calculated for each student in the 1998-2001 data set (probit probability - logit probability). The mean difference was -.0169 , with a standard deviation of .0121 . Figure 8 shows these differences for each student plotted against net price.

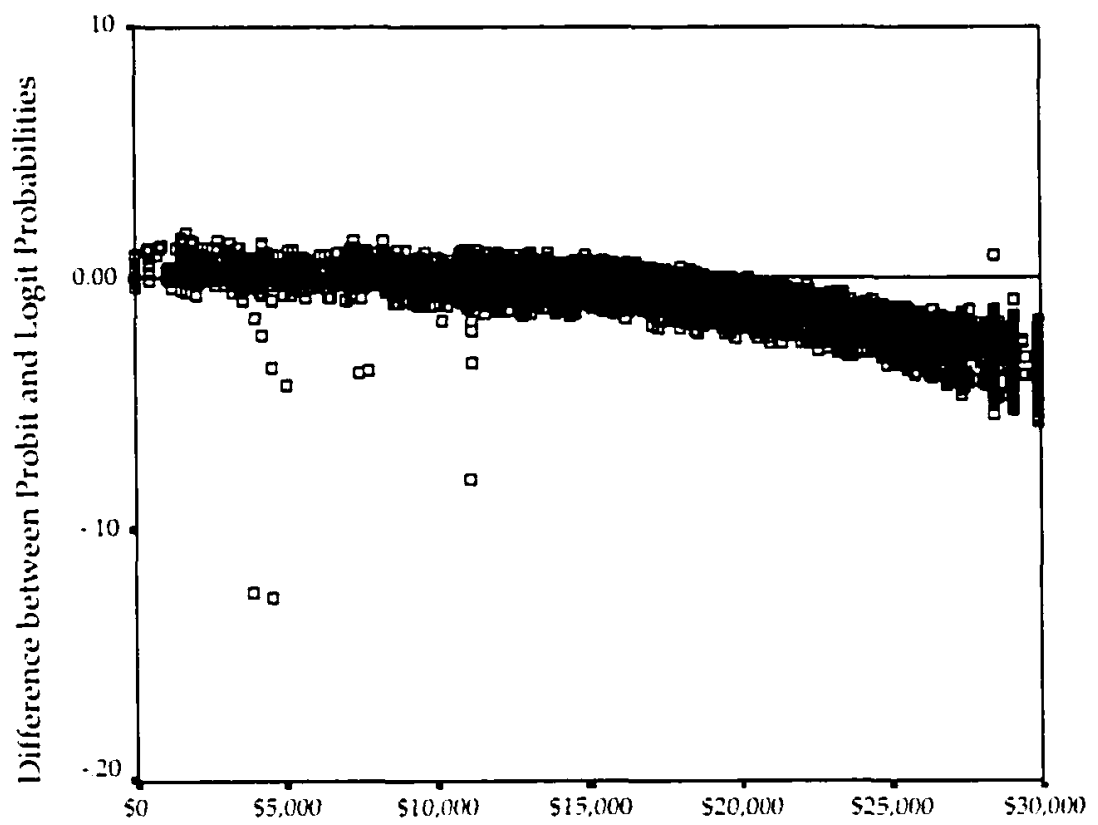

Net Price

Figure 8.

Difference between probit and logit probability plotted against net price.

Note that the difference between the probit and logit probabilities tends to be above zero in the lower range of net price and decreases as net price increases. This suggests that the probit probabilities tend to be above the logit probabilities at the top of 
the S-like curve, and below them at the bottom of the curve. This indicates that the relative shape of the two estimated probability curve is as predicted by the literature (Greene, 1990; Crown, 1998). This literature suggests that the tails of the logit-estimated curve are fatter than those of the probit-estimated curve.

Are there any theoretical arguments for selecting one technique over the other? Theory and common sense would suggest that the probability of enrollment would not hit 1 even at a net price of 0 , because some students that were admitted would not enroll. simply because they have a strong preference for another school. Theory and common sense would also suggest that the probability of enrollment would not hit zero at the full price because some students have a strong emotional or legacy tie to the institution. However, the proportion of students at these two ends would be too hard to predict to justify the use of one of the techniques over the other. If anything, one might argue that for a most selective institution, almost every admitted candidate would enroll if the net price were 0 and there would be a large number of candidates who would enroll at almost any price. This would argue for using the probit estimates at the lower end of the net price range and the logit estimates at the higher end. The oppositive argument would hold for a less selective institution.

There are some technical considerations that may cause a researcher to choose one technique over the other. Within the SPSS program, the logistic regression function provides more statistical output. It provides more types of evidence of significance of the model and goodness of fit. It also provides the output for likelihood ratio tests, where the probit analysis does not. Therefore, with the existing SPSS tools, the use of the logistic 
regression function is preferable. However, with additional software engineering, both programs could be made equally useful.

\section{Use of this Model for Institutional Policy and Practice}

This case study has relevance both for policy makers at the institution itself and for policy makers at other institutions facing similar issues. Therefore this analysis will be discussed under those two headings.

\section{Implications for Case Institution}

The institution used for this study has very specific, well-defined goals, such as developing an ethnically and culturally diverse campus community. Institutional policies and practices are created to help organizations meet such goals. Research helps an organization determine whether those policies and practices are effective in moving towards its goals. The present study provided the case institution with three types of findings: (1) results which were consistent with the assumptions underlying present policy and practice. (2) results which were counter-intuitive and need to be examined further, and (3) insights into institutional data collection and management.

This study confirmed that minority students are less likely to enroll, that students with higher SAT scores and GPAs are less likely to enroll, and that students with a relational legacy with the school and who have visited the school are more likely to enroll. These findings support the present financial aid practices of awarding minority scholarships and merit scholarships, and the present recruitment practices of alumni recruiting and encouraging campus visits.

The study also highlighted some areas that look, on the face of it. inconsistent with present assumptions. It was expected that the effect on enrollment of distance from 
home would be negative, that the effect of being a male applicant would be negative, and that the effect of being a Catholic applicant would be positive. In fact, each of the findings was just the opposite.

The effect of the set of dummy variables for distance from home was significant in the enrollment decision. However, all coefficients were positive (with in-state being the omitted variable), indicating that an out-of-state student was more likely to enroll once admitted than an in-state student was. The value of the coefficients decreased with distance, however, meaning, for out-of-state students, the probability of enrollment decreased with distance. Reasons for the out-of-state coefficients being positive could include the fact that the state schools are this institution's top competitors, and that outof-state students that apply are demonstrating a higher general level of interest because the cost of gathering information is greater for them. Further research through an admitted student questionnaire could provide more information in this area.

Many research studies have included a gender variable but have not discussed the effects of this variable. This was a variable that the case institution was particularly interested in since male enrollment has decreased to well under $40 \%$ of the freshman class. The sign of the coefficient on this variable was positive, although not significantly difference from zero. This and the cross-tabulation evidence show that admitted male candidates enroll at a slightly higher rate than females. Therefore, the solution to the problem seems to lie in recruitment and not enrollment. Funds might be better spent on initial recruiting efforts than on trying to effect enrollment rates. which would lead to gender inequities in pricing. 
Religious affiliation is not generally included in the variables of models that predict student enrollment. However, for this institution, maintaining its Catholic heritage and culture is an important goal. In recent years, the percent of Catholic students enrolling as freshman has run about $55 \%$. This is, of course, down from the near $100 \%$ during the first years of the school's founding institutions. The results of this research showed a negative sign on the coefficient for Catholic affiliation compared to Protestant. although the coefficient was not significantly different from zero. The cross-tabulations showed that Catholic students are slightly more likely to enroll once admitted. However. neither of these findings is strong enough to help make further recommendations.

An exercise of this type is useful to the institution not just for its results, but also for discoveries during the process of the work. This research has shown some gaps in data collection that can be easily addressed. For instance, many researchers (Savoca. 1990: Hossler. Hu. \& Schmidt. 1999) have found significant effects from father's and mother's education level. This data is collected by the institution on the admissions application, but is not recorded into the database. Also, campus visit was shown to have a significant effect on enrollment in previous studies. as well as in the the supplemental analysis done with the two years of data available for this study. The results of the twoyear model showed that this variable would increase the explanatory power of the model.

The results of this research can be implemented at the case institution in a number of ways. First, a process was developed for running the model on a whole class of admitted students. Chapter 4 illustrated this by developing a model for data from 1998 to 2000, and then using the model coefficients to predict enrollment for each admitted student in 2001. The results of a change in financial aid policy could be quickly 
determined for each individual by changing the net price variable, recalculating the predicted probabilities and enrollment rates, and comparing the results to the original policy. This procedure has the advantage that it treats each candidate individually in determining the likelihood that the enrollment decision would change. A disadvantage to this procedure is it may require more statistical expertise than is available.

A second approach is the development of decision-making guidelines that can be quickly checked by admissions officials. An example of such guidelines based on the policy scenarios in Chapter 4 are presented in Table 24. 
Table 24

Sample Financial Aid Decision-making Rules

\begin{tabular}{|c|c|c|c|}
\hline Socio-economic/demographic group & $\begin{array}{c}\text { Initial } \\
\text { Probability of } \\
\text { Enrollment }\end{array}$ & $\begin{array}{c}\text { Initial } \\
\text { Enrollment } \\
\text { Decision } \\
\end{array}$ & $\begin{array}{l}\text { Amount of financial aid } \\
\text { required to change } \\
\text { enrollment decision* }\end{array}$ \\
\hline $\begin{array}{l}\text { la. Caucasian, Protestant male, with } \\
\text { average ability, from within state, } \\
\text { with no financial need (initial net } \\
\text { price }=\$ 29,908 \text { ), regular admission, } \\
\text { no legacy }\end{array}$ & .15 & No & $\$ 11.000$ \\
\hline $\begin{array}{l}\text { lb. Caucasian. Protestant male. with } \\
\text { average ability, from within state. } \\
\text { with no financial need (initial net } \\
\text { price }=\$ 29.908 \text { ), early admission. } \\
\text { no legacy }\end{array}$ & .26 & No & $\$ 5.000$ \\
\hline $\begin{array}{l}\text { 2a. African American. Procestant } \\
\text { female, with above average ability. } \\
\text { from within state, with high } \\
\text { financial need (initial net price = } \\
\$ 12,000 \text { ), regular admission. no } \\
\text { legacy }\end{array}$ & .28 & No & $\$ 1.000$ \\
\hline $\begin{array}{l}2 \mathrm{~b} \text {. African American. Protestant } \\
\text { female. with above average ability. } \\
\text { from within state. with low financial } \\
\text { need (initial net price }=\$ 20.000 \text { ). } \\
\text { regular admission. no legacy }\end{array}$ & .18 & No & $\$ 5.000$ \\
\hline $\begin{array}{l}\text { 3a. Hispanic. Catholic male. with } \\
\text { above average ability, from within } \\
\text { state away, with low financial need } \\
\text { (initial net price }=\$ 20.000 \text { ). regular } \\
\text { admission. no legacy }\end{array}$ & .28 & No & $\$ 1.000$ \\
\hline $\begin{array}{l}\text { 3b. Hispanic. Catholic male, with } \\
\text { above average ability. from over } \\
2000 \text { miles away. with low financial } \\
\text { need (initial net price }=\$ 20.000 \text { ). } \\
\text { regular admission, no legacy }\end{array}$ & .32 & Yes & 0 \\
\hline $\begin{array}{l}\text { til. Cauciasian, Catholic female, with } \\
\text { below average ability. from } 1000 \text { - } \\
\mathbf{2 0 0 0} \text { miles away. with low financial } \\
\text { need (initial net price }=\$ 20.000 \text { ). } \\
\text { regular admission. with a legacy }\end{array}$ & .72 & Yes & 0 \\
\hline $\begin{array}{l}\text { tb. Caucasian. Catholic female. with } \\
\text { below average ability, from less than } \\
1000 \text { miles away, with low financial } \\
\text { need (initial net price }=\$ 20.000 \text { ). } \\
\text { regular admission. with a legacy }\end{array}$ & .75 & Yes & 0 \\
\hline
\end{tabular}

* the amount of institutional aid required above the amount of federal need

An advantage of the decision rules above is that they would be readily available to admissions officials throughout the admissions process. The disadvantage is that the risks of over- or under-estimating price sensitivity are very high as results are generalized 
(averaged) across even individuals with similar characteristics. Therefore, the preferable approach would be for an institution to aquire the expertise necessary to calculate the effects of policy changes using the entire model.

In either case, it is important to note that the model should be estimated each year to include the most recent year's data. Two to four years of historical data should be used each year.

\section{Implications for Other Institutions}

As pointed out in Chapter 2, each institution of higher education can be considered a quasi-monopoly, because each institution offers a unique education and experience. which is made up of a particular combination of history, religious affiliation. course and major offerings, and prestige which are not found anywhere else (Breneman. 1994). Therefore, analysis such as that done in this study would arrive at different findings for each institution. It is not advisable that the exact findings, such as variable coefficients, be used with data from other institutions. For example, the finding that religious affiliation does not have an effect on enrollment at the case institution may not be true at other Catholic universities. This data can be used, however, as a signal to other institutions that the general assumptions they are working under may need to be verified at their institution.

What is generalizable is the process that was developed. Each institution can collect data on and use the variables that are important in its decision-making process to estimate a unique model. And the model can be tested with the unique policy alternatives the administrators are considering. 


\section{Implications for Further Research}

\section{At the Case Institution}

The enrollment behavior of entering freshman is not easy to predict. For one thing, the institution does not have some important information at the time admissions decisions are made. This model was specifically designed to use only information at hand during the admissions process. However, research that incorporates the additional information regarding what other schools were applied to, to which schools he was admitted, and the financial aid package offered by those schools would provide other valuable insights. Development of these after-the-fact models that include this information from admitted student questionnaires would provide more explanatory power, but it must be kept in mind that they do not help directly in decision making at the point the admission decisions are made.

Financial aid strategies not only affect first-time enrollment, they also affect retention. Many researchers have shown the effect of the level of aid on retention (Kreiger. 1980: Voorhees, 1985(b): St. John, 1990(c): Somer, 1992: St. John \& Starkey. 1993: Somers. 1996). Financial aid policies that optimize first-time enrollment may not optimize year-to-year persistence. For instance, a moderate aid package may be enough to affect a student's decision to enroll, but if the aid package is not high enough. persistence might be difficult. The present model can be used as a starting point for research on persistence. However, persistence research requires data from multiple departments of the institution. In the past, this institution, like others, has not integrated data across departments. The case institution is presently in the process of creating a 
university-wide database. The need for this type of research highlights the importance of such efforts for the entire university.

\section{Other Research}

While there is a large body of research on the general topic of higher education enrollment, most existing research has been at the national level. More research needs to be done at the institutional level. This study can be used to guide work on other institutional models. The present study has added to the base for such research in a number of ways. First, it used both logistic regression and probit models for estimation of the model. It showed the viability of using both of these techniques and showed the similarity of results between them. Second, this study included a unique set of explanatory variables, including religious affiliation and distance from home. This shows the ease at which institutions can look at the variables that are important for their goals. policies. and practices. Third, the model was tested for predictive accuracy on the next entering class, and developed a methodogy for doing this. Finally, the model was used to provide the results of policy simulations for cases of specific interest to the institution. again provide the methodology for this step.

As already noted, the development of models such as this one can be very expensive. and many institutions don 't have the funds or the expertise to do this type of work. A general model would be welcomed by such institutions. Future research could compare institution-specific models for similarities and differences to determine the viability of creating a generalized model that could be used. if not for all institutions, at least for certain types of institutions. 


\section{REFERENCES}

Agresti, A. (1990). Categorical data analysis. New York: Wiley and Sons.

Aldrich, J. H. \& Nelson, F. D. (1984). Linear probability, logit and probit models. Sage University Paper Series on Quantitative Applications in the Social Sciences, series no. 07-045). Beverly Hills, CA: Sage Publications.

Angrist, J. \& Krueger, A. (1991). Does compulsory schooling attendance affect schooling and eamings? The Quarterly Journal of Economics, 106(4), 979-1014.

Ashenfleter, O. \& Kruger, A. (1994) Estimates of the economic return to schooling from a new sample of twins. The American Economic Review, 84(5), 1157-1173.

Baldi, S. \& Pearson. R. (1999). A new conceptual and empirical approach to modeling the relationship between student financial aid and tuition. Working Paper.

Becker, G.S. (1993). Human capital: A theoretical and empirical analysis, with special reference to education. Chicago: The University of Chicago Press.

Becker. G.S. (1998). Human capital and poverty. Religion and Liberty. January/February. Online: http://www.action.org/publicat/randl/9Sjan feb/becker.heml

Belfield. C.R. (2000). Economic principles for education. Northampton. MA: Edward Elgar.

Bershadker. A.H. (1998). The effect of financial incentives on postsecondary enrollment. Unpublished doctoral dissertation. University of Wisconsin - Madison.

Bowen. W.G, \& Breneman, D.W. (1993). Student aid: Price discount or educational investment? Brookings Review, Winter, 28-31.

Breneman. D.W. (1994). Liberal arts colleges: Thriving, suniving, or endangered? Washington. D.C. The Brookings Institution. 
Brewer, D. \& Ehrenberg, R. (1996). Does it pay to attend an elite private college? Evidence from the senior high school class of 1980. Research in Labor Economics, 15, 239-271.

Cabrera, A. F. (1994). Logistic regression analysis in higher education: An applied perspective. In Smart. J. C. (Ed.). Higher education: Handbook of theory and research, Vol. X. (pp. 225-256). New York: Agathon Press.

Card, D. (1995a). Earnings, schooling and ability revisited. Research in Labor Economics, 14, 23-48.

Card, D. (1995b). Using geographic variation in college proximity to estimate the return to schooling. In L.N. Christofides, E.K. Grant. \& R. Swidinsky, (Eds.) Aspects of Labour Market Bellavior. (pp 201-222). Toronto: University of Toronto Press.

Chisholm. M.. \& Cohen. B. (1982). A review and introduction to higher education price response studies. Boulder. CO: National Center for Higher Education Management Systems.

The College Board (1998a). Trends in college pricing. Washington, D.C.

The College Board (1998b). Trends in student aid. Washington. D.C.

Coopers \& Lybrand. LLP. (1997). The impact of federal student assistance on college tuition levels. Washington. D.C.

Corrazzini. A.J.. Duga, D.. \& Grabowski. H.G. (1972). Determinants and distributional aspects of enrollment in U.S. higher education. Jourmal of Human Resources, Z(1). 30-59. 
Crown, W.H. (1998). Statistical models for the social and behavior sciences: Multiple regression and limited-dependent variable models. Westport, CT: Praeger Publishers.

Dey, E. L. \& Astin, A. W. (1993). Statistical alternatives for studying college student retention: A comparative analysis of logit, probit, and linear regression. Research in Higher Education, 34(5), 569-581.

Finney, D. (1996). Packaging and competing with financial aid: Merit vs. need based aid. Paper presented at the meeting of the Cooperstown Institute, Cooperstown, NY.

Fuller, W. Manski, C., \& Wise, D. (1982). New evidence on economic determinants of postsecondary schooling choice. Joumal of Human Resources, 12, 477-495.

Gladieux. L.E., \& Hauptman. A.M. (1994). Improving Public Policies to Help Students Pay for College. Discussion paper for College Board/Brookings Colloquium. October 26.

Gray, C. (1995). SME success as a function of human capital development. Proceedings from Skills for Success in Small and Medium Enterprises - Sydney. Australia. June 18-21. 1995. University of Central Arkansas.

Greene, W.H. (1990). Econometric analysis. New York: MacMillan Publishing Company.

Groot. W. (1998). Empirical estimates of the rate of depreciation of education. Applied Economic Letters, 5, 535-538.

Hansen, W.L. (1983). Impact of financial aid on access. In J. Froomkin. (Ed.) The Crisis in Higher Education. (pp. 84-96). New York: The Academy of Political Science. 
Hauptman, A.M. (1990). The college tuition spiral. Report to the College Board and the American Council on Education, Washington, D.C.

Haveman, R. \& Wolfe, B. (1984). Schooling and economic well-being: The role of nonmarket effects. The Journal of Human Resources, 19(3), 377-407.

Hartog, J. (1999). Behind the veil of human capital. OECD Observer, 215. Online: http://www.oecd.org/publications/observer/215/e-harto.htm

Heller, D. E. (1997) Student price response in higher education. Joumal of Higher Education, 68(6), 624-659.

Heller, D. E. (1994). Tuition prices, state grants, and public college enrollments: Are minority youth losing ground? Cambridge, MA: Monograph. Harvard Graduate School of Education.

Henderson. J.M. \& Quandt. R.E. (1971). Microeconomic theory: A mathematical approach. New York: McGraw-Hill Book Company.

Hoenack. S. (1968). Private demand for higher education in Califomia. Unpublished doctoral dissertation. University of Califormia, Berkeley.

Hopkins, D.S.P., \& Massy. W.F. (1981)._Plamning models for colleges and universities. Palo Alto, CA: Stanford University Press.

Hosmer. D. \& Lemeshow. S. (1989). Applied logistic regression. New York: John Wiley \& Sons.

Hossler. D. \& Gallagher, K. (1987). Studying student college choice: A three-phase model and the implications for policymakers. College and University. Spring. 1987. 207-221. 
Hossler, D., Hu, S. \& Schmit, J. (1999). Predicting student sensitivity to tuition and financial aid. Journal of Student Financial Aid, 29(1), 17-31.

Hu, S., \& Hossler, D. (2000). Willingness to pay and preference for private institutions. Research in Higher Education, 34, 685-701.

Jackson, G.A. (1988). Did college choice change during the seventies? Economics of Education Review, 7(1), 15-27.

Jackson, G.A. (1989). Responses of black, Hispanic, and white students to financial aid: College entry among recent highs school graduates. College Park, MD: National Center for Postsecondary Governance and Finance, University of Maryland.

Jackson, G.A. \& Weathersby, G.B. (1975). Individual demand for higher education. Journal of Higher Education. 46, 623-652.

Kane. T.J. (1991). College entry by blacks since 1970: The role of tuition, financial aid. local economic conditions, and family background. Unpublished doctoral dissertation, Harvard University.

Kane. T.J. (1994). The causes and consequences of recent public tuition increases. Cambridge, MA: Monograph. Kennedy School of Government.

Kane. T.J. (1995). Rising public college tuition and college entry: How well do public subsidies promote access to college? Cambridge. MA: National Bureau of Economic Research Working Paper Series No. 5164.

Kane. T.J. \& Rouse. C (1995). Labor market retums to two and four year colleges. American Economic Review, 85(3), 600-614.

Kleinbaum, D. G. (1994). Logistic regression: A self-leaming text. New York: SpringerVerlag. 
Knudsen, O., \& Servelle, P. (1978). The demand for higher education at private institutions of moderate selectivity. American Economist, 22, 30-34.

Leslie, L.L., \& Brinkman, P.T. (1987). Student price response in higher education: The student demand studies. Journal of Higher Education, 58(2), 181-204.

Leslie, L.L., \& Brinkman, P.T. (1988). The economic value of higher education. New York: American Council on Education and Macmillan Publishing Company.

Lay, R., Maguire, J., \& Litten, L. (1982). Identifying distinctive groups in a college applicant pool. Research in Higher Education, 16(3). 195-208.

Manski. C.F. (1993). Adolescent econometricians: How do youth infer the returns to schooling? In C.T. Clotfelter. \& M. Rothschild, (Eds.)._Studies of supply and demand in higher education. (pp.43-60). Chicago: The University of Chicago Press.

Manski. C.F. \& Wise, D. (1983). College choice in America. Cambridge. MA: Harvard University Press.

McMahon, W.W. (1999). Education and development: Measuring the social benefit. Oxford: Oxford University Press.

McPherson, M.S. \& Schapiro, M.O. (1990). Measuring the effects of federal student aid: An assessment of some methodological and empirical problems. Williamstown. MA: Williams Project on the Economics of Higher Education Discussion Paper No. 4.

McPherson, M.S. \& Schapiro, M.O. (1991a). Does student aid affect college enrollment? New evidence on a persistent controversy. American Economic Review, 81(1). $309-318$. 
McPherson, M.S. \& Schapiro, M.O. (1991b). Keeping college affordable: Government and educational opportunity. Washington, DC: Brookings Institution.

McPherson, M.S. \& Schapiro, M.O. (1994). College choice and family income: Changes over time in the higher education destinations of students from different income backgrounds. Williamstown, MA: Williams Project on the Economics of Higher Education Discussion Paper No. 29.

McPherson, M.S. \& Schapiro, M.O. (1998). The student aid game: Meeting need and rewarding talent in American higher education. Princeton. NJ: Princeton University Press.

Menard, S. (1995). Applied logistic regression. Newbury Park, CA: Sage University Paper Series on Quantitative Applications in the Social Sciences, series no. 07107.

Moore. R.L., Studenmund. A.H., \& Slobko, T. (1991). The effect of the financial aid package on the choice of a selective college. Economics of Education Revien. $10(4), 311-321$.

Mortenson Research Seminar on Public Policy Analysis of Opportunity for Postsecondary Education. (1999). Why college? Private correlates of educational attainment. Postsecondary. Education Opportunity. Number 81.

Mumper. M. (1996). Removing college price barriers: What govermment has done and why it hasn't worked. Albany, NY: State University of New York Press.

Pascarella, E. T.. \& Smart. J. C. (1990). Is the effect of grades on early career income general or conditional? Review of Higher Education, I4(1), 83-99. 
Peacock, R. (1993). Designing an effective admissions rating system. The Journal of College Admissions. Spring, 21-25.

Petersen, T. (1984). A comment on presenting results from logit and probit models. American Socialogical Review 50(1), 103-131.

Pigeon, J.G. \& Heyse, J.F. (1999). An improved goodness of fit statistic for probability prediction models. Biometrical Journal 41, $71-82$.

Quann, J. C. (1979). Admissions, academic records, and registrar services. San Francisco: Jossey-Bass Publishers.

Radner, R. \& Miller, L.S. (1970). Demand and supply in U.S. higher education: A progress report. American Economic Review, 60. 326-334.

Reynolds. A. (1997). The real cost of higher education, who should pay and how. Paper submitted to the National Commission on the Cost of Higher Education. Washington, D.C.

Reindl. T. \& Redd. K. (1999). Institutional aid in the 1990.: The consequences of policy connections. American Association of State Colleges and Universities Working Paper. Washington, D.C.: American Association of State Colleges and Universities.

Savoca. E. (1990). Another look at the demand for higher education: Measuring the price sensitivity of the decision to apply to college. Economics of Education Revien: $9(2), 123-134$.

Shea. C. (1996). Sweetening the Pot for the Best Students. Chronicle of Higher Education. May 17. A39-A40. 
Sinha, K.W. (1998). Estimating first-time enrollment for the private, highly selective, national university: A market demography application of logistic regressionbased price sensitivity analysis. Unpublished doctoral dissertation, Bowling Green State University.

Smith. A. (1955). An inquiry in to the nature and causes of the weath of nations. Chicago: Encyclopedia Britannica. Great Books of the Western World, Vol. 39. Somers, P.A. (1992). A dynamic analysis of student matriculation decisions in an urban public university. Unpublished doctoral dissertation, University of New Orleans.

Spies. R. (1973). The future of private colleges: The effect of rising costs on college choice. Princeton, NJ: Industrial Relations Section. Princeton University.

SPSS AnswerNet. (2000). Comparing likelihood in multinomial logistic regression. http://www.spss.com/tech/answer/details.ctm:tech tan id=100007186.

St. John. E. P. (1990). Price response in enrollment decisions: An analysis of the high school and beyond sophomore cohort. Research in Higher Education. 31(2), 161176.

St. John. E. P. (1991). The impact of student financial aid: A review of recent research. Journal of Student Financial Aid, 21(1), 18-31

St. John. E. P. (1992). Workable models for institutional research on the impact of student financial aid. Journal of Student Financial Aid. 22(3), 13-26.

St. John, E.P. (1994). Prices, productivity; and investment: A critical analysis of the higher education cost controversy. Washington, D.C.: Association for the Study of Higher Education. 
St. John, E. P. \& Masten, C. (1990). Return on the federal investment in student financial aid: An assessment of the high school class of 1972._Joumal of Student Financial Aid, 10(3).

St. John, E. P., \& Noell, J. (1989). The effects of student financial aid on access to higher education: An analysis of progress with special consideration of minority enroliment. Research in Higher Education, 30(6), 563-581.

St. John, E.P., \& Somers, P. (1997). Assessing the impact of student financial aid on firsttime enrollment decisions. In J.S. Davis (Ed.). Student aid research: A manual for financial aid administrators (pp. 101-126). Washington, D.C.: National Association of Student Financial Aid Administrators.

Willis, R. \& Rosen, S. (1979). Education and self-selection. Journal of Political Economy, 87(5), S7-S36. 
APPENDLX

1998-2001 Correlation Matrix 
1998-2001 Correlation Matrix, Part 2

\begin{tabular}{|c|c|c|c|c|c|c|c|c|c|c|c|}
\hline & $\begin{array}{l}\text { Alrican } \\
\text { American }\end{array}$ & Asian & Caucasian & Filipino & Mispanic & $\begin{array}{l}\text { Native } \\
\text { American }\end{array}$ & $\begin{array}{l}\text { Other } \\
\text { Ethnicity }\end{array}$ & $\begin{array}{l}\text { Within } \\
\text { Stute }\end{array}$ & $\begin{array}{c}<1000 \\
\text { miles }\end{array}$ & $\begin{array}{l}1000 \text { to } \\
2000 \\
\text { miles }\end{array}$ & $\begin{array}{c}\text { Over } 2000 \\
\text { miles }\end{array}$ \\
\hline Rating & .006 & .0 .32 & -.063 & .021 & .045 & 020 & -.005 & -.044 & .067 & .031 & -.029 \\
\hline HS GPA & -.087 & -.010 & .024 & .041 & .005 & -.035 & .000 & -.016 & .120 & .024 & -.118 \\
\hline SATM & .072 & .078 & .036 & -.001 & -.087 & .014 & .007 & .112 & -.062 & -.131 & .047 \\
\hline SAT V & -.053 & -.018 & .062 & .003 & -.0 .57 & -.006 & .015 & .113 & -.041 & -.114 & .042 \\
\hline SAT & -.116 & .006 & .173 & -.018 & -.162 & .003 & -.019 & -.054 & .015 & .063 & .039 \\
\hline Catholic & -.079 & -.138 & -.066 & .124 & 206 & -.018 & -.047 & .08 .5 & -.032 & -.037 & -.028 \\
\hline Protestant & .052 & .002 & .160 & -.092 &. .162 & .001 & .067 & -.075 & .049 & .057 & .002 \\
\hline Jewish & .013 & -.030 & .030 & -.024 & -.019 & -.009 & .037 & -.006 & .010 & -.022 & .006 \\
\hline Other Religion & .051 & .217 & -.138 & -.047 & .075 & .029 & .151 & -.021 & -.026 & -.016 & .036 \\
\hline Gender & .032 & -.017 & .023 & -.019 & -.023 & 010 & -.006 & -.020 & .013 & -.007 & .014 \\
\hline Legacy & -.036 & -.038 & .030 & -.008 & .008 & .003 & .002 & .088 & -.024 & -.053 & -.044 \\
\hline African Amer. & 1.000 & -.041 & -.226 & -.025 & -.0 .56 & -.019 & -.030 & .026 & .024 & -.005 & .001 \\
\hline Asian & -.041 & 1.000 & -.422 & -.047 & -.105 & -.035 & -.056 & -.037 & -.057 & -.056 & .114 \\
\hline Caucasian & -.226 & -.422 & 1.000 & -.257 & -.579 & -.191 & -.307 & -.118 & .109 & .146 & .070 \\
\hline Filipino & -.02 .5 & .047 & -.257 & 1.000 & -.064 & -.021 & -.034 & .036 & -.045 & -.032 & .045 \\
\hline Hispanic & -.0 .56 & -.105 & -.579 & -.064 & 1.000 & .047 & -.076 & .160 & -.063 & -.114 & -.058 \\
\hline Native Amer. & -.019 & -.035 & $-019 !$ & -.021 & -.047 & 1.000 & -.025 & -.033 & -.021 & .019 & .121 \\
\hline Other Ell & .030 & .0 .56 & -.307 & -.034 & -.076 & .025 & 1.000 & .026 & .004 & -.033 & -.003 \\
\hline Within stalc & .026 & -.037 & -.118 & .036 & .160 & -.033 & .026 & 1.000 & -.517 & -.507 & -.347 \\
\hline$<1000$ miles & -.024 & -.057 & .109 & -.045 & -.063 & -.021 & -.004 & -.517 & 1.000 & -.193 & -.132 \\
\hline $1000-2000$ miles & -.005 & -.056 & 146 & -.032 & -.114 & -.019 & -.033 & -.507 & -.193 & 1.000 & -.129 \\
\hline Over 2000 miles & .001 & .114 & .070 & .045 & -.058 & .121 & -.003 & -.347 & -.132 & -.129 & 1.000 \\
\hline International & .017 & .210 & -.118 & -.014 & .012 &. .013 & .014 & -.165 & -.063 & -.061 & -.042 \\
\hline Adjusted Need & .071 & -.012 & -.155 & .020 & .160 & $.0+1$ & .013 & .067 & -.009 & -.056 & .010 \\
\hline No Need & -.049 & .025 & .111 & .022 &. .122 & -.038 & -.006 & -.061 & .001 & .047 & .004 \\
\hline Low Need & -.019 & -.026 & .035 & .011 & -.021 & -.001 & -.005 & .013 & .011 & -.005 & -.009 \\
\hline High Need & .066 & -.010 & -.142 & .017 & .14 .5 & .042 & .010 & .058 & -.008 & -.047 & .010 \\
\hline Net Price I & -.064 & -.001 & .134 & -.015 & -.136 & -.037 & .001 & -.058 &. .007 & .040 & .014 \\
\hline Net Price 2 & .041 & .006 & .059 & -.015 & -.0 .57 & -.031 & .013 & .053 & -.082 & -.022 & .001 \\
\hline 1998 & .001 & -.029 & .007 & -.009 & -.006 & 012 & .031 & .017 & .006 & -.004 & -.011 \\
\hline 1999 & -.011 & -.017 & .017 & -.007 & -.015 & .003 & 022 & .006 & .003 & .007 & -.015 \\
\hline 2000 & .003 & .016 & -.004 & .000 & .006 & .015 & .014 & -.002 & .007 & -.005 & -.009 \\
\hline 2001 & 00 & .030 & -.020 & .016 & 015 & .000 & -.037 & -.021 & -.004 & .003 & .035 \\
\hline
\end{tabular}


